ipen

INSTITUTO DE PESQUISAS ENERGÉTICAS E NUCLEARES

Autarquia associada à Universidade de São Paulo

PRODUÇÃO E CARACTERIZAÇÃO DE VIDROS DE ÓXIDOS DE METAIS PESADOS DOPADOS COM TERRAS-RARAS E NANOPARTÍCULAS METÁLICAS

FRANCISCO ARAÚJO BOMFIM JÚNIOR

Dissertação apresentada como parte dos requisitos para obtenção do Grau de Mestre em Ciências na Área de Tecnologia Nuclear Materiais.

Orientador:

Dr. José Roberto Martinelli

SÃO PAULO 
ipen

INSTITUTO DE PESQUISAS ENERGÉTICAS E NUCLEARES

Autarquia associada à Universidade de São Paulo

PRODUÇÃO E CARACTERIZAÇÃO DE VIDROS DE ÓXIDOS DE METAIS PESADOS DOPADOS COM TERRAS-RARAS E NANOPARTÍCULAS METÁLICAS

FRANCISCO ARAÚJO BOMFIM JÚNIOR

Dissertação apresentada como parte dos requisitos para obtenção do Grau de Mestre em Ciências na Área de Tecnologia Nuclear Materiais.

Orientador:

Dr. José Roberto Martinelli

SÃO PAULO 
Dedicado este trabalho à minha querida mãe. Minha deusa e meu alicerce. 
A adversidade desperta em nós capacidades que, em circunstâncias favoráveis, teriam ficado adormecidas.

Quinto Horácio Flaco 


\section{AGRADECIMENTOS}

Ao Prof. Dr. José Roberto Martinelli, pela orientação, confiança e liberdade em mim depositada para realização deste trabalho.

À Prof ${ }^{a}$. Dra. Luciana Reyes Pires Kassab da FATEC-SP, pela co-orientação, apoio e confiança.

Ao Prof. Dr. Niklaus Ursus Wetter do CLA-IPEN, pela atenção e por ceder o laboratório para as medidas de emissão óptica.

Aos Mes. Davinson Mariano da Silva da POLI-USP e Jonas Jakutis Neto do CLA-IPEN, pela amizade, auxílio nas análises e discussão dos resultados.

Ao Prof. Dr. Walter Elias Feria Ayta, do Laboratório de Cristais lônicos do Instituto de Física da USP (IFUSP), pela colaboração nas medidas de absorção óptica.

À Simone Perche do Laboratório de Microscopia Eletrônica do IFUSP, pela realização e análise das medidas de Microscopia Eletrônica de Transmissão (MET).

Ao Dr. Sidnei José Buso, do Centro de Ciências e Tecnologia de Materiais do IPEN, pela realização e análise das medidas de MET no microscópio de alta resolução do IPEN.

Ao Prof. Dr. Signo Tadeu dos Reis, do Centro de Pesquisas em Materiais da Universidade de Ciências e Tecnologia do Missouri - EUA, pela realização da Análise de Térmica Diferencial (ATD) dos vidros.

À Comissão Nacional de Energia Nuclear (CNEN), pela concessão da bolsa, a CAPES, pelo apoio financeiro para participação em congressos e eventos.

À Rede Nanofoton, pelo apoio financeiro para compra de materiais e reagentes.

Às Secretárias da Coordenação de Ensino Geral (CPG) do IPEN, pelos esclarecimentos e simpatia.

À FATEC-SP, pelo espaço cedido através do Laboratório de Vidros e Datações (LVD) para a produção e caracterização dos vidros. 
A todos os amigos do LVD da FATEC-SP e Laboratório e Vidros e Compósitos do CCTM/IPEN.

Aos amigos do curso de Materiais, Processos e Componentes Eletrônicos da FATEC-SP, pela amizade e companheirismo durante e após a graduação.

A todos que, de alguma forma, me suportaram durante a realização deste trabalho.

A toda minha família, pela compreensão, paciência e amor a mim oferecidos. 


\title{
PRODUÇÃO E CARACTERIZAÇÃO DE VIDROS DE ÓXIDOS DE METAIS PESADOS DOPADOS COM TERRAS-RARAS E NANOPARTÍCULAS METÁLICAS
}

\author{
Francisco Araújo Bomfim Júnior
}

RESUMO

Vidros de óxido de metais pesados dopados com érbio têm sido estudados e utilizados em diversas aplicações. Entretanto, a eficiência de absorção óptica destes vidros em 980 nm é limitada pela baixa secção de choque de absorção, a qual pode ser aumentada pela presença de íons $\mathrm{Yb}^{3+}$ e de nanopartículas metálicas, as quais contribuem significativamente para o aumento da eficiência das emissões de conversão ascendente. No presente trabalho é investigada a influência da presença de nanopartículas metálicas na luminescência de conversão ascendente de freqüência do íon $\mathrm{Er}^{3+}$ em vidros co-dopados com $\mathrm{Er}^{3+} / \mathrm{Yb}^{3+}$. Vidros com composição $\mathrm{GeO}_{2}-\mathrm{PbO}$ e $\mathrm{PbO}-\mathrm{GeO}_{2}-\mathrm{Ga}_{2} \mathrm{O}_{3}$ co-dopados com $0,5 \%$ de $\mathrm{Er}_{2} \mathrm{O}_{3}$ e diferentes concentrações de $\mathrm{Yb}_{2} \mathrm{O}_{3}$ foram produzidos. Para avaliar os efeitos da presença de nanopartículas metálicas na luminescência de conversão ascendente de freqüência, foram também produzidos vidros co-dopados com $\mathrm{Er}_{2} \mathrm{O}_{3} / \mathrm{Yb}_{2} \mathrm{O}_{3}$ contendo $\mathrm{AgNO}_{3}$, $\mathrm{Au}_{2} \mathrm{O}_{3}$ e $\mathrm{Cu}_{2} \mathrm{O}$. O aumento nas emissões de conversão ascendente de freqüência na região de visível dos íons $\mathrm{Er}^{3+}$ foi observado para os vidros $\mathrm{GeO}_{2}-\mathrm{PbO}$ e $\mathrm{PbO}-\mathrm{GeO}_{2}$ $\mathrm{Ga}_{2} \mathrm{O}_{3}$ co-dopados. Vidros $\mathrm{GeO}_{2}$ - $\mathrm{PbO}$ co-dopados contendo prata apresentam um aumento substancial nas emissões de CAF influenciado pelo aumento do campo atômico local na vizinhança das nanopartículas. Este efeito não foi observado nos vidros $\mathrm{PbO}-\mathrm{GeO}_{2}-\mathrm{Ga}_{2} \mathrm{O}_{3}$ co-dopados contendo ouro e nem nos vidros $\mathrm{GeO}_{2}-\mathrm{PbO}$ codopados contendo $\mathrm{Cu}_{2} \mathrm{O}$. Todas as medidas de conversão ascendente de freqüência foram realizadas por meio da excitação das amostras por um laser de diodo operando em $980 \mathrm{~nm}$. 


\title{
PRODUCTION AND CHARACTERIZATION OF RARE-EARTH AND METALLIC NANOPARTICLE DOPED HEAVY METAL OXIDE GLASSES
}

\author{
Francisco Araújo Bomfim Júnior
}

\begin{abstract}
Erbium doped -heavy metal oxide glasses have been previously studied and used in several applications. However, the $\mathrm{Er}^{3+}$ optical absorption efficiency around $980 \mathrm{~nm}$ is restricted by its low absorption cross-section. To overcome this drawback $\mathrm{Yb}^{3+}$ ions and metallic nanoparticles have been added in the glass matrices which can effectively contribute to increase the efficiency of the frequency upconversion emissions. In the present work the effects of nanoparticles in the frequency upconversion luminescence of $\mathrm{Er}^{3+}$ in $\mathrm{Er}^{3+} / \mathrm{Yb}^{3+}$ co-doped glasses were investigated. $\mathrm{GeO}_{2}-\mathrm{PbO}$ and $\mathrm{PbO}-\mathrm{GeO}_{2}-\mathrm{Ga}_{2} \mathrm{O}_{3}$ glasses co-doped with $0.5 \mathrm{wt} / \%$ of $\mathrm{Er}_{2} \mathrm{O}_{3}$ and different concentrations of $\mathrm{Yb}_{2} \mathrm{O}_{3}$ were produced. To evaluate the effects of metallic nanoparticles in the frequency upconversion luminescence, $\mathrm{AgNO}_{3}, \mathrm{Au}_{2} \mathrm{O}_{3}$, and $\mathrm{Cu}_{2} \mathrm{O}$ were also added to the glass compositions. The increase of the visible $\mathrm{Er}^{3+}$ frequency upconversion luminescence emissions was observed for $\mathrm{Er}^{3+} \mathrm{Mb}^{3+}$ codoped $\mathrm{PbO}-\mathrm{GeO}_{2}-\mathrm{Ga}_{2} \mathrm{O}_{3}$ and $\mathrm{GeO}_{2}-\mathrm{PbO}$ glasses. The $\mathrm{GeO}_{2}-\mathrm{PbO}$ glasses containing silver NPs presented a substantial increase of the $\mathrm{Er}^{3+}$ frequency upconversion luminescence emissions. This is probably due to the local atomic field increase in the vicinity of the metallic NPs, which affects the rare-earth ion transitions. However, this effect was not observed in co-doped $\mathrm{PbO}-\mathrm{GeO}_{2}-\mathrm{Ga}_{2} \mathrm{O}_{3}$ glasses containing $\mathrm{Au}_{2} \mathrm{O}_{3}$ and co-doped $\mathrm{GeO}_{2}-\mathrm{PbO}$ glasses containing $\mathrm{Cu}_{2} \mathrm{O}$. All frequency upconversion luminescence emissions were stimulated by exciting samples with a diode laser operating in $980 \mathrm{~nm}$.
\end{abstract}




\section{LISTA DE FIGURAS}

FIGURA 1 - ANALOGIA BIDIMENSIONAL ESQUEMÁTICA, SEGUNDO ZACARIASEN, PARA ILUSTRAR A DIFERENÇA ENTRE: (A) ESTRUTURA REGULAR REPETIDA DE UM CRISTAL E (B) REDE CAÓTICA DO VIDRO DE MESMA COMPOSIÇÃO [15].

FIGURA 2 - DIFERENTES TAXAS DE RESFRIAMENTO PARA FORMAÇÃO DO VIDRO E CRISTAL.......................... 5

FIGURA 3 - TíPICA CURVA DE ATD PARA UM VIDRO PBO-GEO ${ }_{2}-\mathrm{GA}_{2} \mathrm{O}_{3}$. [19].

FIGURA 4 - (A) DENSIDADE EM FUNÇÃO DA CONCENTRAÇÃO DE MODIFICADORES E (B) DISTÂNCIA DE GE-O DETERMINADA EXPERIMENTALMENTE POR ESPALHAMENTO DE RAIO X E EXAF [27].

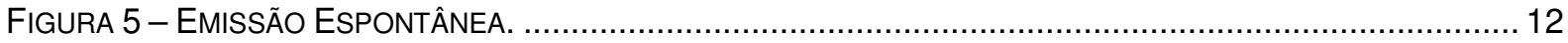

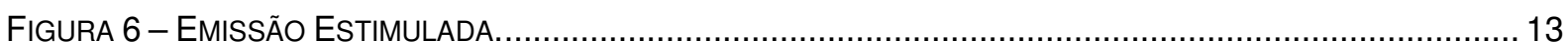

FIGURA 7 - ESQUEMA REPRESENTANDO ALGUNS PROCESSOS DE CAF. (ETU) CONVERSÃO ASCENDENTE DE FREQÜÊNCIA POR TRANSFERÊNCIA DE ENERGIA; (AEE) ABSORÇÃO DO ESTADO EXCITADO; (SC) SENSITIZAÇÃO COOPERATIVA; (LC) LUMINESCÊNCIA COOPERATIVA [38].

FIGURA 8 - DIAGRAMA DE ENERGIA DOS ÍONS $E^{3+} / \mathrm{YB}^{3+}$ E OS MECANISMOS DE CAF PARA VIDROS CODOPADOS COM $\mathrm{ER}^{3+} / \mathrm{YB}^{3+}$. AS LINHAS SÓLIDAS INDICAM O COMPRIMENTO DE ONDA DE BOMBEIO, AS TRANSIÇÕES DE CAF, E AS TRANSIÇÕES RADIATIVAS, RESPECTIVAMENTE. AS LINHAS PONTILHADAS E EM AZUL ESTÃO RELACIONADAS AOS PROCESSOS DE TRANSFERÊNCIA DE ENERGIA E A RELAXAÇÃO NÃO RADIATIVA, RESPECTIVAMENTE.

FIGURA 9 - ESQUEMA DA OSCILAÇÃO DOS PLASMONS DE SUPERFÍCIE EM NPS METÁLICAS [1].

FIGURA 10 - BANDA DE RESSONÂNCIA DO PLASMON DE PARTÍCULAS DE PRATA EM VIDROS DE GERMANATO DOPADO COM ER ${ }^{3+}$ PARA DIFERENTES TRATAMENTOS TÉRMICOS [48].

FIGURA 11 - INTERFERÊNCIA DA FORMA DAS NPS NA POSIÇÃO DAS BANDAS DE ABSORÇÃO DOS PLÁSMONS SUPERFICIAIS, EM COLÓIDES COM NPS DE PRATA [51].

FIGURA 12 - ESPECTRO DE ABSORÇÃO DE NPS DE OURO COM DIFERENTES TAMANHOS [2]........................ 21

FIGURA 13 - ETAPAS UTILIZADAS PARA PRODUÇÃO DOS VIDROS.

FIGURA 14 - FOTOGRAFIA DOS VIDROS GP DOPADO COM 0,5\% DE ER ${ }_{2} \mathrm{O}_{3}$ E DIFERENTES CONCENTRAÇÕES DE $\mathrm{YB}_{2} \mathrm{O}_{3}$.

FIGURA 15 - FotOGRAFIA DO VIDRO GP-Y3, CONTENDO 0,5\% DE ER $\mathrm{O}_{2} \mathrm{O}_{3}, 3,0 \%$ DE $\mathrm{YB}_{2} \mathrm{O}_{3} \mathrm{E} 1,0 \%$ DE $\mathrm{AGNO}_{3}$

FIGURA 16 - FOTOGRAFIA DO VIDRO GP-A3, CONTENDO 0,5\% DE ER $\mathrm{O}_{2}, 1,0 \%$ DE $\mathrm{YB}_{2} \mathrm{O}_{3}$ E 3,0\% DE $\mathrm{AGNO}_{3}$

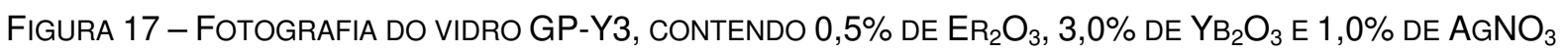
PRODUZIDO EM CADINHO DE ALUMINA PURA.

FIGURA 18 - FOTOGRAFIA DO VIDRO GP-CY3, CONTENDO 0,5\% DE $\mathrm{ER}_{2} \mathrm{O}_{3}, 3,0 \% \mathrm{DE} \mathrm{Y}_{2} \mathrm{O}_{3}$ E 0,1\% DE $\mathrm{CU}_{2} \mathrm{O}$.

FIGURA 19 - FOTOGRAFIA DOS VIDROS GPG DOPADO COM 0,5\% DE ER $\mathrm{O}_{3} \mathrm{O}_{3}$ E DIFERENTES CONCENTRAÇÕES $\mathrm{DE} \mathrm{YB}_{2} \mathrm{O}_{3}$.

FIGURA 20 - FotOGRAFIA DO VIDRO GPG-Y3, CONTENDO 0,5\% DE $\mathrm{ER}_{2} \mathrm{O}_{3}, 3,0 \%$ DE $\mathrm{YB}_{2} \mathrm{O}_{3} \mathrm{E}$ 1,0\% DE $\mathrm{AU}_{2} \mathrm{O}_{3}$. 
FIGURA 21 - FOTOGRAFIA DO VIDRO GPG-O3, CONTENDO 0,5\% DE $\mathrm{ER}_{2} \mathrm{O}_{3}, 1,0 \%$ DE $\mathrm{YB}_{2} \mathrm{O}_{3}$ E 3,0\% DE

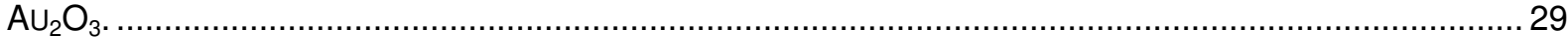

FIGURA 22 - REPRESENTAÇÃO ESQUEMÁTICA DA NUCLEAÇÃO DE NPS.

FIGURA 23 - O CICLO DO TRATAMENTO TÉRMICO UTILIZADO PARA NUCLEAÇÃO DAS NPS. AS TEMPERATURAS, $T_{A}, T_{T}, T_{F}$, SÃO AS TEMPERATURAS AMBIENTE, DE TRATAMENTO E DE FUSÃO, RESPECTIVAMENTE [49]......... 31

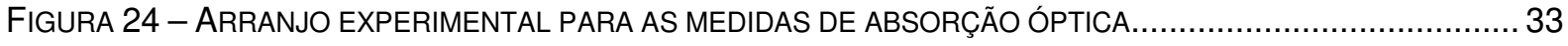

FIGURA 25 - DIAGRAMA EXPERIMENTAL PARA MEDIDAS DE EMISSÃO NO VISÍVEL E INFRAVERMELHO............. 34

FIGURA 26 - CURVAS DE ATD DO VIDRO GP-Y3 (A) E DO VIDRO GP DOPADO COM 3,0\% DE $\mathrm{AGNO}_{3}$ (B)...... 39

FIGURA 27 - CURVAS DE ATD DO VIDRO GPG-Y3 (A) E DO VIDRO GP DOPADO COM 5,0\% DE AU $\mathrm{O}_{2}$ (B)... 40

FIGURA 28 - DifRATOGRAMAS DE RAIOS X DOS VIDROS GP (A) E GPG (B) COM 3,0\% DE $\mathrm{AGNO}_{3}$ E $5,0 \% \mathrm{AU}_{2} \mathrm{O}_{3}, \mathrm{RESPECTIVAMENTE}$.

NAS FIGURAS 29 E 30 SÃO MOSTRAdOS OS DRX DOS VIDROS GPG $\left(5,0 \% \mathrm{AU}_{2} \mathrm{O}_{3}\right)$ E GPG-Y3, RESPECTIVAMENTE, TRATADOS TERMICAMENTE NAS TEMPERATURAS DE CRISTALIZAÇÃO DETERMINADAS POR MEIO DA ATD. ESTE TRATAMENTO TÉRMICO FOI REALIZADO COM INTUITO DE SE DETERMINAR A FORMAÇÃO DE FASES CRISTALINAS DISTINTAS, RELACIONADAS COM UMA TENDÊNCIA DE SEPARAÇÃO DE FASE DOS VIDROS DO SISTEMA GPG.

FIGURA 29 - DiFRATOGRAMAS DE RAIOS X DO VIDRO GPG DOPADO COM 5,0\% DE $\mathrm{AU}_{2} \mathrm{O}_{3}$ TRATADOS TERMICAMENTE A 479,533 E $566^{\circ} \mathrm{C}$

FIGURA 30 - DIFRATOGRAMAS DE RAIOS X DO VIDRO GPG-Y3 TRATADOS TERMICAMENTE A 479, 533 E $566^{\circ} \mathrm{C}$.

FIGURA 31 - ESPECTRO DE ESPALHAMENTO RAMAN DOS VIDROS GP (A) E GPG (B).

FIGURA 32 - (A) TRANSMITÂNCIA DO VIDRO GP SEM DOPANTE E CO-DOPADOS COM DIFERENTES CONCENTRAÇÕES DE PRATA; (B) TRANSMITÂNCIA DO VIDRO GPG SEM DOPANTE E CO-DOPADOS COM DIFERENTES CONCENTRAÇÕES DE OURO.

FIGURA 33 - ESPECTROS DE ABSORÇÃO ÓPTICA NA REGIÃO DO VISÍVEL E INFRAVERMELHO DO VIDRO GPG CO-DOPADO COM 0,5\% $\mathrm{ER}_{2} \mathrm{O}_{3}$ E DIFERENTES CONCENTRAÇÕES DE $\mathrm{YB}_{2} \mathrm{O}_{3}$.

FIGURA 34 - ESPECTRO DE EMISSÃO DE CAF DO VIDRO GPG COM DIFERENTES CONCENTRAÇÕES DE $\mathrm{YB}_{2} \mathrm{O}_{3}$ EXCITADO EM 980 NM.

FIGURA 35 - RAZÃO DAS INTENSIDADES INTEGRADAS EM FUNÇÃO DA CONCENTRAÇÃO DE $\mathrm{YB}_{2} \mathrm{O}_{3}$ DO VIDRO GPG.

FIGURA 36 - DIAGRAMA DE ENERGIA DOS ÍONS $\mathrm{ER}^{3+} / \mathrm{YB}^{3+}$ E OS MECANISMOS DE CAF NO VIDRO GPG. AS LINHAS SÓLIDAS INDICAM O COMPRIMENTO DE ONDA DE BOMBEIO, AS TRANSIÇÕES DE CAF, E AS TRANSIÇÕES RADIATIVAS, RESPECTIVAMENTE. AS LINHAS PONTILHADAS E EM AZUL ESTÃO RELACIONADAS AOS PROCESSOS DE TRANSFERÊNCIA DE ENERGIA E RELAXAÇÃO NÃO RADIATIVA, RESPECTIVAMENTE. 48

FIGURA 37 - INTENSIDADE DE EMISSÃO DE CAF EM 545 NM (A) E EM 657 NM (B), RESPECTIVAMENTE EM FUNÇÃO DA POTÊNCIA DE BOMBEIO DO VIDRO GPG.

FIGURA 38 - ESPECTROS DE ABSORÇÃO ÓPTICA NA REGIÃO DO VISÍVEL E INFRAVERMELHO DO VIDRO GP CODOPADO COM $0,5 \% \mathrm{ER}_{2} \mathrm{O}_{3}$ E DIFERENTES CONCENTRAÇÕES DE $\mathrm{YB}_{2} \mathrm{O}_{3}$.

FIGURA 39 - ESPECTRO DE EMISSÃO DE CONVERSÃO ASCENDENTE DO VIDRO GP COM DIFERENTES CONCENTRAÇÕES DE $\mathrm{YB}_{2} \mathrm{O}_{3}$ EXCITADO, EM $980 \mathrm{NM}$.

FIGURA 40 - RAZÃO DAS INTENSIDADES INTEGRADAS EM FUNÇÃO DA CONCENTRAÇÃO DE $\mathrm{YB}_{2} \mathrm{O}_{3}$.

FIGURA 41 - INTENSIDADE DE EMISSÃO DE CAF EM 547 NM (A) E EM 659 NM (B), RESPECTIVAMENTE EM FUNÇÃO DA POTÊNCIA DE BOMBEIO EM 980 NM. 
FIGURA 42 - DIAGRAMA DE ENERGIA DOS ÍONS $\mathrm{ER}^{3+} / \mathrm{YB}^{3+}$ E OS MECANISMOS DE CAF NO VIDRO GP. AS LINHAS SÓLIDAS INDICAM O COMPRIMENTO DE ONDA DE BOMBEIO, AS TRANSIÇÕES DE CAF, E AS TRANSIÇÕES RADIATIVAS, RESPECTIVAMENTE. AS LINHAS PONTILHADAS E ONDULADAS ESTÃO RELACIONADAS AOS PROCESSOS DE TRANSFERÊNCIA DE ENERGIA E RELAXAÇÃO NÃO RADIATIVA, RESPECTIVAMENTE.

FIGURA 43 - MICROGRAFIA (A) E DISTRIBUIÇÃO DO TAMANHO DE PARTÍCULA (B) DO VIDRO GP-Y3 TRATADO POR $2 \mathrm{H}$.

FIGURA 44 - MICROGRAFIA (A) E DISTRIBUIÇÃO DO TAMANHO DE PARTíCULA (B) DO VIDRO GP-Y3 TRATADO POR 48H......

FIGURA 45 - MICROGRAFIA (A) E DISTRIBUIÇÃO DO TAMANHO DE PARTíCULA (B) DO VIDRO GP-A3 TRATADO POR $2 \mathrm{H}$.

FIGURA 46 - MICROGRAFIA (A) E DISTRIBUIÇÃO DO TAMANHO DE PARTíCULA (B) DO VIDRO GP-A3 TRATADO POR $48 \mathrm{H}$.

FIGURA 47 - ESPECTRO DE EDS DA NP DO VIDRO GP-A3 TRATADO TERMICAMENTE POR 2H. ................. 58

FIGURA 48 - ESPECTRO DE EDS DA NP DO VIDRO GP-A3 TRATADO TERMICAMENTE POR 48H. 58

FIGURA 49 - ESPECTROS DE ABSORÇÃO ÓPTICA NA REGIÃO DO VISÍVEL E INFRAVERMELHO DOS VIDROS GPY3 TRATADOS TERMICAMENTE POR 2, 24, 48 E 72H.

FIGURA 50 - ESPECTROS DE ABSORÇÃO ÓPTICA NA REGIÃO DO VISÍVEL DOS VIDROS GP-A3 TRATADOS TERMICAMENTE POR 2, 24, 48 E 72H.....

FIGURA 51 - ESPECTROS DE EMISSÃO ÓPTICA NA REGIÃO DO VISÍVEL DO VIDRO GP-Y3 TRATADO TERMICAMENTE POR 1, 12, 28, 40 E 72H.

FIGURA 52 - RAZÃO ENTRE AS ÁREAS DAS BANDAS DE EMISSÃO DO VIDRO GP-Y3 EM FUNÇÃO DO TEMPO DE TRATAMENTO TÉRMICO. A CURVA FOI AJUSTADA PARA AUXILIAR NA ORIENTAÇÃO E NÃO ESTÁ RELACIONADA COM NENHUM MODELO TEÓRICO.

FIGURA 53 - ESPECTROS DE EMISSÃO ÓPTICA NA REGIÃO DO VISÍVEL DO VIDRO GP-A3 TRATADO TERMICAMENTE POR 2, 24, 48 E 72H.

FIGURA 54 - RAZÃO ENTRE AS ÁREAS DAS BANDAS DE EMISSÃO DO VIDRO GP-A3 EM FUNÇÃO DO TEMPO DE TRATAMENTO TÉRMICO. A CURVA FOI AJUSTADA PARA AUXILIAR NA ORIENTAÇÃO E NÃO ESTÁ RELACIONADA COM NENHUM MODELO TEÓRICO.

FIGURA 55 - INTENSIDADE DE EMISSÃO DE CAF EM 523, 547 E 659 NM DO VIDRO GP-Y3 EM FUNÇÃO DA POTÊNCIA DE BOMBEIO EM 980 NM.

FIGURA 56 - INTENSIDADE DE EMISSÃO DE CAF EM 523, 547 E 659 NM DO VIDRO GP-A3 EM FUNÇÃO DA POTÊNCIA DE BOMBEIO EM 980 NM.

FIGURA 57 - ESPECTROS DE ABSORÇÃO ÓPTICA NA REGIÃO DO VISÍVEL DOS VIDROS GP-Y3N TRATADOS TERMICAMENTE POR 2, 24, 48 E 72H.....

FIGURA 58 - ESPECTROS DE EMISSÃO ÓPTICA NA REGIÃO DO VISÍVEL DO VIDRO GP-Y3N TRATADO TERMICAMENTE POR 1H, 24H E DO VIDRO SEM PRATA.

FIGURA 59 - (A) RAZÃO ENTRE AS BANDAS 523 NM/408 NM, 547 NM/408 NM E 659 NM/408 NM E (B) RAZÃO ENTRE 523 NM/547 NM, 547 NM/659 NM E 523 NM/659 NM.

FIGURA 60 - INTENSIDADE DE EMISSÃO DE CAF EM 408 E 480 NM DO VIDRO GP-Y3N EM FUNÇÃO DA POTÊNCIA DE BOMBEIO EM 980 NM.

FIGURA 61 - DIAGRAMA ESQUEMÁTICO DOS NÍVEIS DE ENERGIA DOS ÍONS $\mathrm{ER}^{3+} \mathrm{E} \mathrm{YB}^{3+}$, EVIDENCIANDO OS PROCESSOS RESPONSÁVEIS PELAS EMISSÕES EM 408NM E O PROCESSO COOPERATIVO RESPONSÁVEL PELA EMISSÃO EM 480NM.

FIGURA 62 - MICROGRAFIA (A) E DISTRIBUIÇÃO DO TAMANHO DE PARTíCULA (B) DO VIDRO GP-CY3 TRATADO POR $2 \mathrm{H}$. 
FIGURA 63 - MICROGRAFIA DO VIDRO GP-CY3 TRATADO POR 48H.

FIGURA 64 - ESPECTROS DE ABSORÇÃO ÓPTICA NA REGIÃO DO VISÍVEL DOS VIDROS GP-CY3 TRATADOS TERMICAMENTE POR 2, 24, 48 E 72H

FIGURA 65 - ESPECTROS DE EMISSÃO ÓPTICA NA REGIÃO DO VISÍVEL DO VIDRO GP-Y3 TRATADO TERMICAMENTE POR 1, 12, 28, 40 E 72H.

FIGURA 66 - RAZÃO ENTRE AS ÁREAS DAS BANDAS DE EMISSÃO DO VIDRO GP-CY3 EM FUNÇÃO DO TEMPO DE TRATAMENTO TÉRMICO. A CURVA FOI AJUSTADA PARA AUXILIAR NA ORIENTAÇÃO E NÃO ESTÁ RELACIONADA COM NENHUM MODELO TEÓRICO.

FIGURA 67 - INTENSIDADE DE EMISSÃO DE CAF EM 523, 547 E 659 NM DO VIDRO GP-CY3 EM FUNÇÃO DA POTÊNCIA DE BOMBEIO EM 980 NM.

FIGURA 68 - MICROGRAFIAS OBTIDAS POR MET DOS VIDROS GPG-O3 TRATADO POR 28H. .78

FIGURA 69 - MICROGRAFIAS OBTIDAS POR MET DOS VIDROS GPG-O3 TRATADO POR 52H. 78

FIGURA 70 - DISTRIBUIÇÃO DO TAMANHO DE PARTíCULA DO VIDRO GPG-O3 TRATADO POR 28H. 79

FIGURA 71 - DISTRIBUIÇÃO DO TAMANHO DE PARTÍCULA DO VIDRO GPG-O3 TRATADO POR 52H. 79

FIGURA 72 - MICROGRAFIA E DISTRIBUIÇÃO DO TAMANHO DE PARTÍCULA DO VIDRO GPG-Y3 TRATADO POR $48 \mathrm{H}$. 80

FIGURA 73 - ESPECTRO DE EDS DAS NPS DO VIDRO GPG-Y3 TRATADO TERMICAMENTE POR 48H. 81

FIGURA 73 - ESPECTRO DE EDS DAS NPS DO VIDRO GPG-Y3 TRATADO TERMICAMENTE POR 48H. 82

FIGURA 74 - ESPECTROS DE ABSORÇÃO ÓPTICA NA REGIÃO DO VISÍVEL E INFRAVERMELHO DO VIDRO GPG-O3 TRATADOS TERMICAMENTE POR $1,12,28,40$ E $52 \mathrm{H}$.

FIGURA 75 - ESPECTROS DE ABSORÇÃO ÓPTICA NA REGIÃO DO VISÍVEL E INFRAVERMELHO DO VIDRO GPG-Y3 TRATADOS TERMICAMENTE POR 1, 24, 48, E $72 \mathrm{H}$.

FIGURA 76 - ESPECTROS DE EMISSÃO ÓPTICA NA REGIÃO DO VISÍVEL DO VIDRO GPG-O3 TRATADO TERMICAMENTE POR 1, 12, 28, 40 E $72 \mathrm{H}$.

FIGURA 77 - ESPECTROS DE EMISSÃO ÓPTICA NA REGIÃO DO VISÍVEL DO VIDRO GPG-Y3 TRATADO TERMICAMENTE POR 1, 12, 48 E $72 \mathrm{H}$.

FIGURA 78 - RAZÃO ENTRE AS ÁREAS DAS BANDAS DE EMISSÃO INTEGRADAS DO VIDRO GPG-O3 TRATADO POR 1, 12, 28, 40 E 52H.

FIGURA 79 - RAZÃO ENTRE AS ÁREAS DAS BANDAS DE EMISSÃO INTEGRADAS DO VIDRO GPG-Y3 TRATADO POR 1, 12, 28, 40 E 52H.

FIGURA 80 - INTENSIDADE DE EMISSÃO DE CAF EM FUNÇÃO DA EXCITAÇÃO EM 980 NM DO VIDRO GPG-O3.87

FIGURA 81 - INTENSIDADE DE EMISSÃO DE CAF EM FUNÇÃO DA EXCITAÇÃO EM 980 NM DO VIDRO GPG-Y3. 88 


\section{LISTA DE TABELAS}

TABELA 1 - ENERGIA DE FÔNON DE DIFERENTES SISTEMAS VÍTREOS [21-22] ........................................................... 8

TABELA 2 - CONFIGURAÇÃO ELETRÔNICA DOS ÍONS LANTANÍDEOS [32] .................................................................. 11

TABELA 3 - CONCENTRAÇÕES DE $\mathrm{YB}_{2} \mathrm{O}_{3}$ PARA AS MATRIZES GP E GPG DOPADAS COM 0,5\% EM PESO DE ER $\mathrm{O}_{3} \mathrm{O}_{3} \ldots \ldots \ldots \ldots \ldots \ldots \ldots . . . . . . . . . . .24$

TABELA 5 - PARÂMETROS E TIPO DE CADINHO UTILIZADOS NA PRODUÇÃO DAS AMOSTRAS.................................................... 26

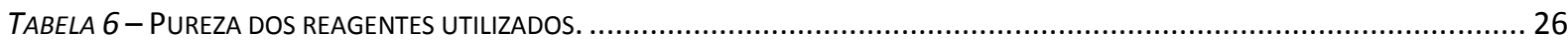

TABELA 7 - COMPOSIÇÃO EXPERIMENTAL (\% EM PESO) DETERMINADA POR EDX DOS VIDROS GP CO-DOPADOS COM DIFERENTES

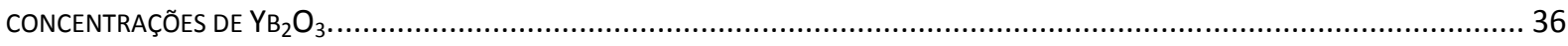

TABELA 8 - COMPOSIÇÃO EXPERIMENTAL (\% EM PESO) DETERMINADA POR EDX DOS VIDROS GPG CO-DOPADOS COM DIFERENTES

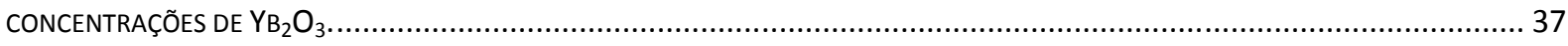

TABELA 9 - COMPOSIÇÃO EXPERIMENTAL (\% EM PESO) DETERMINADA POR EDX DOS VIDROS GP CO-DOPADOS CONTENDO PRATA E

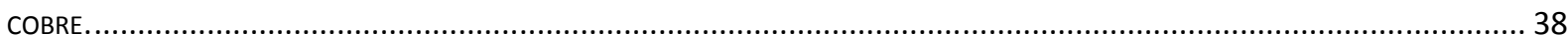

TABELA 10 - COMPOSIÇÃO EXPERIMENTAL (\% EM PESO) DETERMINADA POR EDX DOS VIDROS GPG CO-DOPADOS CONTENDO OURO. 


\section{LISTA DE ABREVIATURAS E SIGLAS}

\begin{tabular}{|c|c|}
\hline AEE & Absorção do estado excitado \\
\hline ATD & Análise Térmica Diferencial \\
\hline CAF & Conversão ascendente de freqüência \\
\hline CCTM & Centro de Ciências e Tecnologia de Materiais \\
\hline CLA & Centro de Lasers e Aplicações \\
\hline $\mathrm{DRX}$ & Difração de Raio X \\
\hline EDS & Fluorescência de raios $x$ por energia dispersiva acoplado ao MET \\
\hline EDX & Fluorescência de Raios X por Energia Dispersiva \\
\hline ETU & Conversão ascendente de freqüência por transferência de energia \\
\hline EUA & Estados Unidos da América \\
\hline EXAF & Espalhamento de Raio X \\
\hline FATEC-SP & Faculdade de Tecnologia de São Paulo \\
\hline GP & $\mathrm{GeO}_{2}-\mathrm{PbO}$ \\
\hline GPG & $\mathrm{PbO}-\mathrm{GeO}_{2}-\mathrm{Ga}_{2} \mathrm{O}_{3}$ \\
\hline GP-A3 Vidro & GP contendo $1,0 \%$ de $\mathrm{Yb}_{2} \mathrm{O}_{3}, 0,5 \%$ de $\mathrm{Er}_{2} \mathrm{O}_{3}$ e $3,0 \%$ de $\mathrm{AgNO}_{3}$ \\
\hline GPG-O3 & Vidro GPG contendo $1,0 \%$ de $\mathrm{Yb}_{2} \mathrm{O}_{3}, 0,5 \%$ de $\mathrm{Er}_{2} \mathrm{O}_{3}$ e $3,0 \%$ de $\mathrm{Au}_{2} \mathrm{O}_{3}$ \\
\hline GP-YC3 & Vidro GP contendo $3,0 \%$ de $\mathrm{Yb}_{2} \mathrm{O}_{3}, 0,5 \%$ de $\mathrm{Er}_{2} \mathrm{O}_{3}$ e $0,1 \%$ de $\mathrm{Cu}_{2} \mathrm{O}$ \\
\hline GPG-Y3 & Vidro GPG contendo $3,0 \%$ de $\mathrm{Yb}_{2} \mathrm{O}_{3}, 0,5 \%$ de $\mathrm{Er}_{2} \mathrm{O}_{3}$ e $3,0 \%$ de $\mathrm{AgNO}_{3}$ \\
\hline GP-Y3 & Vidro GP contendo $3,0 \%$ de $\mathrm{Yb}_{2} \mathrm{O}_{3}, 0,5 \%$ de $\mathrm{Er}_{2} \mathrm{O}_{3}$ e $1,0 \%$ de $\mathrm{AgNO}_{3}$ \\
\hline GP-Y3N & Vidro GP-Y3N produzido em cadinho de alumina pura \\
\hline IFUSP & Instituto de Física da USP \\
\hline IPEN & Instituto de Pesquisas Energéticas e Nucleares \\
\hline LC & Luminescência cooperativa \\
\hline LVD & Laboratório de Vidros e Datações \\
\hline MET & Microscopia Eletrônica de Transmissão \\
\hline NPs & Nanopartículas metálicas \\
\hline SC & Sensitização cooperativa \\
\hline USP & Universidade de São Paulo \\
\hline UFPE & Universidade Federal de Pernambuco \\
\hline
\end{tabular}




\section{LISTA DE SÍMBOLOS}

$\begin{array}{ll}2 \mathrm{R} & \text { Diâmetro da partícula } \\ \mathrm{E}_{1} & \text { Estado de energia fundamental } \\ \mathrm{E}_{2} & \text { Estado de energia excitado } \\ f & \text { Freqüência de vibração } \\ h & \text { Constante de Plank } \\ \mathrm{I}_{\mathrm{CAF}} & \text { Intensidade de emissão de CAF } \\ \mathrm{I}_{\mathrm{R}} & \text { Potência de excitação do infravermelho } \\ i \epsilon_{m 2} & \text { Parte imaginária da função dielétrica da NP } \\ \kappa & \text { Força elástica de restauração } \\ l_{\infty} & \text { Livre caminho médio do elétron em um material } \\ m_{0} & \text { Massa atômica de oxigênio } \\ m_{c} & \text { Massa do cátion } \\ m_{e f f} & \text { Carga e a massa efetiva do elétron } \\ \mathrm{n} & \text { Número de fótons absorvidos } \\ n & \text { Índice de refração do meio hospedeiro } \\ N_{e} & \text { Densidade eletrônica } \\ \mathrm{R} & \text { Raio da partícula } \\ t & \text { Tempo de relaxação } \\ \mathrm{T}_{\mathrm{A}} & \text { Temperatura ambiente } \\ \mathrm{T}_{\mathrm{C}} & \text { Temperatura de cristalização } \\ \mathrm{T}_{\mathrm{f}} & \text { Temperatura de fusão da fase cristalina } \\ \mathrm{T}_{\mathrm{g}} & \text { Temperatura de transição vítrea } \\ \mathrm{T}_{\mathrm{T}} & \text { Temperatura de tratamento } \\ V & \text { Número atômico } \\ \mathrm{Z} & \text { Massa reduzida dos íons } \\ \mu & \end{array}$




$\begin{array}{ll}v & \text { Freqüência da radiação } \\ v_{f} & \text { Velocidade de Fermi }=1,39 \times 10^{8} \mathrm{~cm} / \mathrm{s} \\ \epsilon_{m} & \text { Função dielétrica } \\ \epsilon_{m 1} & \text { Parte real da função dielétrica da NP } \\ \tau & \text { Constante de amortecimento (damping) } \\ \omega & \text { Freqüência angular da radiação incidente } \\ \omega_{p} & \text { Freqüência de plasma do metal }\end{array}$




\section{SUMÁRIO}

1. INTRODUÇÃO

OBJETIVO

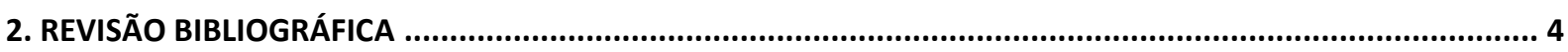

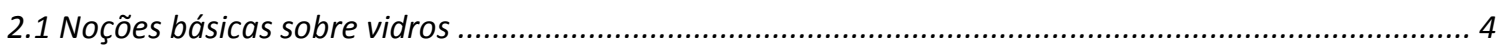

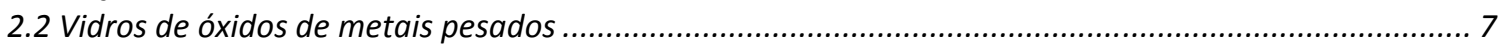

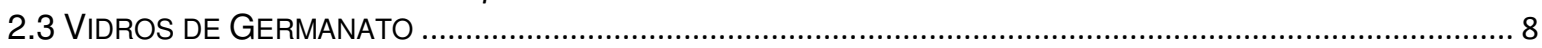

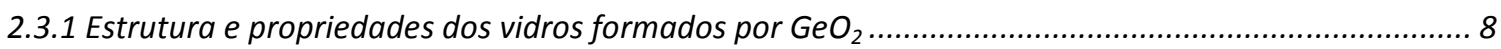

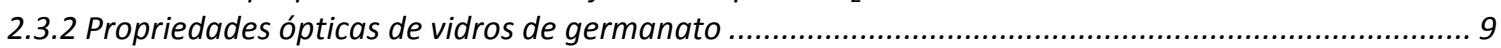

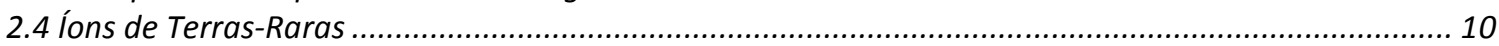

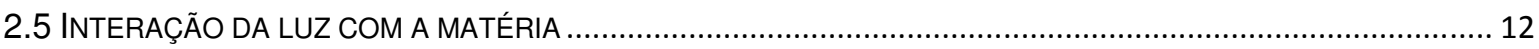

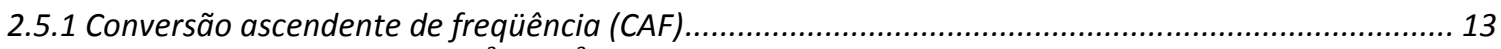

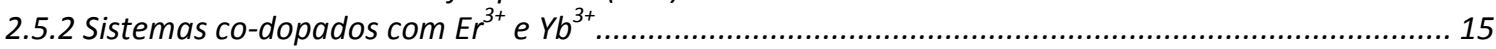

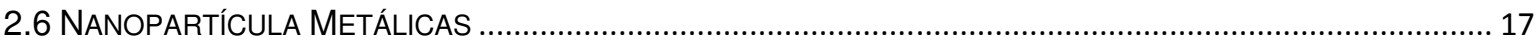

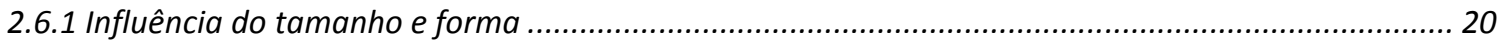

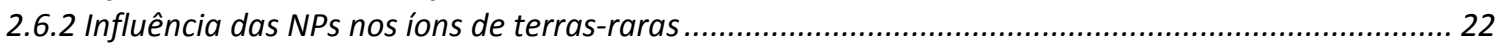

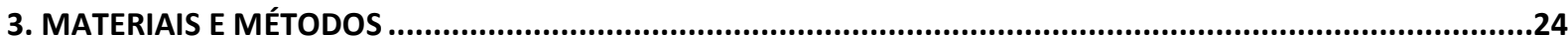

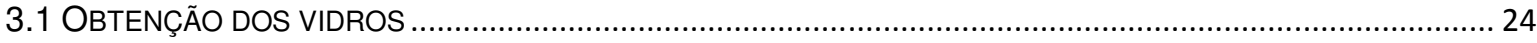

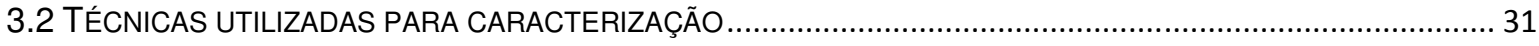

3.2.1 Espectroscopia de Fluorescência de Raios X por Energia Dispersiva (EDX)...................................... 31

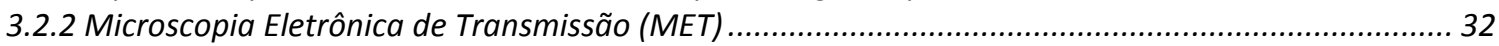

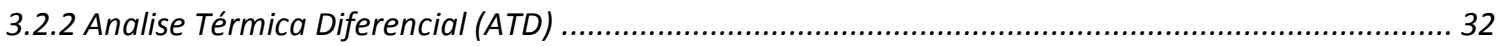

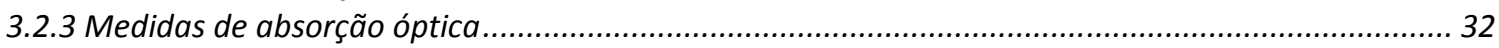

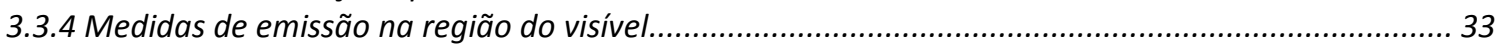

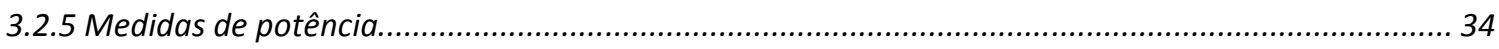

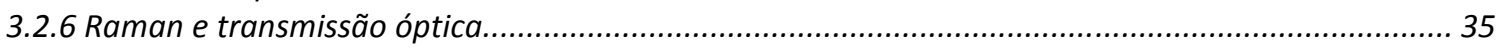

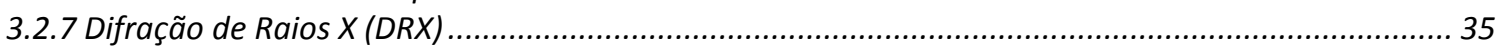

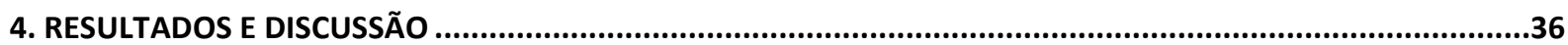

4.1 ESPECTROMETRIA DE FLUORESCÊNCIA DE RAIOS X POR ENERGIA DISPERSIVA (EDX) ........................36

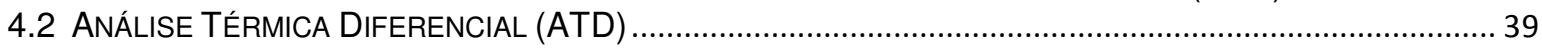

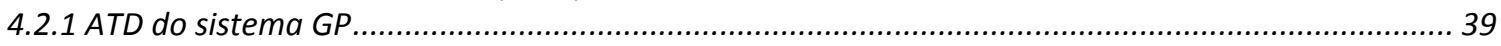

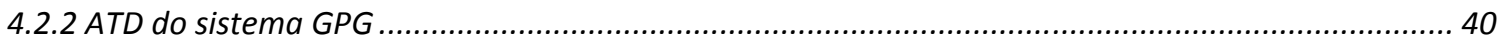

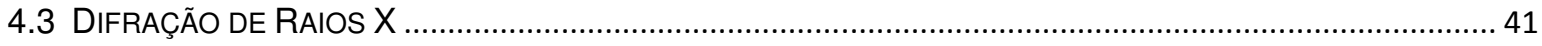

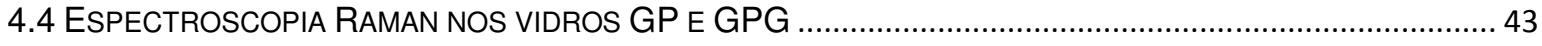

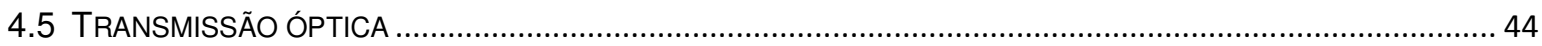

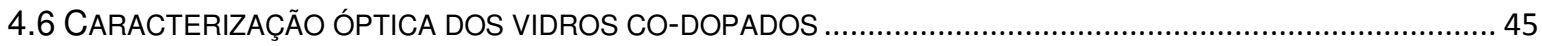

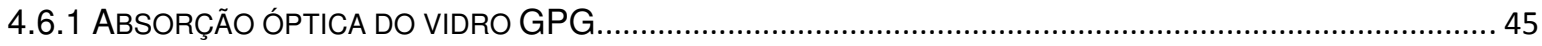

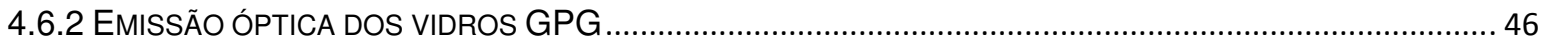

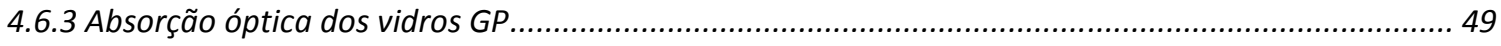

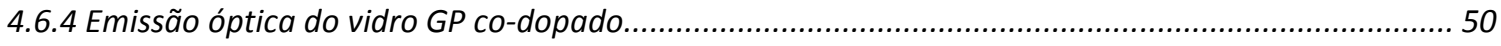

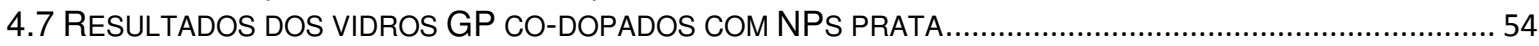

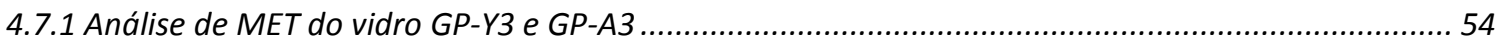

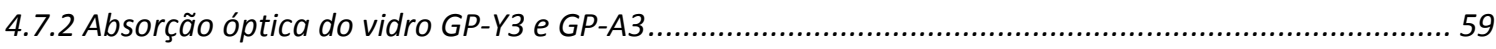

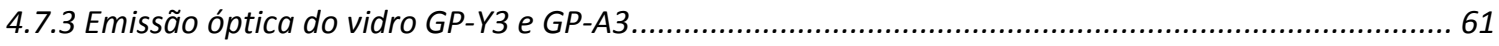

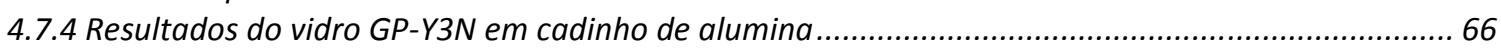




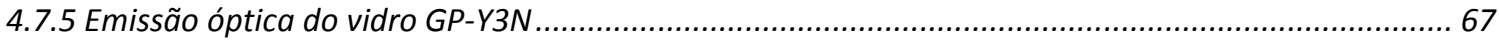

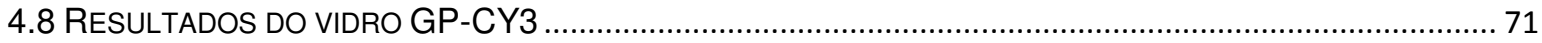

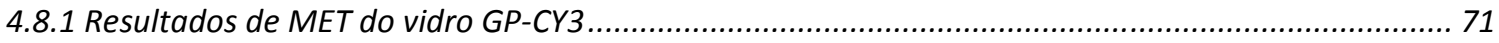

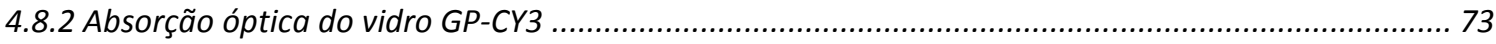

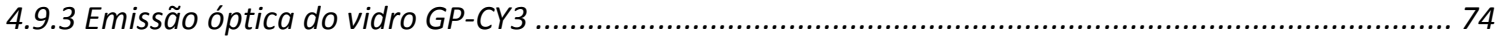

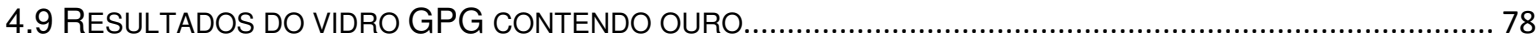

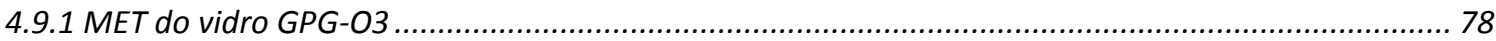

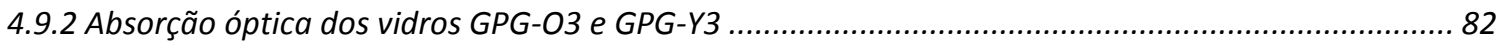

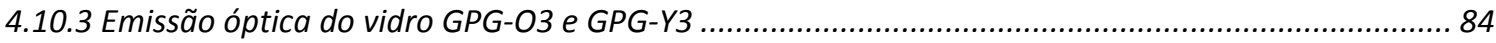

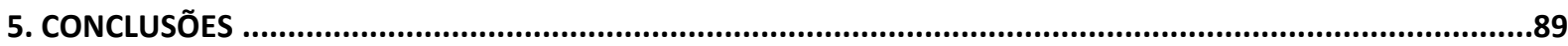

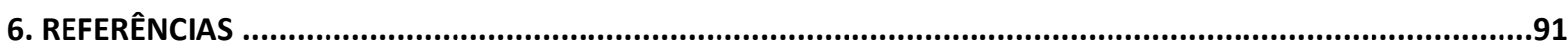

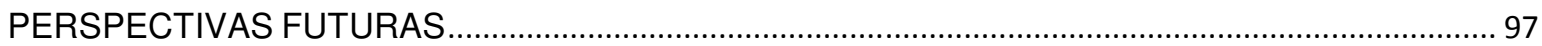

TRABALHOS PUBLICADOS E PARTICIPÃO EM EVENTOS .....................................................98 


\section{INTRODUÇÃO}

A nanotecnologia tem como marco a célebre palestra intitulada "There's Plenty of Room at the Bottom - Há mais espaço lá embaixo", tradução livre, proferido pelo físico norte-americano Richard P. Feynman", em 1959. Feynman defendia que não havia limite teórico para a construção de dispositivos em escala atômica, mas existiam limites práticos e tecnológicos que deveriam ser superados. Somente na década de 80 , a palavra "nanotecnologia" se popularizou, por meio das idéias propostas pelo também cientista norte-americano Eric Drexler $^{2}$, no qual propunha a construção de robôs e motores em escala nanométrica, além de computadores menores do que uma célula [1-2]. Todas essas idéias foram sugeridas e são estudadas até os dias de hoje, pelo mesmo cientista e por diversos outros entusiastas ao redor do mundo.

Dentre as diversas possibilidades do emprego da nanotecnologia para o desenvolvimento científico e tecnológico, a área do conhecimento conhecida como plasmônica, que lida com iteração da luz com nanopartículas metálicas (NPs), possui propriedades e fenômenos ainda não bem compreendidos, demandando extensos estudos. Entretanto, algumas aplicações estão se concretizando, como a obtenção de lasers e amplificadores ópticos mais eficientes [2-3], e não muito distante, as nanoesferas para tratamento de câncer e marcadores biológicos [4].

$\mathrm{O}$ uso de terras-raras tem sido extensivamente empregado em diversas aplicações tecnológicas, desde telas de monitores coloridos contendo túlio, térbio e európio capazes de emitir as cores primárias quando estimulados com luz ultravioleta [5], a fibras ópticas amplificadoras dopadas com praseodímio e érbio, operando em $1300 \mathrm{~nm}$ e $1530 \mathrm{~nm}$, respectivamente, possibilitando a extensão do alcance do sinal em fibras ópticas a distâncias cada vez maiores [6-9]. O érbio, além de possuir emissões no infravermelho, também emite em diversos comprimentos de onda na região do visível ( 530, 550 e $660 \mathrm{~nm}$ ) quando estimulado por um laser a

${ }^{1}$ Prêmio Nobel de Física, em 1965, devido aos seus estudo relacionados com a Eletrodinâmica Quântica.

2 Autor de diversos trabalhos, dentre eles o livro "Engines of creation - Máquinas da Criação", tradução livre. 
$980 \mathrm{~nm}$. Este processo é conhecido como conversão ascendente de freqüência (CAF) e será o alvo de estudo do presente trabalho.

Os íons de $\mathrm{Er}^{3+}$ possuem baixa secção de choque de absorção de luz no comprimento de onda de $980 \mathrm{~nm}$, tornando-o um meio emissor de baixa eficiência. Tal deficiência pode ser suprida pela presença dos íons de $\mathrm{Yb}^{3+}$, que possuem alta secção de choque de absorção nessa região do espectro e um mecanismo eficiente de transferência de energia $\mathrm{Yb}^{3+}\left({ }^{2} \mathrm{~F}_{5 / 2} \rightarrow{ }^{2} \mathrm{~F}_{7 / 2}\right) \rightarrow \mathrm{Er}^{3+}\left({ }^{4} \mathrm{I}_{15 / 2} \rightarrow{ }^{4} \mathrm{I}_{11 / 2}\right)$ [10-11]. Tais mecanismos de transferência de energia do itérbio para érbio já foram extensivamente estudados, mas não é de nosso conhecimento publicações que reportem os efeitos plasmônicos provenientes da redução de NPs em vidros codopados com érbio e itérbio.

Vidros dopados com terras-raras e NPs têm recebido grande atenção devido ao aumento das taxas de emissão radiativas e do campo local na vizinhança das NPs [1]. Nesse sentido, vidros de óxidos de metais pesados são considerados bons hospedeiros para a nucleação de NPs, além de possuírem alto índice de refração ( 2), baixa energia de fônon $\left(\sim 700 \mathrm{~cm}^{-1}\right)$, larga janela de transmissão (400 nm até $4500 \mathrm{~nm}$ ), alta resistência mecânica e alta durabilidade química [12].

Os vidros produzidos neste trabalho foram caracterizados por meio de medidas de absorção, transmissão e emissão óptica, e espectroscopia Raman. Além da caracterização óptica, também foram realizadas análise de Fluorescência de Raios X por Energia Dispersiva (EDX) e Difração de Raio X (DRX), com a finalidade de se determinar a composição e a estrutura das amostras, respectivamente, e Análise Térmica Diferencial (ATD), com intuito de se determinar as temperaturas e transição vítrea, cristalização e fusão das fases cristalinas e Microscopia Eletrônica de Transmissão (MET), para se determinar o tamanho e morfologia das NPs.

Este trabalho consiste de cinco capítulos, iniciando-se pela introdução, revisão bibliográfica, onde são introduzidos os conceitos de vidros de óxidos de metais pesados, terras-raras e NPs (Capítulo 2 - Revisão da Literatura), as técnicas experimentais para a fabricação e caracterização dos vidros (Capítulo 3 - Materiais e Métodos), a apresentação e discussão dos resultados (Capítulo 4 - Resultados e Discussões), e finalmente as conclusões do trabalho. 


\section{OBJETIVO}

Este trabalho tem como objetivo a produção e caracterização de vidros óxidos de metais pesados co-dopados com $\mathrm{Yb}_{2} \mathrm{O}_{3}$ e $\mathrm{Er}_{2} \mathrm{O}_{3}$ contendo nanopartículas metálicas para possíveis aplicações em fotônica. 


\section{REVISÃO BIBLIOGRÁFICA}

\subsection{Noções básicas sobre vidros}

Os vidros são muitas vezes considerados como sendo líquidos superresfriados. Entretanto apenas alguns poucos líquidos podem ser super-resfriados e formarem vidros [13]. Uma das possíveis definições é considerar os vidros como sólidos não cristalinos que apresentam o fenômeno de transição vítrea [14]. A Figura 1 mostra um esquema bidimensional de uma estrutura ordenada representando um cristal e uma estrutura e uma estrutura desordenada, semelhante à de um vidro.

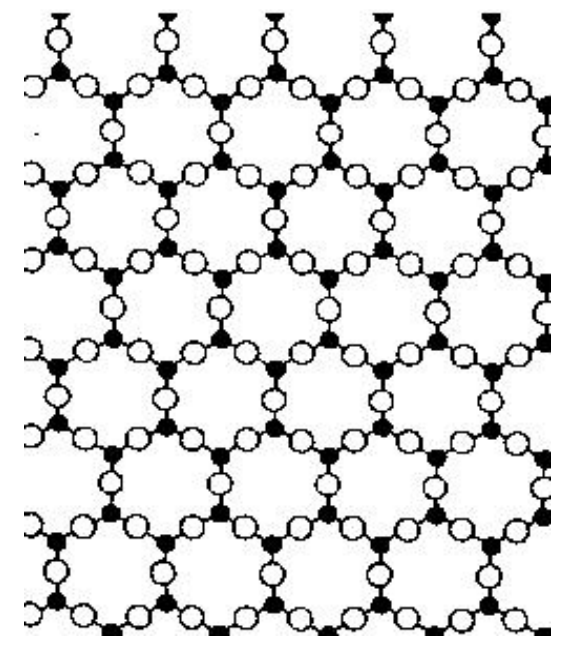

(a)

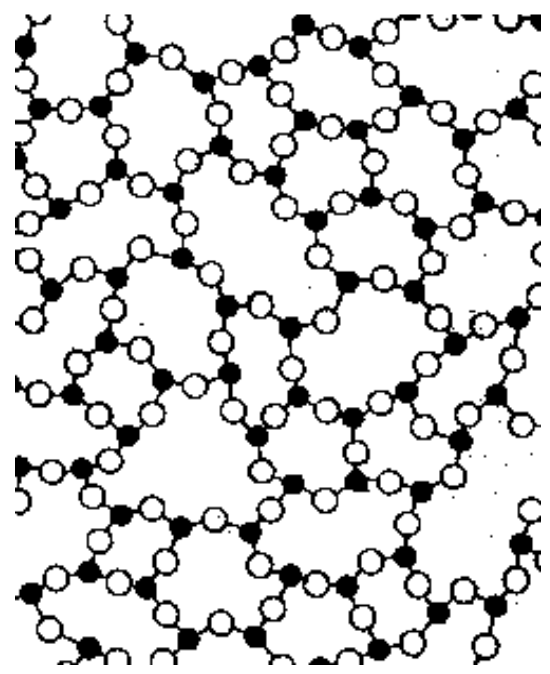

(b)

Figura 1 - Analogia bidimensional esquemática, segundo Zacariasen, para ilustrar a diferença entre: (a) estrutura regular repetida de um cristal e (b) rede caótica do vidro de mesma composição [15].

Para a formação de vidros é necessário que um líquido seja resfriado até o estado sólido sem cristalizar-se. Durante o resfriamento do líquido, ocorre a passagem por uma temperatura conhecida como temperatura de transição vítrea (ou 
Tg), na qual um líquido super-resfriado passa por mudanças nas taxas de variações das propriedades físicas e termodinâmicas. O gráfico da Figura 2 mostra o volume de um material em função da temperatura, com destaque para a temperatura de transição vítrea $(\mathrm{Tg})$, isto é, a temperatura de transformação líquido-vidro, e a temperatura de cristalização (Tc) [16].

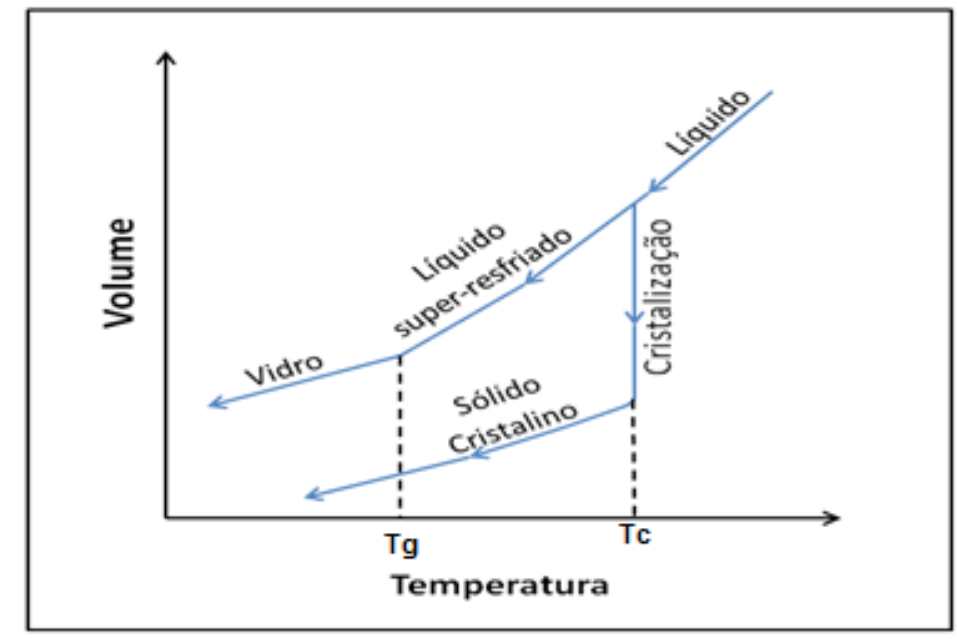

Figura 2 - Diferentes taxas de resfriamento para formação do vidro e cristal.

Os vidros podem ser tanto inorgânicos como orgânicos e têm como característica a ausência de ordenamento atômico em longas distâncias, possuindo ordenamento atômico somente em pequenas distâncias.

Uma técnica experimental extremamente útil para caracterização dos vidros é a Análise Térmica Diferencial (ATD) [17]. Trata-se de uma técnica que permite comparar a temperatura de uma amostra (objeto de estudo) em relação a um material de referência (material inerte) por meio de um aquecimento ou resfriamento linear em um forno elétrico. A diferença de temperatura entre a amostra e a referência é a função armazenada. Transições que envolvam trocas de calor podem então ser detectadas como uma mudança na linha de base (background) da curva ou como picos exotérmicos ou endotérmicos. Transições de segunda ordem, como a transição vítrea [18], são associadas à mudanças na linha de base da curva. Picos endotérmicos podem ser associados a reações de fusão como também a reações de 
decomposição ou dissociação. Por outro lado, picos exotérmicos são associados a mudanças de fase cristalina, ou cristalização.

A Figura 3 mostra uma típica curva obtida por ATD para o vidro $\mathrm{PbO}-\mathrm{GeO}_{2}$ $\mathrm{Ga}_{2} \mathrm{O}_{3}$, tomado como exemplo. Nessa Figura observa-se claramente a temperatura de transição vítrea $\boldsymbol{T g}$, temperatura de cristalização $\boldsymbol{T c}$ e temperatura de fusão $\boldsymbol{T f}$. Obtém-se a temperatura que determina o início de cada transição pela intersecção de uma linha que extrapola a linha base com outra linha tangente à curva no ponto de inflexão, (linhas tracejadas) [18].

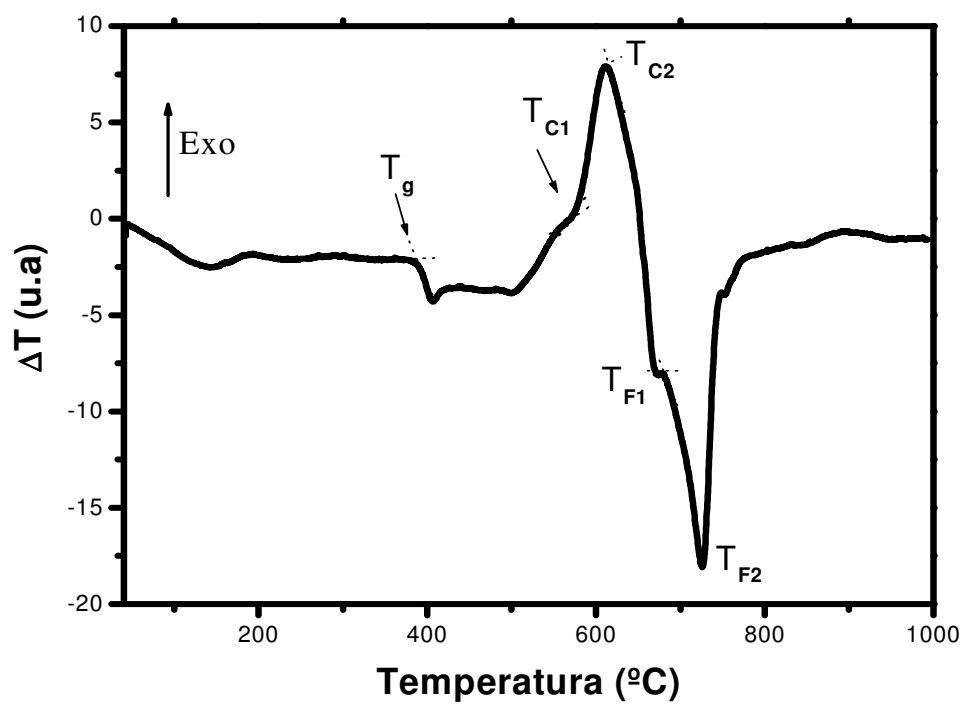

Figura 3 - Típica curva de ATD para um vidro $\mathrm{PbO}-\mathrm{GeO}_{2}-\mathrm{Ga}_{2} \mathrm{O}_{3}$. [19].

Observa-se neste caso particular por meio da curva de ATD acima, que há duas temperaturas de cristalização ( $T_{C 1}$ e $T_{C 2}$ ), e duas temperaturas de fusão ( $T_{F 1}$ e $\mathrm{T}_{\mathrm{F} 2}$ ), relacionadas com as transições exotérmicas e endotérmicas, respectivamente. 


\subsection{Vidros de óxidos de metais pesados}

Os vidros de óxido de metais pesados [20] têm características específicas, pois são formados por cátions com massa atômica superior a 50, e com baixas energias de ligação entre estes cátions e os átomos de oxigênio. Estas baixas energias de ligação proporcionam transmissão de luz com longos comprimentos de onda na região do infravermelho (até $8 \mu \mathrm{m}$ ). A influência da ligação cátion-oxigênio no limiar de transmissão no infravermelho é dada pela Equação 1 :

$$
v=\frac{1}{2 \pi} \sqrt{\frac{\kappa}{f}}
$$

onde $f$ é freqüência de vibração, $\kappa$ é a força elástica de restauração e $\mu$ é massa reduzida dos íons, dada por:

$$
\mu=\frac{m_{c} m_{o}}{m_{c}+m_{o}}
$$

Onde $m_{c}$ é a massa do cátion e $m_{0}$ é a massa atômica de oxigênio

A baixa energia de ligação tem como conseqüência a obtenção de vidros com baixas energias de fônon, de aproximadamente $750 \mathrm{~cm}^{-1}$, que são inferiores a de outros vidros, como mostrado na Tabela 1. Esses vidros também apresentam densidades superiores a $6 \mathrm{~g} / \mathrm{cm}^{3}$ e índice de refração superiores a 2,0, tendo muitas aplicações em fotônica e em circuitos optoeletrônicos. O alto índice de refração é também proveniente da presença de elementos com grande massa atômica na composição química [20]. 


\begin{tabular}{cc} 
Tabela 1 - Energia de fônon de diferentes sistemas vítreos [21-22]. \\
\hline Vidros & Energia de fônon $\left(\mathrm{cm}^{-1}\right)$ \\
\hline Boratos & 1400 \\
Fosfatos & 1100 \\
Silicatos & 1000 \\
Teluretos & 750 \\
Germanato & 750 \\
Fluoretos & 500 \\
Calcogenetos & 320 \\
\hline
\end{tabular}

Deste modo, as perdas por processos não-radiativos são pequenas e a eficiência da luminescência produzida pelas terras-raras são mais significativas. Apesar dos vidros de Fluoretos e Calcogenetos apresentarem baixas energias de fônon, tais vidros possuem durabilidade química e estabilidade térmica inferiores em relação a outros vidros. Isso faz com que os vidros de óxidos de metais pesados sejam mais apropriados em aplicações práticas [22].

\subsection{Vidros de Germanato}

\subsubsection{Estrutura e propriedades dos vidros formados por $\mathrm{GeO}_{2}$}

O dióxido do germânio é um forte candidato para formação de novas matrizes e meios ópticos. A capacidade do dióxido de germânio em formar vidro é conhecida há muito tempo. Em 1926, Dennis e Laubengayer [23] sintetizaram o vidro de dióxido de germânio seguido por Krakau [24] em 1939. Estudos mais detalhados sobre os vidros de germanato, entretanto, foram realizados somente nas últimas décadas.

Um dos fenômenos que ainda tem sido investigado é a descontinuidade das curvas de densidade (Figura 4 a) quando modificadores de rede (em geral óxidos 
alcalinos) são introduzidos ao vidro binários de $\mathrm{GeO}_{2}$. Ivanov e Evstropiev $[25,26]$ atribuíram tal descontinuidade a formação de octaedros $\mathrm{GeO}_{6}$ na faixa compreendida entre $0-15 \%$ em mol de $\mathrm{R}_{2} \mathrm{O}$ ligado ao aumento da densidade; para concentrações acima de $15 \%$ em mol de óxidos alcalinos ocorre a formação de tetraedros de $\mathrm{GeO}_{4}$ e a de oxigênios não ligados. Uma evidência experimental do aumento do número de coordenação do Ge pode ser compreendida pelo aumento na distância de ligação Ge-O mostrado na Figura 4 (b) [27].

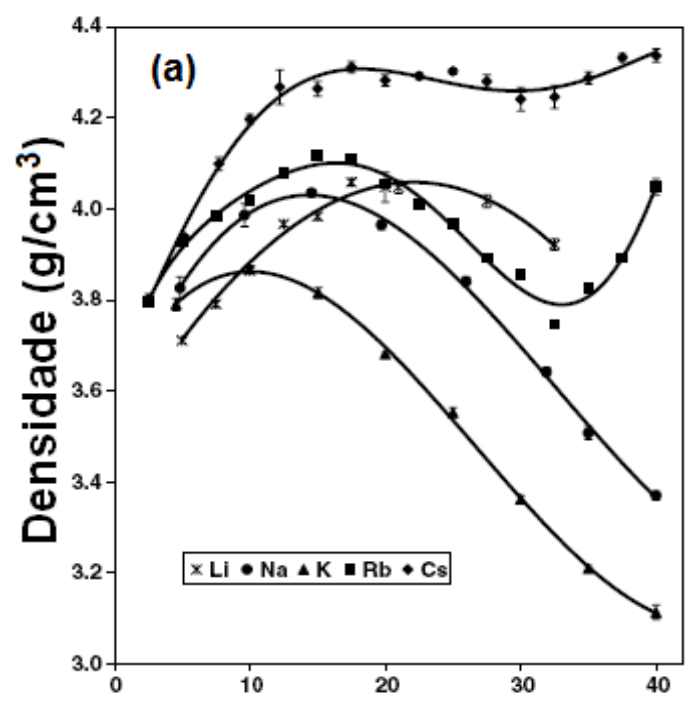

$\%$ molar de alcalinos

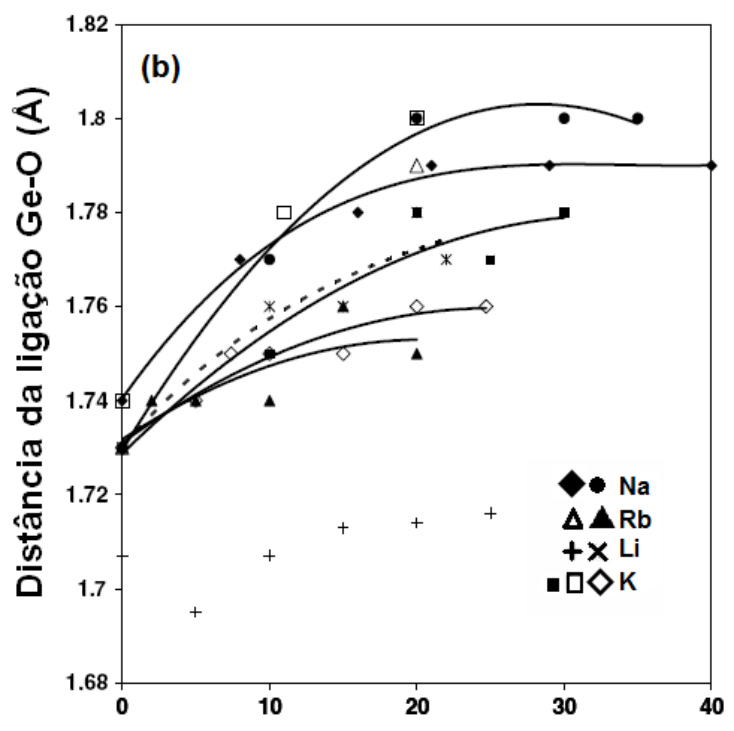

$\%$ molar de alcalinos

Figura 4 - (a) Densidade em função da concentração de modificadores e (b) distância de Ge-O determinada experimentalmente por espalhamento de Raio X e EXAF [27].

\subsubsection{Propriedades ópticas de vidros de germanato}

Uma série de estudos foram conduzidos [28,29] para obter novos materiais ópticos, especialmente estudos de vidros com características específicas de dispersão. Poluklin $[28,29]$ descobriu que o formador de vidro por dióxido de 
germânio tem uma pequena constante de dispersão, a qual é menor na região azul do espectro visível, similar aos vidros boratos.

Quando os vidros a base de germanato são comparados aos sistemas silicato e borato, observa-se que altos índices de refração podem ser obtidos adicionandose teores de óxidos de metais pesados $\left(\mathrm{PbO}, \mathrm{TiO}_{2}, \mathrm{Nb}_{2} \mathrm{O}_{5}, \mathrm{Ta}_{2} \mathrm{O}_{5}\right)$ consideravelmente mais baixos. Para índices de refração na faixa de 1,60-1,65, estes óxidos não são necessários. O dióxido de germânio permite a obtenção de vidros com alto índice de refração que não podem ser obtidos em vidros borossilicatos $[30,31]$.

\section{4 Íons de Terras-Raras}

Desde a década de 60, diversas aplicações envolvendo íons de terras-raras vêm sendo desenvolvidas, como dispositivo fotônicos na região do visível e amplificadores ópticos na região do infravermelho. Tais aplicações só são possíveis devido a propriedades únicas, caracterizadas por linhas estreitas e bandas de emissão e absorção característica de cada íon de terra-rara.

Os elementos terras-raras possuem a camada $4 f$ fortemente blindada [32] pelos elétrons mais externos que formam uma camada chamada "xenon" com dois elétrons na camada $5 s$ e seis na camada $5 p$. A camada $4 f$ é vizinha e interna à "camada xenon". Enquanto a camada $4 f$ não completamente preenchida com 14 elétrons, um dado número de níveis $4 f$ permanecerá desocupado; os elétrons presentes na camada $4 f$ podem ser levados por absorção de radiação eletromagnética para estes níveis vazios. Estas transições originam os espectros de absorção e de emissão das terras-raras. Tais espectros são mais estreitos do que os relativos às transições de metais de transições. Isto se deve ao fato de que durante a transição, o elétron fica na região interna à "camada xenon" e interage fracamente com íons externos.

Na Tabela 2 é mostrada a configuração eletrônica dos íons lantanídeos. A distribuição eletrônica pode ser facilmente compreendida a partir da estrutura 
eletrônica do átomo de xenônio, cujo número atômico (Z) é 54 e configuração eletrônica representada abaixo:

$$
1 s^{2} 2 s^{2} 2 p^{6} 3 s^{2} 3 p^{6} 3 d^{10} 4 s^{2} 4 p^{6} 4 d^{10} 5 s^{2} 5 p^{6}
$$

Os estados eletrônicos dos íons de terras-raras podem ser descritos a partir dos números quânticos $L, S$ e $J$ para formar a notação espectroscópica ${ }^{2 s+1} L_{J}$, onde $L$ é igual à somatória do momento angular da camada $4 \mathrm{f}\left(L=\sum l_{i}\right)$, especificado pelas letras $S, P, D, F, G \ldots$, podendo assumir os valores $0,1,2,3,4 \ldots$, respectivamente; $S$ $\left(S=\Sigma s_{i}\right)$ representa o momento do spin total, podendo assumir valores de acordo com o principio de exclusão de Pauli, e $\boldsymbol{J}$ é o momento angular total, dado pela soma vetorial de $L+S$.

Tabela 2 - configuração eletrônica dos íons lantanídeos [32].

\begin{tabular}{|c|c|c|c|}
\hline $\begin{array}{c}\text { Número atômico } \\
(\mathrm{Z})\end{array}$ & $\begin{array}{l}\text { Elemento } \\
\text { (Símbolo) }\end{array}$ & Íon trivalente & $\begin{array}{c}\text { Estado } \\
\text { Fundamental }\end{array}$ \\
\hline 58 & Cério $(\mathrm{Ce})$ & $\mathrm{Xe}_{4} \mathrm{f}^{1}$ & ${ }^{2} \mathrm{~F}_{5 / 2}$ \\
\hline 59 & Praseodímio (Pr) & $\mathrm{Xe} 4 \mathrm{f}^{2}$ & ${ }^{3} \mathrm{H}_{4}$ \\
\hline 60 & Neodímio (Nd) & $\mathrm{Xe} 4 \mathrm{f}^{3}$ & ${ }^{4} l_{9 / 2}$ \\
\hline 61 & Promécio (Pm) & $\mathrm{Xe} 4 \mathrm{f}^{4}$ & ${ }^{5} I_{4}$ \\
\hline 62 & Samário (Sm) & $\mathrm{Xe} 4 \mathrm{f}^{5}$ & ${ }^{6} \mathrm{H}_{5 / 2}$ \\
\hline 63 & Európio (Eu) & $\mathrm{Xe} 4 \mathrm{f}^{6}$ & ${ }^{7} \mathrm{~F}_{0}$ \\
\hline 64 & Gadolínio (Gd) & $\mathrm{Xe} 4 \mathrm{f}^{7}$ & ${ }^{8} S_{7 / 2}$ \\
\hline 65 & Térbio (Tb) & $\mathrm{Xe} 4 \mathrm{f}^{8}$ & ${ }^{7} \mathrm{~F}_{6}$ \\
\hline 66 & Disprósio (Dy) & $\mathrm{Xe} 4 \mathrm{f}^{9}$ & ${ }^{6} \mathrm{H}_{15 / 2}$ \\
\hline 67 & Hólmio (Ho) & $\mathrm{Xe} 4 \mathrm{f}^{10}$ & ${ }^{5} I_{8}$ \\
\hline 68 & Érbio (Er) & $\mathrm{Xe} 4 \mathrm{f}^{11}$ & ${ }^{4} I_{15 / 2}$ \\
\hline 69 & Túlio (Tm) & $\mathrm{Xe} 4 \mathrm{f}^{12}$ & ${ }^{3} \mathrm{H}_{6}$ \\
\hline 70 & Itérbio (Yb) & $\mathrm{Xe} 4 \mathrm{f}^{13}$ & ${ }^{2} \mathrm{~F}_{7 / 2}$ \\
\hline 71 & Lutécio (Lu) & $\mathrm{Xe} 4 \mathrm{f}^{14}$ & ${ }^{1} S_{0}$ \\
\hline
\end{tabular}




\subsection{Interação da luz com a matéria}

Os processos de interação da radiação com a matéria podem ser explicados, considerando as transições energéticas entre dois estados energéticos de um átomo $\left(E_{2}\right.$ e $E_{1}$ ) na presença de um campo eletromagnético e que são descritos através da relação de Bohr (Equação 3). Tais processos são classificados em absorção, emissão espontânea e emissão estimulada e são explicados a partir dos diagramas mostrados na Figura 5 e 6.

$$
h v=E_{2}-E_{1}
$$

onde $h$ é a constante de Plank, e $v$ a freqüência da radiação

O processo de absorção ocorre quando um fóton com energia equivalente a transição $E_{2}-E_{1}$ é absorvido pelo átomo (Figura 5), levando a uma transição do estado de menor energia $\left(E_{1}\right)$ para um estado de maior energia ou excitado $\left(E_{2}\right)$. Após um determinado tempo característico, o átomo pode decair espontaneamente emitindo radiação na forma radiativa ou não-radiativa, retornando assim para seu estado fundamental ou de menor energia $\left(E_{1}\right)$.

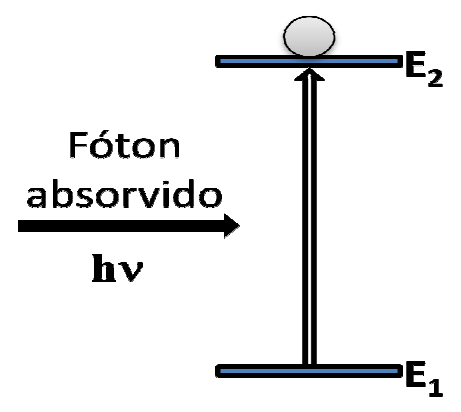

Absorção

(a)

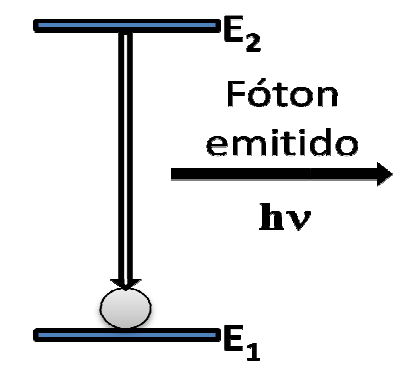

Emissão

(b)

Figura 5 - Emissão Espontânea. 
A emissão estimulada ocorre quando um fóton com energia $h v=E_{2}-E_{1}$ incide sobre um átomo que está no estado excitado $E_{2}$, estimulando seu decaimento ao estado $E_{1}$ com emissão de um fóton de energia $h v=E_{2}-E_{1}$. Neste processo de emissão estimulada, o fóton emitido é idêntico ao incidente (são coerentes, isto é, têm a mesma energia, movem-se na mesma direção e possuem a mesma fase de radiação). $O$ resultado do processo é que 2 fótons idênticos emergem do átomo de uma só vez, o incidente e o estimulado, como mostrado na Figura 6. O processo de emissão estimulada é o fundamento da geração de luz laser.

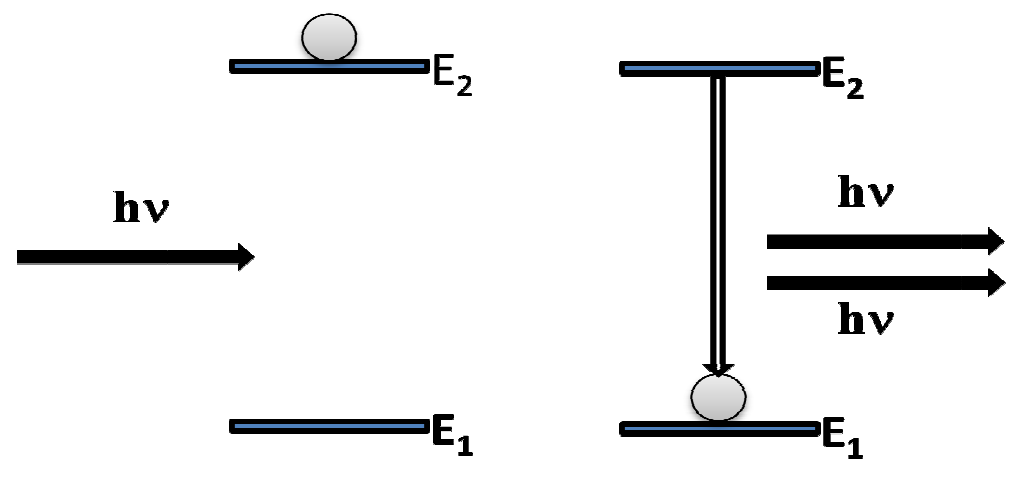

Figura 6 - Emissão Estimulada.

\subsubsection{Conversão ascendente de freqüência (CAF)}

O fenômeno de CAF consiste, basicamente, na emissão de fótons com energia maior do que a energia dos fótons de bombeio. Atualmente, existem diversas aplicações baseadas nos processos de conversão ascendente, tais como sensores de temperatura, emissão laser na região do visível e "displays" 3D [33-37]. $\mathrm{Na}$ Figura 7 são mostrados alguns dos possíveis mecanismos de CAF que podem ocorrer em íons de terras-raras, conhecidos como: conversão ascendente de freqüência por transferência de energia (acrônimo em inglês ETU), absorção do estado excitado (AEE), sensitização cooperativa (SC) e luminescência cooperativa (LC), com eficiência (n) igual a $10^{3}, 10^{5}, 10^{6} \mathrm{e} 10 \mathrm{em} \mathrm{W} / \mathrm{cm}^{2}$, respectivamente [38]. 


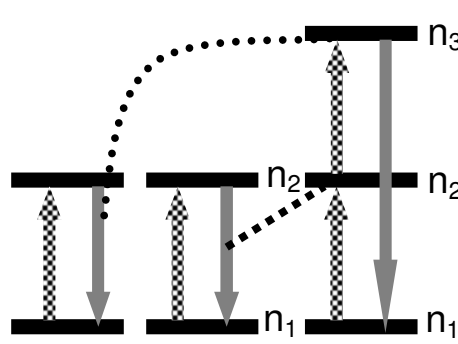

ETU

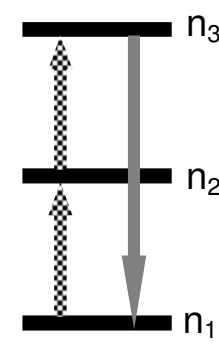

AEE

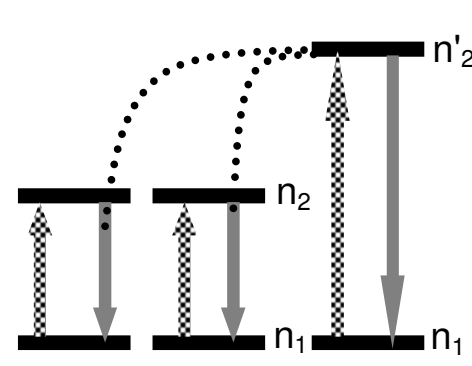

SC

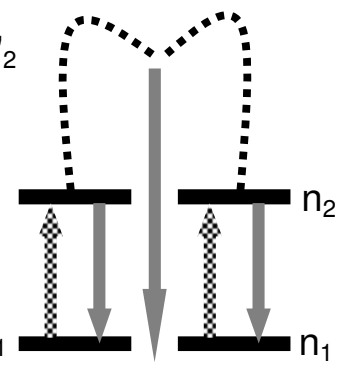

LC

Figura 7 - Esquema representando alguns processos de CAF. (ETU) conversão ascendente de freqüência por transferência de energia; (AEE) absorção do estado excitado; (SC) sensitização cooperativa; (LC) luminescência cooperativa [38].

Os dois primeiros processos (ETU e AEE) são os mais conhecidos e

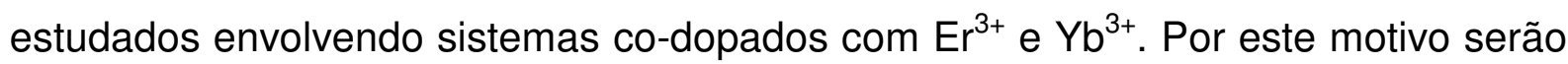
discutidos mais detalhadamente no item abaixo, a partir do esquema apresentado na Figura 8.

- ETU: Este mecanismo envolve a interação entre dois ou mais íons distintos, o primeiro íon, já no estado metaestável $\left(\mathrm{n}_{2}\right)$, interage com um segundo íon, que também está no estado metaestável; o segundo íon decai para o estado fundamental $\left(n_{1}\right)$, transferindo sua energia para o primeiro íon, levando-o para um estado de maior energia $\left(n_{3}\right)$. A partir deste nível ocorre a emissão de um fóton com maior energia, resultante da interação de dois fótons;

- $\underline{A E E}:$ Neste processo, um único íon no estado fundamental $\left(\mathrm{n}_{1}\right)$, absorve seqüencialmente dois fótons provenientes da excitação, levando-o para um estado metaestável $\left(n_{2}\right)$ e posteriormente ao nível de maior energia $\left(n_{3}\right)$. A partir deste último nível ocorre o decaimento para o estado fundamental, resultando na emissão de um fóton de maior energia (Figura 7).

A partir da seguinte expressão é possível determinar, experimentalmente, a quantidade de fótons que participam do processo de CAF:

$$
\mathrm{I}_{\mathrm{CAF}} \alpha \mathrm{I}_{\mathbb{R}^{n}}{ }^{\mathrm{n}}
$$


A intensidade de emissão de CAF ( $\mathrm{I}_{\mathrm{CAF}}$ ) é proporcional à potência de excitação do infravermelho, $I_{\mathbb{R}}$, ou seja, $I_{C A F} \alpha I_{\mathbb{R}^{n}}{ }^{n}$, onde $n$ representa o número de fótons absorvidos e necessários para popular os estados emissores [39]; n é determinado pelo coeficiente angular da reta do gráfico da intensidade de CAF em função da potência de bombeio.

\subsubsection{Sistemas co-dopados com $\mathrm{Er}^{3+}$ e $\mathrm{Yb}^{3+}$}

Vidros dopados com íons de érbio têm sido usados em diversas aplicações fotônicas, tais como emissões lasers na região do visível, baseados na emissão de CAF do érbio, e de emissões na região do infravermelho para aplicações na terceira janela de telecomunicações, "displays" coloridos e sensores [33-37]. Entretanto, o bombeio eficiente desse sistema é limitado pela baixa seção de choque de absorção do $\mathrm{Er}^{3+}$ em $980 \mathrm{~nm}$ que pode ser aumentada com a co-dopagem de íons de $\mathrm{Yb}^{3+}$ [40-42].

O termo co-dopagem é utilizado quando em um material existem mais de um tipo de íon; neste caso pode ocorrer transferência de energia de íons doadores para aceitadores. Neste trabalhado será estudada a transferência do íon doador $\mathrm{Yb}^{3+}$ para o íon aceitador $\mathrm{Er}^{3+}$. A transferência de energia em íons de terras-raras é causada por interação entre dois íons, geralmente através do acoplamento dipolodipolo.

Uma importante propriedade do íon $\mathrm{Yb}^{3+}$ é a sobreposição espectral de sua banda de emissão $\left({ }^{2} \mathrm{~F}_{5 / 2} \rightarrow{ }^{2} \mathrm{~F}_{7 / 2}\right)$ com a banda de absorção do íon $\mathrm{Er}^{3+}\left({ }^{4} \mathrm{I}_{15 / 2} \rightarrow\right.$ ${ }^{4} I_{11 / 2}$ ), o que permite um eficiente mecanismo de transferência de energia entre os referidos íons $\left(\mathrm{Yb}^{3+} \rightarrow \mathrm{Er}^{3+}\right)[21,43]$. Além disso, íons $\mathrm{Yb}^{3+}$ colaboram para minimizar a potência necessária para iniciar a emissão laser do $\mathrm{Er}^{3+}$ em torno de 1530 nm [42].

Outra vantagem da co-dopagem é que com uma pequena quantidade de íons aceitadores $\left(\mathrm{Er}^{3+}\right)$ consegue-se melhorar as características do laser apenas aumentando a quantidade de íons doadores $\left(\mathrm{Yb}^{3+}\right)$. Essas melhorias podem ser 
significativas, fazendo com que uma matriz co-dopada com baixo teor de érbio tenha uma eficiência laser superior a uma matriz dopada apenas com um elemento de terra-rara mesmo com maiores teores [42].

A Figura 8 mostra, de forma simplificada, a transferência de energia entre íons $\mathrm{Yb}^{3+} \mathrm{e} \mathrm{Er}^{3+}\left({ }^{2} \mathrm{~F}_{5 / 2} \rightarrow{ }^{4} \mathrm{I}_{11 / 2}\right)$.

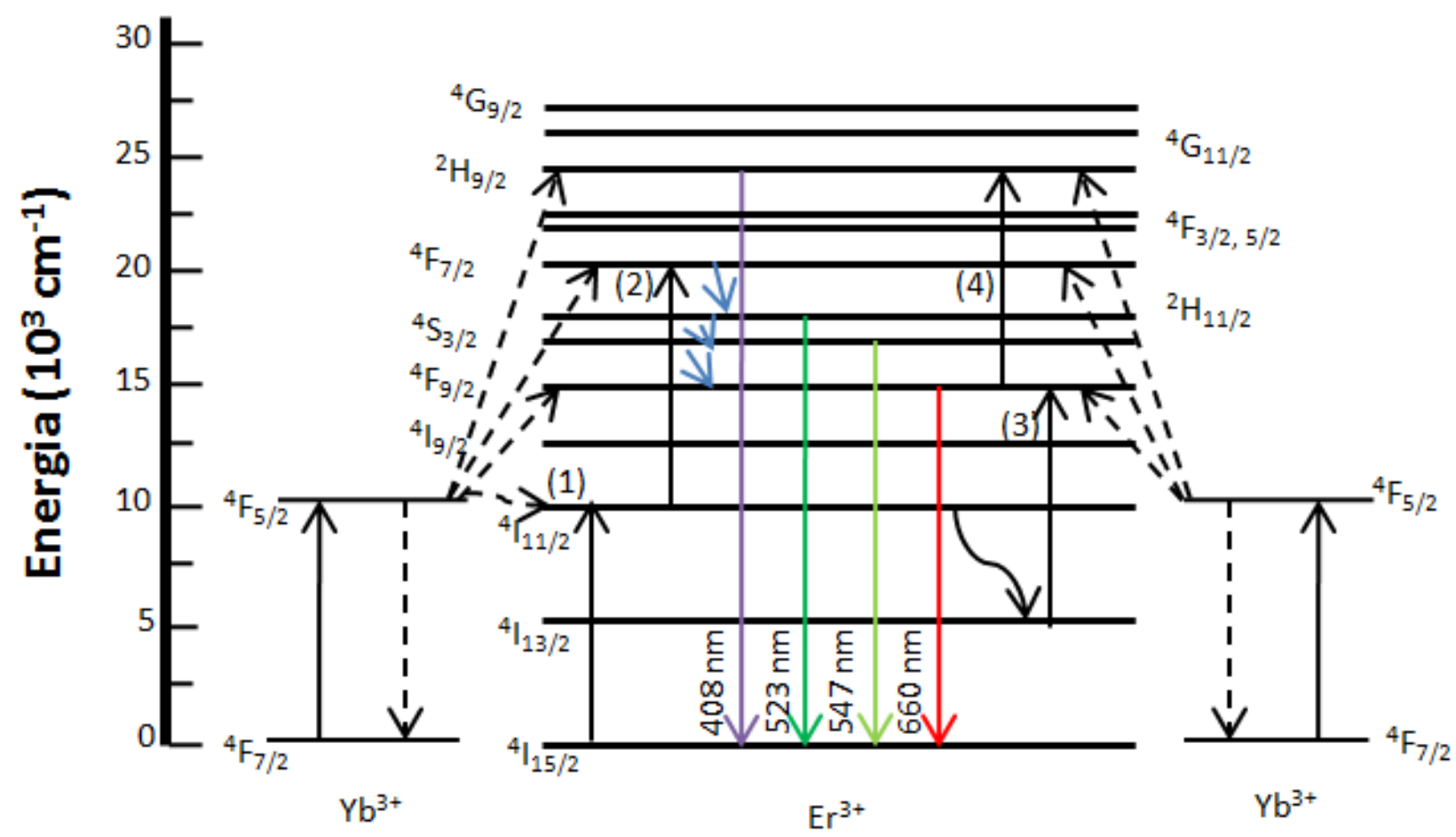

Figura 8 - Diagrama de energia dos íons $\mathrm{Er}^{3+} / \mathrm{Yb}^{3+}$ e os mecanismos de CAF para vidros co-dopados com $\mathrm{Er}^{3+} / \mathrm{Yb}^{3+}$. As linhas sólidas indicam o comprimento de onda de bombeio, as transições de CAF, e as transições radiativas, respectivamente. As linhas pontilhadas e em azul estão relacionadas aos processos de transferência de energia e a relaxação não radiativa, respectivamente.

Para as emissões na região do verde, o íon $\mathrm{Yb}^{3+}$ é excitado do nível ${ }^{2} \mathrm{~F}_{7 / 2}$ para o nível ${ }^{2} F_{5 / 2}$ pelo bombeio em $980 \mathrm{~nm}$; a seguir, este íon decai para o estado fundamental, e então transfere essa energia ao íon $\mathrm{Er}^{3+}$ que é conduzido do estado fundamental ${ }^{4} \mathrm{I}_{15 / 2}$ para o estado excitado ${ }^{4} \mathrm{I}_{11 / 2}$, sendo em seguida promovido ao nível excitado ${ }^{4} F_{7 / 2}$ (processos 1 e 2, Figura 8) [39, 41-43]. Em seguida, ocorre 0 
decaimento não-radiativo para os níveis ${ }^{2} \mathrm{H}_{11 / 2} \mathrm{e}^{4} \mathrm{~S}_{3 / 2}$ de onde ocorrem as transições ${ }^{2} \mathrm{H}_{1 / / 2} \rightarrow{ }^{4} \mathrm{I}_{15 / 2}$ e ${ }^{4} \mathrm{~S}_{3 / 2} \rightarrow{ }^{4} \mathrm{I}_{15 / 2}$, responsáveis pelas emissões em torno de $520 \mathrm{~nm}$ e em $545 \mathrm{~nm}$, respectivamente. A emissão vermelha em $660 \mathrm{~nm}$ resulta da transição ${ }^{4} \mathrm{~F}_{9 / 2} \rightarrow{ }^{4} \mathrm{I}_{15 / 2}$. A população do nível ${ }^{4} \mathrm{~F}_{9 / 2}$ ocorre de duas formas: uma delas a partir do nível ${ }^{4} S_{3 / 2}$ por meio de uma relaxação não-radiativa para o nível ${ }^{4} \mathrm{~F}_{9 / 2}$, a outra está relacionada com o nível ${ }^{4} \mathrm{I}_{13 / 2}$, que é populado por relaxação não-radiativa a partir do estado excitado ${ }^{4} \mathrm{I}_{1 / 2 / 2}$. Assim, o íon $\mathrm{Er}^{3+}$ no nível ${ }^{4} \mathrm{I}_{13 / 2}$ pode ser excitado ao nível ${ }^{4} \mathrm{~F}_{9 / 2}$ (processo 3, Figura 8) pela mesma transferência de energia do $\mathrm{Yb}^{3+}$ mencionada anteriormente. $\mathrm{O}$ quarto caminho mostrado na Figura 8 está relacionado com a emissão em $408 \mathrm{~nm}$, associada com a transição do ${ }^{2} \mathrm{H}_{9 / 2}$ para o estado fundamental.

\subsection{Nanopartícula Metálicas}

Nanopartículas (NPs) metálicas têm sido objeto de extensos estudos devido às características únicas relacionadas com a interação da luz e a oscilação coletiva dos elétrons de condução [1]. Este novo campo recebe o nome de plasmônica e possui diversas aplicações práticas, tais como, marcadores biológicos, nanoesferas para tratamento de câncer e diversas aplicações em fotônica [1-4]. O interesse deste trabalho está nas aplicações fotônicas provenientes do aumento do campo local na vizinhança dos íons das NPs.

Muitos modelos teóricos foram propostos [1] para descrever as propriedades ópticas de materiais contendo NPs metálicas. No entanto, o modelo clássico de Mie é o mais utilizado. Este modelo descreve a interação da radiação eletromagnética, que resulta na oscilação coletiva dos elétrons de condução, denominado plasmons de superfícies, que induz o surgimento de momento de dipolo (Figura 9), e como conseqüência, uma força de restauração nas NPs que tenta compensar, resultando na banda de ressonância (Figura 10) [1]. 


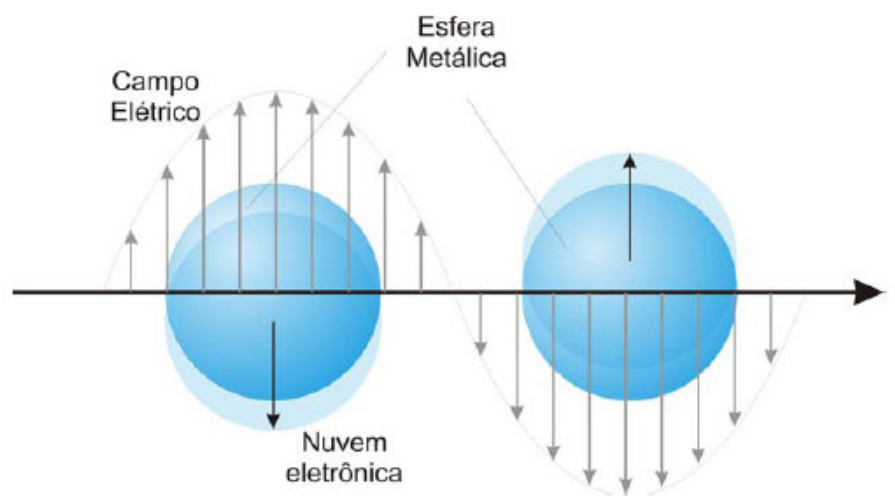

Figura 9 - Esquema da oscilação dos plasmons de superfície em NPs metálicas [1].

Quando os plasmons de superfície são excitados com radiação eletromagnética correspondente a sua freqüência de ressonância, há normalmente, o surgimento de uma banda de absorção ou ressonância em resposta ao campo eletromagnético da radiação incidente (Figura 10). Diversas características relacionadas com a banda de ressonância plasmon (freqüência e largura) estão diretamente relacionadas com a composição (prata, ouro, platina, etc.), morfologia (tamanho e forma) e mais recentemente, pelo processo de preparação das NPs [4447].

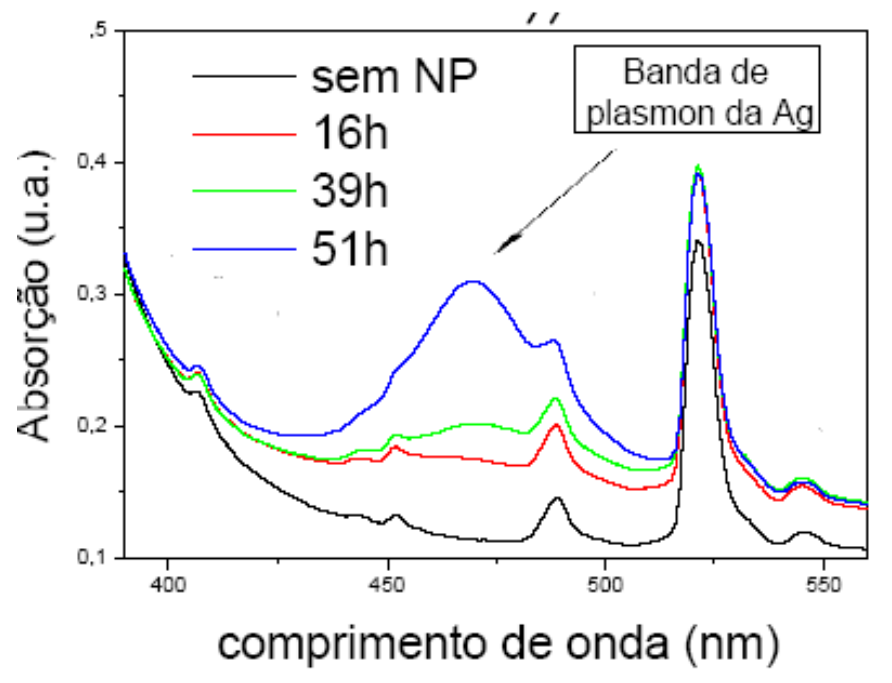

Figura 10 - banda de ressonância do plasmon de partículas de prata em vidros de germanato dopado com $\mathrm{Er}^{3+}$ para diferentes tratamentos térmicos [48]. 
A característica do pico de absorção relacionado à ressonância dos plasmons de superfície é explicada a partir da teoria clássica de espalhamento de luz de Mie e da teoria do elétron livre de Drude [49-50]. Abaixo de um tamanho característico (15 $\mathrm{nm}$ para $\mathrm{Ag}$ e $25 \mathrm{~nm}$ para o $\mathrm{Au}$ ) o efeito eletrodinâmico do aumento do campo local, descrito pela teoria de Mie, torna-se dependente do raio $\mathrm{R}$ da partícula [50]. Deste modo, a seção de choque de extinção para NPs menores que o comprimento de onda incidente $(2 \mathrm{R}<<\lambda)$ é dada por:

$$
\alpha(\omega)=\frac{9 V n^{3} \omega}{c} \frac{\epsilon_{m 2}(\omega)}{\left[\epsilon_{m 1}(\omega)+2 n^{2}\right]^{2}+\epsilon_{m 2}(\omega)^{2}}
$$

onde, $n$ é o índice de refração do meio hospedeiro, $V$ é o volume da NP, dada por: $V=(4 \pi / 3) R^{3}, \omega$ é a frequência angular da radiação incidente e $\epsilon_{m}=\left(\epsilon_{m 1}+i \epsilon_{m 2}\right)$ é a função dielétrica da NP, formada pela parte real $\left(\epsilon_{m 1}\right)$ e parte imaginária ( $\left.i \epsilon_{m 2}\right)$.

A freqüência de ressonância é determinada pela condição $\epsilon_{m 1}(\omega)=-2 n^{2}$, quando $\epsilon_{m 2}(\omega)$ não for grande e não variar próximo à freqüência de ressonância. Existem dois tipos de contribuição para a função dielétrica do metal, a primeira é dos elétrons da camada $d$, que descrevem transições interbandas (do orbital d para a camada de condução), e dos elétrons livres que é descrito pela Equação 6:

$$
\epsilon_{m}(\omega)=1+\frac{\omega_{p}^{2}}{\omega(1-i \omega \tau)}
$$

onde, $\tau$ é a constante de amortecimento (damping) e $\omega_{p}=\left(N_{e} e^{2} / \epsilon_{0} m_{e f f}\right)^{1 / 2}$ é a freqüência de plasma do metal $\left(N_{e}, e\right.$ e $m_{e f f}$ são densidade eletrônica, carga e a massa efetiva do elétron, respectivamente). $\mathrm{Na}$ teoria clássica, a constante de amortecimento do elétron livre do metal é devido ao espalhamento elétron-elétron, elétron-fônon, elétron-defeito ou elétron-impureza.

Para uma partícula esférica muito menor do que o livre caminho médio do elétron em um material, $l_{\infty}$, as colisões dos elétrons de condução com a superfície da partícula tornam-se importantes, como um processo de relaxação adicional e o 
livre caminho médio, $l$, é restrito pelo tamanho da partícula, 2R. Deste modo, o tempo de relaxação $t$ pode ser substituído pela constante de amortecimento:

$$
\tau_{c}=\frac{2 R}{v_{f}}
$$

onde $v_{f}\left(1,39 \times 10^{8} \mathrm{~cm} / \mathrm{s}\right)$ é a velocidade de Fermi

A localização e forma da banda de ressonância plasmônica, depende da função dielétrica $\left(\epsilon_{m}\right)$, que por sua vez depende do tamanho e da forma da NP. Portanto, NPs de mesma composição e diferentes tamanhos apresentarão bandas de ressonância distintas.

\subsubsection{Influência do tamanho e forma}

Para NPs relativamente grandes, distorções com significativa magnitude na nuvem eletrônica (como quadrupolo) tornam-se importantes. Estas contribuições induzem um deslocamento ainda maior das condições de ressonância, à medida que a NP fica maior. Este efeito para as NPs grandes corresponde ao efeito extrínseco de tamanho [2].

A posição e forma da banda de absorção das NPs dependem da função dielétrica do meio envolvente. Portanto, um aumento da função dielétrica acarreta em um aumento na intensidade e largura da banda de plasmon, além de favorecer o deslocamento do comprimento de onda de ressonância para valores maiores (em direção ao infravermelho). O efeito da forma das NPs e a interferência na posição da banda de ressonância plasmônica são mostrados na Figura 11. A Figura 12 mostra a dependência da banda de absorção dos plasmons superficiais com o tamanho das NPs [51]. 


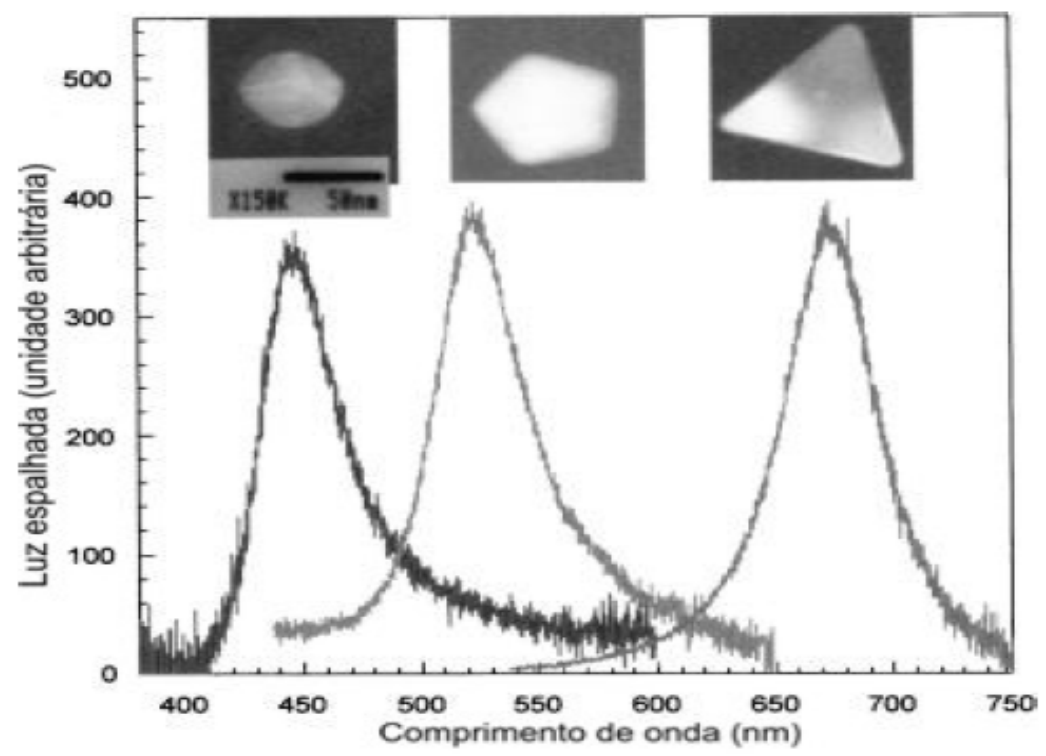

Figura 11 - Interferência da forma das NPs na posição das bandas de absorção dos plásmons superficiais, em colóides com NPs de prata [51].

Comprimento de onda (nm)

$\begin{array}{llllllllll}350 & 400 & 450 & 500 & 550 & 600 & 650 & 700 & 750 & 800\end{array}$

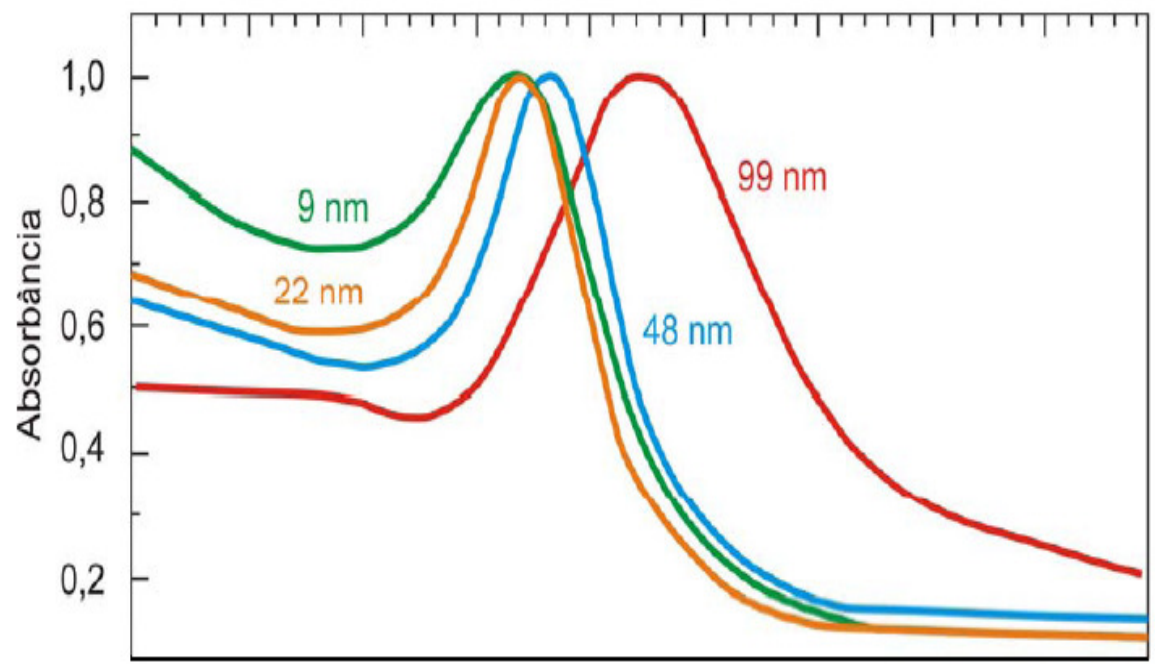

Figura 12 - Espectro de absorção de NPs de ouro com diferentes tamanhos [2]. 


\subsubsection{Influência das NPs nos íons de terras-raras}

Poucos estudos relacionando os efeitos das NPs na luminescência de íons de terras-raras, mais especificamente o érbio, foram reportados na literatura [52-55]. Entretanto, existem diversas propriedades bastante promissoras para aplicações fotônicas. Dentre as várias aplicações podemos citar chaves e limitadores ópticos, e "displays", além do aumento na eficiência dos lasers.

Entre os efeitos que podem influenciar a emissão dos íons de terras-raras, estão a transferências de energia, aumento do campo local na proximidade das partículas metálicas e o aumento das taxas radiativas, descritas a seguir:

Aumento do campo local: o aumento do campo local na vizinhança dos íons de terras-raras devido à presença das NPs metálicas concentra a densidade de excitação local ao redor dos íons, aumentando a emissão luminescente.

Transferência de energia entre as NPs e o íons de terras-raras: esta interação introduz um canal adicional de decaimento não-radiativo, que depende da distância entre o íon e a NP. Assim, íons mais próximos do que $5 \mathrm{~nm}$ da superfície das NP têm geralmente sua luminescência diminuída.

Aumento da taxa radiativa: se o aumento do campo local e das taxas radiativas forem maiores que as taxas não-radiativas, observa-se o aumento na luminescência dos íons de terras-raras. Caso o aumento da taxa radiativa seja muito maior do que o aumento do campo local, observa-se uma diminuição significativa do tempo de vida. Por outro lado, se a taxa de decaimento não-radiativo predominar em relação ao aumento do campo local e ao aumento das taxas radiativas ocorrerá uma redução na luminescência.

A transferência de energia entre os íons de terras-raras para as NPs, responsável pela diminuição da luminescência, predomina quando a distância entre os íons de terras-raras e as NPs é muito pequena $(<5 \mathrm{~nm})$ [1]. Para distâncias entre 
5 e $20 \mathrm{~nm}$, o aumento da luminescência pode ser favorecido, tanto pelo aumento do campo local, como pelo aumento das taxas radiativas. 


\section{MATERIAIS E MÉTODOS}

\subsection{Obtenção dos vidros}

Foram produzidos dois tipos de vidros germanatos, cujas composições nominais são: $72,76 \mathrm{PbO}-17,07 \mathrm{GeO}_{2}-10,17 \mathrm{Ga}_{2} \mathrm{O}_{3}$ (GPG) e $59,0 \mathrm{GeO}_{2}-41,0 \mathrm{PbO}$ (GP) (\% em peso). Os vidros foram co-dopados com diferentes teores de $\mathrm{Yb}_{2} \mathrm{O}_{3}$, de acordo com a Tabela 3, e mantendo-se o teor de 0,5\% de $\mathrm{Er}_{2} \mathrm{O}_{3}$ fixo. Para avaliar o efeito da introdução de NPs sobre a luminescência desses vidros foram produzidas cinco amostras (GP-Y3, GP-A3, GP-YC3, GPG-O3, GPG-Y3) co-dopadas com 0,5\% $\mathrm{Er}_{2} \mathrm{O}_{3}$ e com diferentes teores de $\mathrm{Yb}_{2} \mathrm{O}_{3}$ e reagentes metálicos $\left(\mathrm{Au}_{2} \mathrm{O}_{3}, \mathrm{AgNO}_{3} \mathrm{e}\right.$ $\mathrm{Cu}_{2} \mathrm{O}$ ), conforme mostrado na Tabela 4 .

Tabela 3- Concentrações de $\mathrm{Yb}_{2} \mathrm{O}_{3}$ para as matrizes GP e GPG dopadas com 0,5\% em peso de $\mathrm{Er}_{2} \mathrm{O}_{3}$.

\begin{tabular}{cc}
\hline \hline $\begin{array}{c}\text { Matriz GP } \\
\left(\% \text { de } \mathrm{Yb}_{2} \mathrm{O}_{3}\right)\end{array}$ & $\begin{array}{c}\text { Matriz GPG } \\
\left.\text { Nominal de } \mathrm{Yb}_{2} \mathrm{O}_{3}\right) \\
\text { Nominal }\end{array}$ \\
\hline 1,0 & 1,0 \\
1,5 & 2,0 \\
2,0 & 3,0 \\
2,5 & 4,0 \\
3,0 & 5,0 \\
\hline
\end{tabular}


Tabela 4 - Teores de $\mathrm{Yb}_{2} \mathrm{O}_{3}$ e de reagentes metálicos adicionados às matrizes GP e GPG. Todos os vidros foram preparados com $0,5 \%$ em peso de $\mathrm{Er}_{2} \mathrm{O}_{3}$.

Matriz

(denominação)
Concentração de dopantes

(em \% de peso)

\begin{tabular}{ccc}
\hline \hline GP-(Y3) & $3,0 \mathrm{Yb}_{2} \mathrm{O}_{3}$ & $1,0 \mathrm{AgNO}_{3}$ \\
GP-(A3) & $1,0 \mathrm{Yb}_{2} \mathrm{O}_{3}$ & $3,0 \mathrm{AgNO}_{3}$ \\
GP-(CY3) & $3,0 \mathrm{Yb}_{2} \mathrm{O}_{3}$ & $0,1 \mathrm{Cu}_{2} \mathrm{O}$ \\
GPG-(Y3) & $3,0 \mathrm{Yb}_{2} \mathrm{O}_{3}$ & $1,0 \mathrm{Au}_{2} \mathrm{O}_{3}$ \\
GPG-(O3) & $1,0 \mathrm{Yb}_{2} \mathrm{O}_{3}$ & $3,0 \mathrm{Au}_{2} \mathrm{O}_{3}$ \\
\hline
\end{tabular}

Com o intuito de avaliar a influência da presença de $\mathrm{SiO}_{2}$ provenientes do cadinho de $\mathrm{Al}_{2} \mathrm{O}_{3}-\mathrm{SiO}_{2}$, foi produzido um vidro com composição GP-Y3, denominado GP-Y3N, mas utilizando cadinho de alumina de alta pureza. Além disso, foram produzidos dois vidros do tipo GP (em cadinho de alumina) e GPG (em cadinho de platina) dopados com $3,0 \%$ e $5,0 \%$, respectivamente, de forma a avaliar as características estruturais e ópticas desses sistemas.

A Figura 13 mostra um fluxograma das etapas de processo e a Tabela 5 apresenta os parâmetros utilizados para a produção dos vidros. O cadinho para cada matriz é indicado em cada caso.

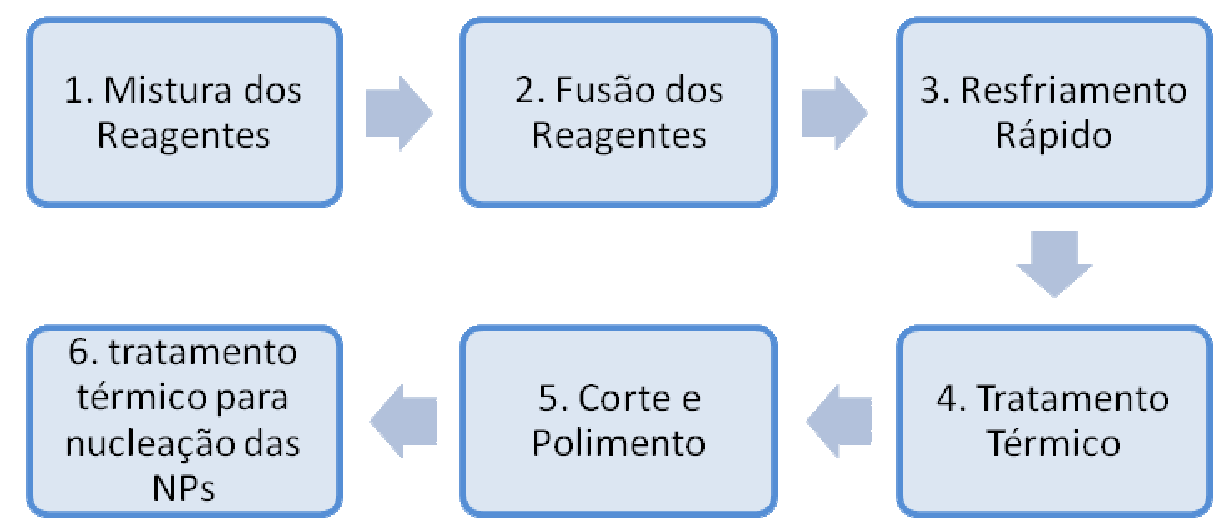

Figura 13 - Etapas utilizadas para produção dos vidros. 
Tabela 5 - parâmetros e tipo de cadinho utilizados na produção das amostras.

\begin{tabular}{ccccc}
\hline Amostra & $\begin{array}{c}\text { Temperatura de } \\
\text { Fusão }\left({ }^{\circ} \mathrm{C}\right)\end{array}$ & $\begin{array}{c}\text { Temperatura de } \\
\text { tratamento }\left({ }^{\circ} \mathrm{C}\right)\end{array}$ & $\begin{array}{c}\text { Tempo de } \\
\text { fusão }(\mathrm{h})\end{array}$ & $\begin{array}{c}\text { Cadinho } \\
\text { GP }\end{array}$ \\
1200 & 420 & 2 & $\mathrm{Al}_{2} \mathrm{O}_{3}-\mathrm{SiO}_{2}$ \\
PGG & 1200 & 390 & 1 & Platina \\
\hline
\end{tabular}

Segue abaixo detalhes do procedimento utilizado para a obtenção dos vidros.

1. Mistura dos reagentes: Os reagentes de alta pureza, de acordo com a Tabela 6, são pesados em béqueres, limpos com álcool, numa balança digital com precisão de $\pm 10^{-4} \mathrm{~g}$. Os reagentes que formam o vidro foram pesados e misturados dentro dos respectivos cadinhos.

\begin{tabular}{cc}
\multicolumn{2}{c}{ Tabela 6- Pureza dos reagentes utilizados. } \\
\hline Reagente & Pureza (\%) \\
\hline $\mathrm{GeO}_{2}$ & 99,999 \\
$\mathrm{PbO}$ & 99,9 \\
$\mathrm{Ga}_{2} \mathrm{O}_{3}$ & 99,99 \\
$\mathrm{Er}_{2} \mathrm{O}_{3}$ & 99,9 \\
$\mathrm{Yb}_{2} \mathrm{O}_{3}$ & 99,9 \\
$\mathrm{Au}_{2} \mathrm{O}_{3}$ & $85-86$ \\
$\mathrm{AgNO}_{3}$ & 99,9999 \\
$\mathrm{Cu}_{2} \mathrm{O}$ & 99,99 \\
\hline
\end{tabular}

2. Fusão dos reagentes: $O$ cadinho contendo os reagentes é colocado dentro de um forno em ar e mantido durante o tempo necessário para a fusão e homogeneização de acordo com a Tabela 5. 
3. Solidificação rápida em molde de latão pré-aquecido: $O$ material é vertido rapidamente em um molde de latão pré-aquecido. Antes do seu uso, o molde é lixado e lavado para evitar a contaminação da amostra por resíduos que eventualmente possam estar retidos na superfície. O molde também é pré-aquecido para reduzir o choque térmico da amostra de acordo com a temperatura de tratamento térmico mostrada na Tabela 5.

4. Tratamento Térmicos: Após a solidificação rápida, os vidros GPG e GP são submetidos a um tratamento térmico durante $1 \mathrm{~h}$ e $2 \mathrm{~h}$, respectivamente, à temperaturas de tratamento térmico mostradas na Tabela 5. Em seguida, o forno é desligado até atingir a temperatura ambiente. Este tratamento deve ser realizado para minimizar tensões internas; após a solidificação da amostra, os átomos encontram se desordenados e geram tensões na estrutura do material, favorecendo o surgimento de trincas.

5. Polimento e corte: Após o resfriamento, as amostras são retiradas do forno para serem polidas, com lixas d'agua (de diferentes granulações) até atingir uma espessura aproximada de $2 \mathrm{~mm}$ e com faces paralelas. Cabe acrescentar que todas as amostras são submetidas a este processo. Na seqüência as amostras contendo NPs são cortadas em várias partes iguais, para, na seqüência, serem submetidas à próxima etapa de nucleação das NPs.

Nas Figuras que seguem são mostradas as fotografias dos vidros dopados com $0,5 \% \mathrm{Er}_{2} \mathrm{O}_{3}$ e diferentes concentrações de $\mathrm{Yb}_{2} \mathrm{O}_{3}$. Também são mostradas as fotografias dos vidros GP e GPG, contento NPs. 


\section{f the tterbi n cor sntrat in on ${ }^{3+}$ eo- oped $\left.\left.\lrcorner \theta-G\right)_{2}=6 a_{3}\right)_{3}$ gli $1,0 \%$ de $\mathrm{Yb}_{2} \mathrm{O}_{3} \quad 1,5 \%$ de $\mathrm{Yb}_{2} \mathrm{O}_{3} \quad 2,0 \%$ de $\mathrm{Yb}_{2} \mathrm{O}_{3} \quad 2,5 \%$ de $\mathrm{Yb}_{2} \mathrm{O}_{3} \quad 3,0 \%$ de $\mathrm{Yb}_{2} \mathrm{O}_{3}$}

Figura 14 - Fotografia dos vidros GP dopado com $0,5 \%$ de $\mathrm{Er}_{2} \mathrm{O}_{3}$ e diferentes concentrações de $\mathrm{Yb}_{2} \mathrm{O}_{3}$.

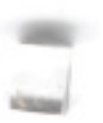

$2 h$

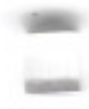

$24 h$

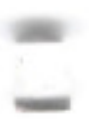

$48 h$

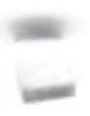

$72 \mathrm{~h}$

Figura 15 - Fotografia do vidro GP-Y3, contendo 0,5\% de $\mathrm{Er}_{2} \mathrm{O}_{3}, 3,0 \%$ de $\mathrm{Yb}_{2} \mathrm{O}_{3}$ e $1,0 \%$ de $\mathrm{AgNO}_{3}$.

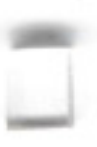

$2 \mathrm{~h}$

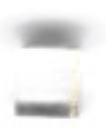

$24 \mathrm{~h}$

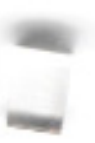

$48 h$

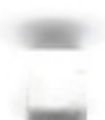

$72 \mathrm{~h}$

Figura 16 - Fotografia do vidro GP-A3, contendo $0,5 \%$ de $\mathrm{Er}_{2} \mathrm{O}_{3}, 1,0 \%$ de $\mathrm{Yb}_{2} \mathrm{O}_{3}$ e $3,0 \%$ de $\mathrm{AgNO}_{3}$.

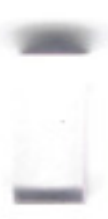

$2 h$

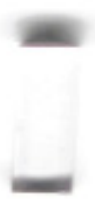

$24 \mathrm{~h}$

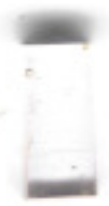

48h

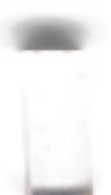

$72 \mathrm{~h}$

Figura 17 - Fotografia do vidro GP-Y3, contendo $0,5 \%$ de $\mathrm{Er}_{2} \mathrm{O}_{3}, 3,0 \%$ de $\mathrm{Yb}_{2} \mathrm{O}_{3}$ e $1,0 \%$ de $\mathrm{AgNO}_{3}$ produzido em cadinho de alumina pura. 


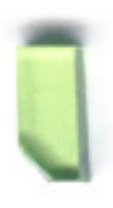

$2 h$

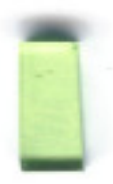

$24 \mathrm{~h}$

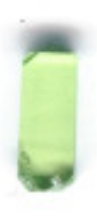

$48 \mathrm{~h}$

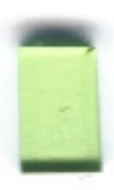

$72 \mathrm{~h}$

Figura 18 - Fotografia do vidro GP-CY3, contendo $0,5 \%$ de $\mathrm{Er}_{2} \mathrm{O}_{3}, 3,0 \%$ de $\mathrm{Yb}_{2} \mathrm{O}_{3}$ e $0,1 \%$ de $\mathrm{Cu}_{2} \mathrm{O}$.
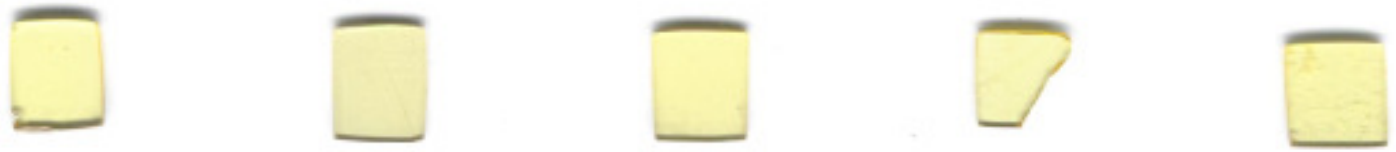

$1,0 \%$ de $\mathrm{Yb}_{2} \mathrm{O}_{3}$

Figura 19 - Fotografia dos vidros GPG dopado com 0,5\% de $\mathrm{Er}_{2} \mathrm{O}_{3}$ e diferentes concentrações de $\mathrm{Yb}_{2} \mathrm{O}_{3}$.

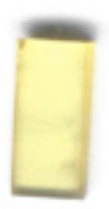

$1 \mathrm{~h}$

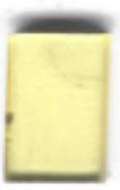

$24 \mathrm{~h}$

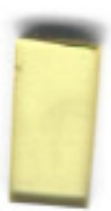

$48 h$

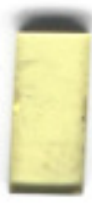

$72 \mathrm{~h}$

Figura 20 - Fotografia do vidro GPG-Y3, contendo $0,5 \%$ de $\mathrm{Er}_{2} \mathrm{O}_{3}, 3,0 \%$ de $\mathrm{Yb}_{2} \mathrm{O}_{3}$ e $1,0 \%$ de $\mathrm{Au}_{2} \mathrm{O}_{3}$.

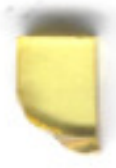

$1 \mathrm{~h}$

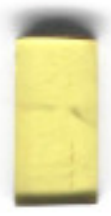

$12 \mathrm{~h}$

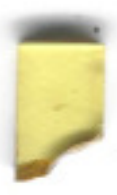

$28 \mathrm{~h}$
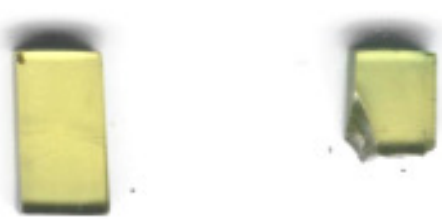

$40 \mathrm{~h}$

$52 h$

Figura 21 - Fotografia do vidro GPG-O3, contendo $0,5 \%$ de $\mathrm{Er}_{2} \mathrm{O}_{3}, 1,0 \%$ de $\mathrm{Yb}_{2} \mathrm{O}_{3}$ e $3,0 \%$ de $\mathrm{Au}_{2} \mathrm{O}_{3}$. 
6. Tratamento Térmico para nucleação das NPs: As amostras contendo precursores metálicos foram submetidas a diferentes tempos de tratamento térmico nas temperaturas indicadas na Tabela 5 para cada matriz vítrea. Esta última etapa tem como finalidade a redução dos íons metálicos, para que na seqüência possam formar as NPs metálicas, como mostrado no exemplo da Figura 22, no qual os íons $\mathrm{Ag}^{+}$são reduzidos a $\mathrm{Ag}^{0}$.

$$
\mathrm{AgNO}_{3} \rightarrow \mathrm{Ag}^{+}+\mathrm{NO}_{3}^{-}
$$
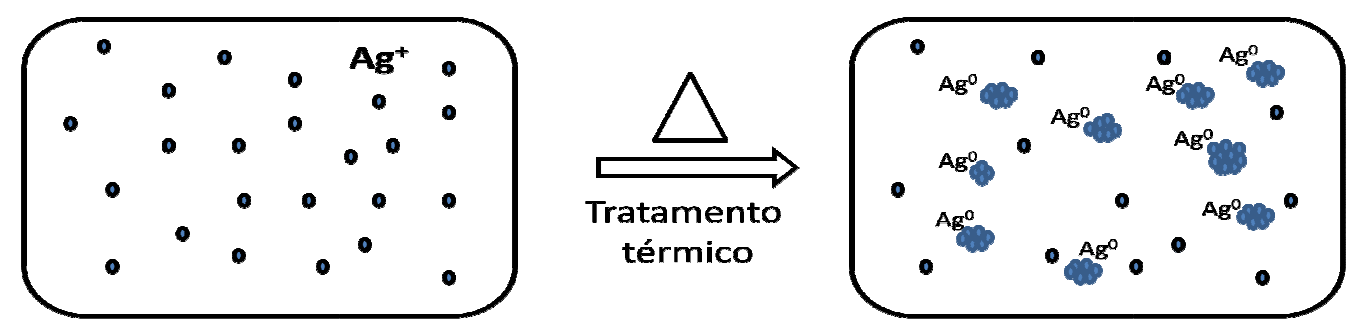

Figura 22 - Representação esquemática da nucleação de NPs.

O ciclo do tratamento térmico para redução e nucleação é mostrado na Figura 23. Observa-se que são realizados vários ciclos de tratamentos e resfriamentos. Cabe acrescentar que a capacidade de nucleação das NPs depende do tratamento térmico e da matriz hospedeira utilizada que limita e controla o processo de crescimento das NPs [49]. 


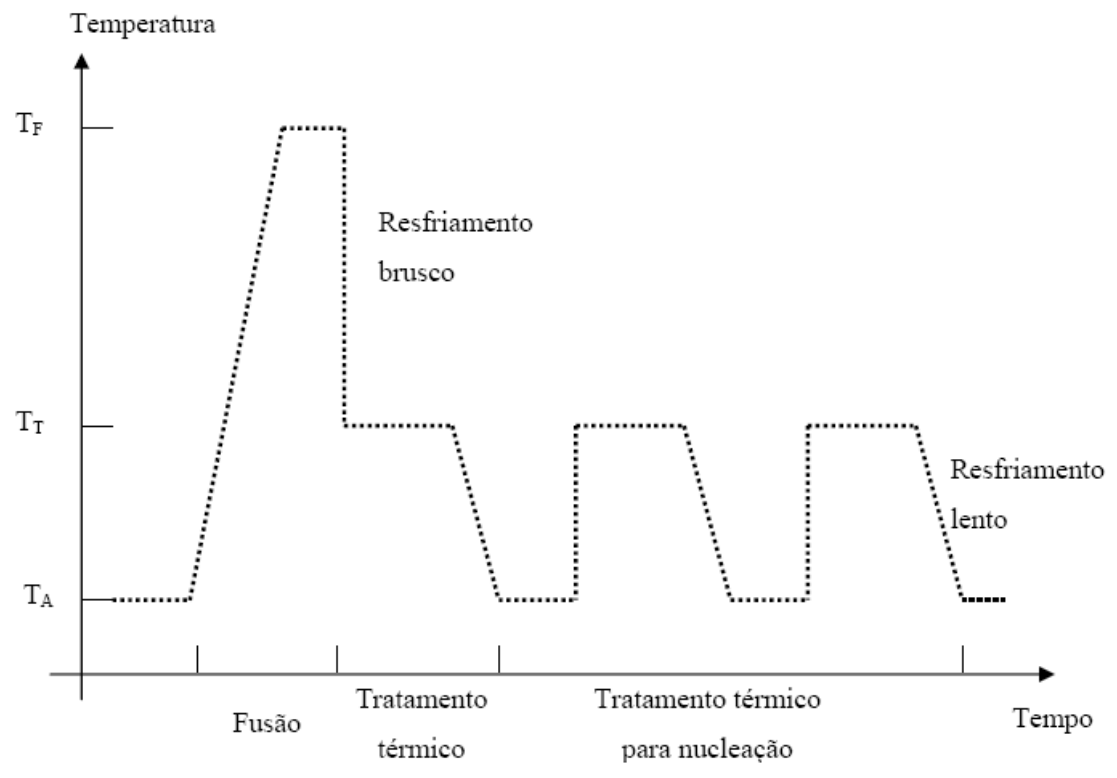

Figura 23 - O ciclo do tratamento térmico utilizado para nucleação das NPs. As temperaturas, $T_{A}, T_{T}, T_{F}$, são as temperaturas ambiente, de tratamento e de fusão, respectivamente [49].

\subsection{Técnicas utilizadas para caracterização}

\subsubsection{Espectroscopia de Fluorescência de Raios X por Energia Dispersiva (EDX)}

A composição química de todas as amostra produzidas foram determinadas por meio da técnica de EDX utilizando-se um equipamento da marca Shimadzu, modelo 720. Utilizou-se a técnica Quali-quanti e os parâmetros fundamentais da calibração do equipamento para determinação do elemento. A composição dos vidros apenas co-dopados com $\mathrm{Er}_{2} \mathrm{O}_{3}$ e $\mathrm{Yb}_{2} \mathrm{O}_{3}$ foi determinada uma única vez, ao passo que para os vidros co-dopados contendo NPs, a análise foi executada em cada parte da amostra cortada para os diferentes tratamentos térmicos. Todas essas análises foram realizadas no Centro de Ciências e Tecnologia de Materiais - CCTM IPEN. 


\subsubsection{Microscopia Eletrônica de Transmissão (MET)}

Está técnica propicia imagens diretas de NPs, possibilitando a determinação do tamanho, da distribuição, da forma, além da estrutura cristalina. Para a caracterização dos vidros GP-Y3, GP-A3, GP-CY3 e GPG-Y3 foi utilizado um microscópio eletrônico de transmissão do Laboratório de Microscopia Eletrônica do Instituto de Física da USP - IFUSP, modelo Philips CM 200 operado a 200 KV e no caso do vidro GPG-O3, foi utilizado o microscópio eletrônico de transmissão do IPEN, da marca Jeol, modelo JEM 200C e tensão operacional de $200 \mathrm{KV}$.

O tamanho e quantidade das NPs foi determinado manualmente por meio da análise das micrografias com auxílio do software CorelDraw 12.

\subsubsection{Analise Térmica Diferencial (ATD)}

As temperaturas de transformação exotérmica e endotérmica foram determinadas através da técnica de Análise Térmica Diferencial, utilizando o equipamento da marca Perkin/Elmer, modelo DTA 7 da Missouri University - Rola EUA. Para tanto, as amostras foram moídas e aquecidas a $10^{\circ} \mathrm{C} / \mathrm{min}$, a partir da temperatura ambiente até a temperatura final de $950^{\circ} \mathrm{C}$ e $1200^{\circ} \mathrm{C}$ para os vidros GPG e GP, respectivamente. Todas as análises foram realizadas em cadinho de alumina e em atmosfera dinâmica de argônio.

\subsubsection{Medidas de absorção óptica}

Para as medidas de absorção óptica é necessário que as amostras tenham suas faces paralelas e polidas para as perdas relativas a refração sejam minimizadas. O diagrama experimental para este tipo de medida é mostrado na Figura 24. 


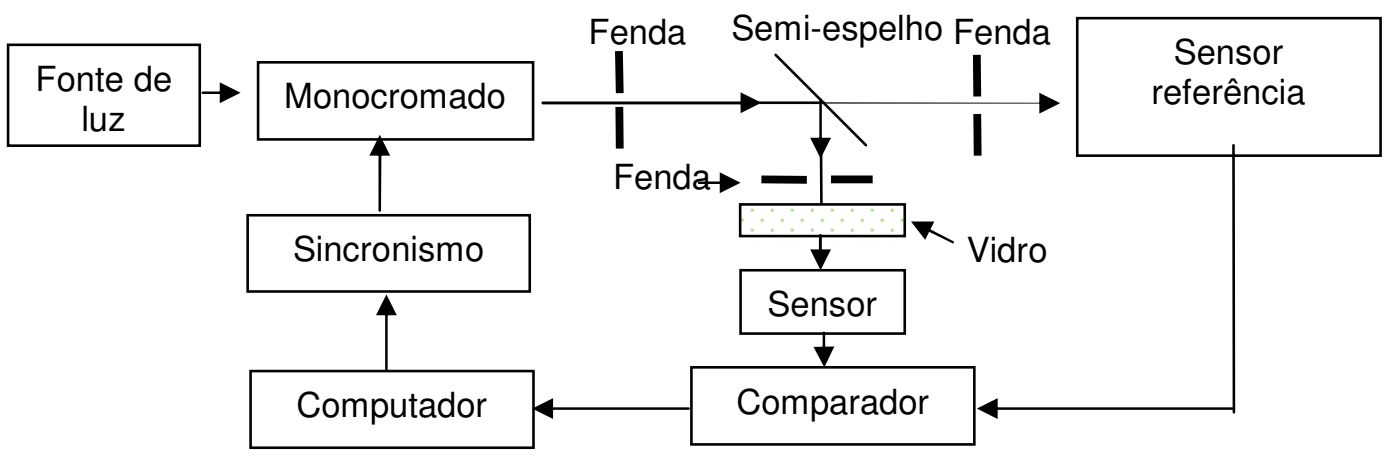

Figura 24 - Arranjo experimental para as medidas de absorção óptica.

Um feixe de luz passa por uma rede de difração no monocromador que o separa em vários comprimentos de onda; cada comprimento depende do ângulo formado entre a fonte de luz e a rede de difração. Este monocromador gira sincronizado com uma registradora. O feixe de luz, com comprimento de onda determinado pelo monocromador, passa por um divisor de feixe (semi-espelho); parte da luz atravessa a amostra, é detectada pelo sensor e a outra parte, pelo sensor de referência. Os sinais de ambos os sensores são comparados tendo como saída, um sinal proporcional à transmissão óptica, que é gravado pela registradora. Todas essas medidas foram realizadas no Laboratório de Cristais lônicos do Instituto de Física da USP.

\subsubsection{Medidas de emissão na região do visível}

Para as medidas de luminescências na região do visível utilizou-se o arranjo experimental mostrado na Figura 25. A fonte de excitação é um laser contínuo de diodo, operando em aproximadamente $960 \mathrm{~nm}$. O feixe incidente é colimado por uma lente, de modo que a amostra seja bombeada perpendicularmente á direção de detecção (bombeio lateral). A luz emitida pela amostra é colimada por outra lente e 
passa pelo disco do "chopper". O "chopper" tem como função controlar a freqüência em que o laser atinge a amostra. Isto é feito para evitar o risco de detectar a luz ambiente $(60 \mathrm{hz})$.

A luz emitida é então, filtrada por um monocromador, e por fim coletada por uma fotomultiplicadora ( $\mathrm{GaAs}$ ). O sinal detectado é amplificado por lock-in e os dados são enviados para o computador. Tais medidas foram realizadas no Centro de Lasers e Aplicações - CLA - IPEN.

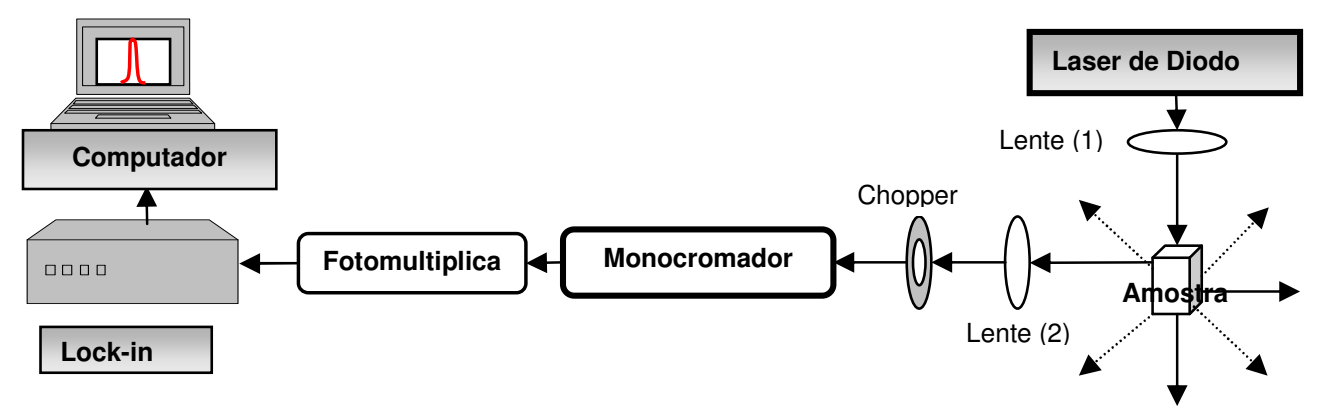

Figura 25 - Diagrama experimental para medidas de emissão no visível e infravermelho.

\subsubsection{Medidas de potência}

Para a realização das medidas de intensidade de CAF em função da potência do laser em $980 \mathrm{~nm}$, foi calibrada previamente utilizando-se um medidor de potência para diferentes correntes da fonte do laser. Desta maneira, variando-se a corrente da fonte, obtém-se uma variação da potência do feixe que chega à amostra. Por fim, o feixe que sai da amostra é coletado por um osciloscópio para determinação da potência de saída. Tais medidas foram realizadas no Centro de Lasers e Aplicações (CLA) - IPEN. Cabe acrescentar que as medidas dos vidros GP-Y3N foram feitas através de filtros com transmitância de 40, 80, 90\% no Laboratório de Vidros e Datações (LVD) da Faculdade de Tecnologia de São Paulo - FATEC-SP. 


\subsubsection{Raman e transmissão óptica}

As medidas de transmitância dos vidros foram realizadas por meio do equipamento FT-IR da marca THERMO, modelo THERMO NICOLET 6700, do Centro de Lasers e Aplicações do IPEN; as medidas de espalhamento Raman foram realizadas para determinação da máxima energia fônon, por meio da excitação das amostras por um laser de diodo em 800 nm e coletada por um sistema eletrônico associado. Tais análises foram realizadas na Universidade Federal de Pernambuco (UFPE).

\subsubsection{Difração de Raios X (DRX)}

A técnica de difratometria de raios $X(D R X)$ foi utilizada para identificar halos relacionados com a estrutura amorfa dos vidros produzidos e os possíveis picos relacionados à fases cristalinas presentes no vidro. As amostras foram analisadas sob a forma de pós, utilizando-se um difratograma da marca Rigaku X-Ray Diffractometer, modelo DMAX100. Estes pós foram adequadamente compactados possibilitando o posicionamento em um suporte do goniômetro do equipamento. $\mathrm{O}$ intervalo de varredura foi de $10^{\circ}$ a $80^{\circ}$, com velocidade de $2^{\circ} /$ min e a radiação incidente foi $\mathrm{K}_{\alpha}$ do cobre. 


\section{RESULTADOS E DISCUSSÃO}

Neste capítulo serão apresentados e discutidos os resultados obtidos para os vidros produzidos neste trabalho. Os primeiros resultados que serão mostrados dizem respeito à caracterização química e física tais como, a caracterização por EDX, DRX, Raman, ATD e transmissão óptica. Em uma segunda etapa serão discutidos os resultados relacionados com as características ópticas (absorção e emissão óptica) e determinação da composição, estrutura e distribuição das NPs encontradas.

\subsection{Espectrometria de Fluorescência de Raios X por Energia Dispersiva (EDX)}

As composições dos vidros co-dopados GP e GPG determinadas por meio da técnica de EDX são mostradas nas Tabelas 7 e 8. Cabe lembrar que os vidros codopados GP e GPG foram produzido em cadinho de $\mathrm{Al}_{2} \mathrm{O}_{3}-\mathrm{SiO}_{2}$ e platina, respectivamente.

Tabela 7 - Composição experimental (\% em peso) determinada por EDX dos vidros GP co-dopados com diferentes concentrações de $\mathrm{Yb}_{2} \mathrm{O}_{3}$.

\begin{tabular}{ccccccc}
\hline $\begin{array}{c}\mathrm{Yb}_{2} \mathrm{O}_{3}(\%) \\
\text { Nominal }\end{array}$ & $\mathrm{PbO}$ & $\mathrm{GeO}_{2}$ & $\mathrm{Er}_{2} \mathrm{O}_{3}$ & $\mathrm{Yb}_{2} \mathrm{O}_{3}$ & $\mathrm{SiO}_{2}$ & $\mathbf{A l}_{2} \mathrm{O}_{3}$ \\
\hline $\mathbf{1 , 0}$ & 56,63 & 33,96 & 0,40 & 0,81 & 4,00 & 4,20 \\
$\mathbf{1 , 5}$ & 57,54 & 34,91 & 0,40 & 1,32 & 2,73 & 3,10 \\
$\mathbf{2 , 0}$ & 56,83 & 33,61 & 0,41 & 1,70 & 4,21 & 3,24 \\
$\mathbf{2 , 5}$ & 57,34 & 33,44 & 0,38 & 2,10 & 4,11 & 2,63 \\
$\mathbf{3 , 0}$ & 57,33 & 34,00 & 0,31 & 2,23 & 3,01 & 2,71 \\
\hline
\end{tabular}


Tabela 8 - Composição experimental (\% em peso) determinada por EDX dos vidros GPG co-dopados com diferentes concentrações de $\mathrm{Yb}_{2} \mathrm{O}_{3}$.

\begin{tabular}{cccccc}
\hline $\begin{array}{c}\mathrm{Yb}_{2} \mathrm{O}_{3}(\%) \\
\text { Nominal }\end{array}$ & $\mathrm{PbO}$ & $\mathrm{GeO}_{2}$ & $\mathrm{Ga}_{2} \mathrm{O}_{3}$ & $\mathrm{Er}_{2} \mathrm{O}_{3}$ & $\mathrm{Yb}_{2} \mathrm{O}_{3}$ \\
\hline $\mathbf{1 , 0}$ & 73,91 & 15,44 & 9,25 & 0,45 & 0,94 \\
$\mathbf{2 , 0}$ & 73,20 & 14,87 & 9,75 & 0,40 & 1,77 \\
$\mathbf{3 , 0}$ & 73,36 & 14,25 & 9,26 & 0,51 & 2,62 \\
$\mathbf{4 , 0}$ & 72,25 & 14,64 & 9,60 & 0,36 & 3,15 \\
$\mathbf{5 , 0}$ & 72,50 & 14,25 & 8,91 & 0,29 & 4,06 \\
\hline \hline
\end{tabular}

Observa-se na Tabelas 7, uma boa concordância entre as composições nominais e determinadas experimentalmente. Entretanto, é observada uma redução substancial de $\mathrm{GeO}_{2}$ em comparação com a composição nominal, devido à introdução de $\mathrm{SiO}_{2}$ e $\mathrm{Al}_{2} \mathrm{O}_{3}$ provenientes do cadinho cuja composição de $55 \mathrm{Al}_{2} \mathrm{O}_{3^{-}}$ $45 \mathrm{SiO}_{2}$. A introdução desses elementos na composição do vidro limitou a codopagem do sistema GP para concentrações superiores a 2,0\% em peso de $\mathrm{Yb}_{2} \mathrm{O}_{3}$, provocando uma distorção nos espectros de emissão óptica desses vidros, como será visto posteriormente.

Os resultados de EDX dos vidros co-dopados do sistema GPG mostram uma concordância ainda maior entre os valores nominais e determinados experimentalmente, além do mais, não é observado o ataque químico do cadinho, visto que não foi encontrada a presença de platina nas análises de EDX. Cabe acrescentar que não foi possível a co-dopagem desse sistema para concentrações superiores a 5,0\% de $\mathrm{Yb}_{2} \mathrm{O}_{3}$.

As composições dos componentes dos vidros co-dopados GP e GPG contendo precursores metálicos $\left(\mathrm{AgNO}_{3}, \mathrm{Au}_{2} \mathrm{O}_{3}\right.$ e $\left.\mathrm{Cu}_{2} \mathrm{O}\right)$ determinadas no $\mathrm{EDX}$ são mostradas nas Tabelas 9 e 10, respectivamente. Cabe lembrar que os vidros codopados GP-Y3, GP-A3 e GP-CY3 foram produzidos em cadinho de $\mathrm{Al}_{2} \mathrm{O}_{3}-\mathrm{SiO}_{2}$ e o vidro GP-Y3N foi produzido em cadinho de alumina pura. 
Tabela 9 - Composição experimental (\% em peso) determinada por EDX dos vidros GP co-dopados contendo prata e cobre.

\begin{tabular}{cccccccc}
\hline $\begin{array}{c}\text { Vidro } \\
\text { GP }\end{array}$ & $\mathrm{PbO}$ & $\mathrm{GeO}_{2}$ & $\mathrm{Er}_{2} \mathrm{O}_{3}$ & $\mathrm{Yb}_{2} \mathrm{O}_{3}$ & $\mathrm{Ag}_{2} \mathrm{O}$ & $\mathrm{SiO}_{2}$ & $\mathrm{Al}_{2} \mathrm{O}_{3}$ \\
\hline \hline GP-(Y3) & $56,26 \pm 0,26$ & $32,90 \pm 0,37$ & $0,31 \pm 0,07$ & $2,32 \pm 0,05$ & $0,53 \pm 0,01$ & $4,67 \pm 0,28$ & $3,02 \pm 0,19$ \\
GP-(A3) & $54,23 \pm 0,82$ & $31,63 \pm 0,67$ & $0,36 \pm 0,03$ & $0,62 \pm 0,09$ & $1,63 \pm 0,16$ & $5,88 \pm 0,38$ & $5,65 \pm 0,08$ \\
GP-(Y3N) & $58,72 \pm 0,12$ & $32,37 \pm 0,06$ & $0,27 \pm 0,02$ & $2,23 \pm 0,05$ & $0,60 \pm 0,01$ & - & $5,71 \pm 0,13$ \\
GP-(CY3) & $56,65 \pm 0,30$ & $33,05 \pm 0,31$ & $0,33 \pm 0,08$ & $2,41 \pm 0,09$ & - & $4,52 \pm 0,24$ & $3,41 \pm 0,21$ \\
\hline \hline
\end{tabular}

Tabela 10 - Composição experimental (\% em peso) determinada por EDX dos vidros GPG co-dopados contendo ouro.

\begin{tabular}{ccccccc}
\hline $\begin{array}{c}\text { Vidro } \\
\text { GPG }\end{array}$ & $\mathrm{PbO}$ & $\mathrm{GeO}_{2}$ & $\mathrm{Ga}_{2} \mathrm{O}_{3}$ & $\mathrm{Er}_{2} \mathrm{O}_{3}$ & $\mathrm{Yb}_{2} \mathrm{O}_{3}$ & $\mathrm{Au}_{2} \mathrm{O}_{3}$ \\
\hline GPG-(Y3) & $73,30 \pm 0,87$ & $13,76 \pm 0,54$ & $9,28 \pm 0,25$ & $0,33 \pm 0,01$ & $2,23 \pm 0,23$ & $1,10 \pm 0,15$ \\
GPG-(O3) & $74,35 \pm 0,34$ & $13,96 \pm 0,53$ & $8,91 \pm 0,35$ & $0,42 \pm 0,01$ & $0,92 \pm 0,03$ & $1,44 \pm 0,22$ \\
\hline \hline
\end{tabular}

Para o caso dos vidros GP contendo prata, é observada uma boa concordância entre as composições nominais e determinada experimentalmente. Entretanto, é observada uma redução substancial de $\mathrm{GeO}_{2}$ em comparação com a composição nominal, devido à introdução de $\mathrm{SiO}_{2}$ e $\mathrm{Al}_{2} \mathrm{O}_{3}$, provenientes do cadinho $\mathrm{Al}_{2} \mathrm{O}_{3}-\mathrm{SiO}_{2}$. No entanto, ao produzir-se um vidro (GP-Y3N) em cadinho de alumina, observa-se a ausência de $\mathrm{SiO}_{2}$; a presença de $\mathrm{Al}_{2} \mathrm{O}_{3}$ ainda é encontrada em grande quantidade, indicando que o cadinho continua sendo atacado.

Não foi encontrado a presença de cobre no vidro GP-CY3, que pode estar relacionado com a baixa concentração nominal desse elemento quando adicionado ao vidro, estando, portando, abaixo do limite de detecção da técnica utilizada.

No caso dos vidros do sistema GPG, há uma boa relação entre os valores nominais e experimentais da matriz (Tabela 10). Entretanto, há uma discrepância na 
concentração de $\mathrm{Au}_{2} \mathrm{O}_{3}$ do vidro GPG-O3, que pode estar associado com a precipitação de parte do ouro no fundo do cadinho.

\subsection{Análise Térmica Diferencial (ATD)}

\subsubsection{ATD do sistema GP}

Na Figura 26(a) e 26(b) são mostradas as curvas de ATD do vidro GP-Y3 e do vidro GP dopado com 3,0\% de prata, respectivamente.

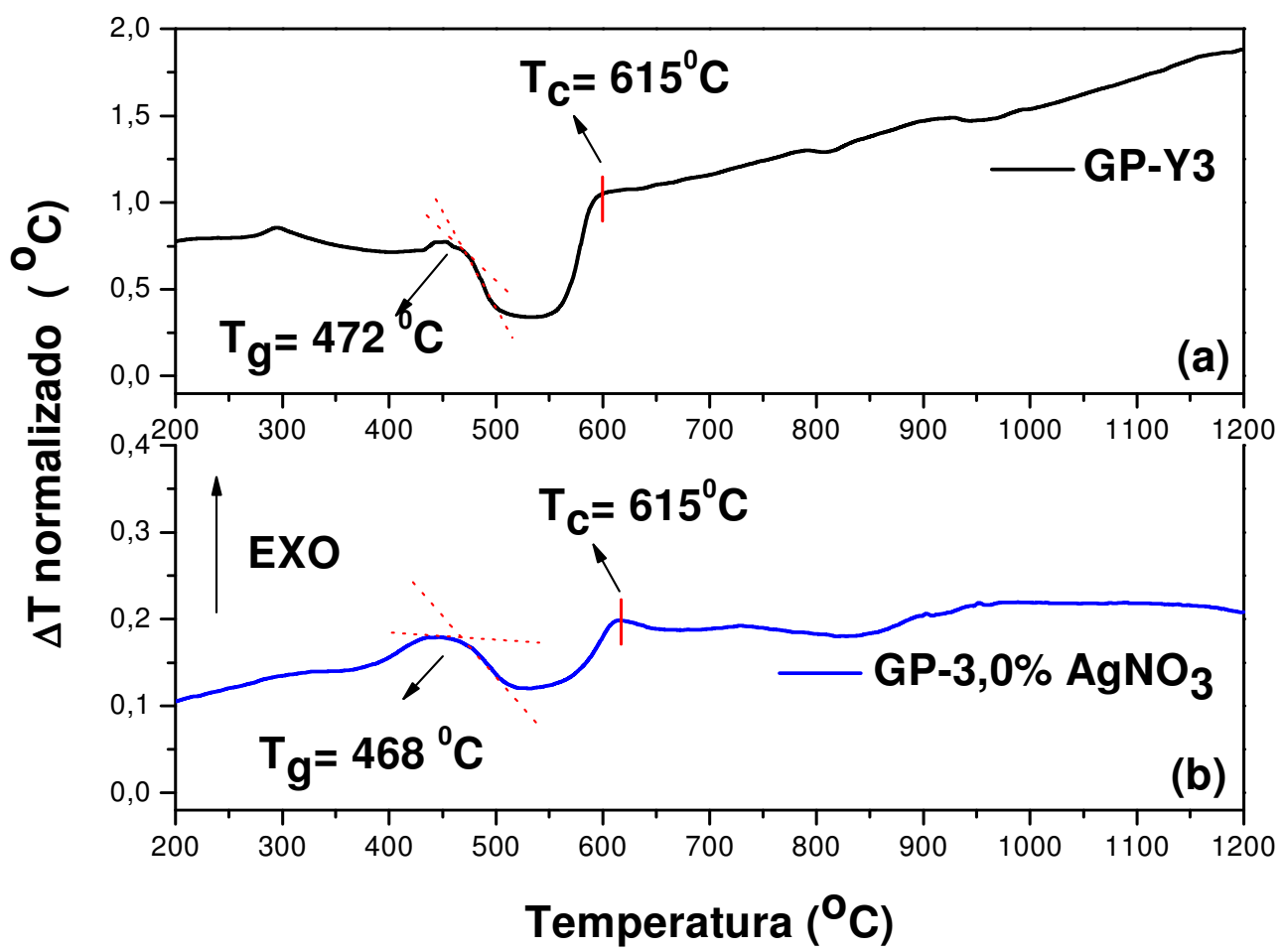

Figura 26 - Curvas de ATD do vidro GP-Y3 (a) e do vidro GP dopado com 3,0\% de $\mathrm{AgNO}_{3}(\mathrm{~b})$.

Por meio das curvas de ATD do vidro GP-Y3 é possível identificar as temperaturas de transição vítrea $\left(T_{g}\right)$, em $472^{\circ} \mathrm{C}$ e cristalização $\left(T_{c}\right)$, em $615^{\circ} \mathrm{C}$. A 
temperatura de fusão da fase cristalina $\left(T_{f}\right)$ não pode ser determinada e pode estar relacionada com a baixa taxa de nucleação e crescimento de cristais, dificultando a observação de um pico exotérmico de cristalização da fase cristalina e como conseqüência o de fusão. A temperatura de transição vítrea do vidro GP contendo $3,0 \%$ de $\mathrm{AgNO}_{3}$ é de $468^{\circ} \mathrm{C}$ e a temperatura de cristalização é a mesma do vidro GP-Y3.

\subsubsection{ATD do sistema GPG}

Na Figura 27 (a) e (b) são mostradas as curvas de ATD dos vidros GPG-Y3 e do vidro GPG dopado com 5,0\% de prata, respectivamente.

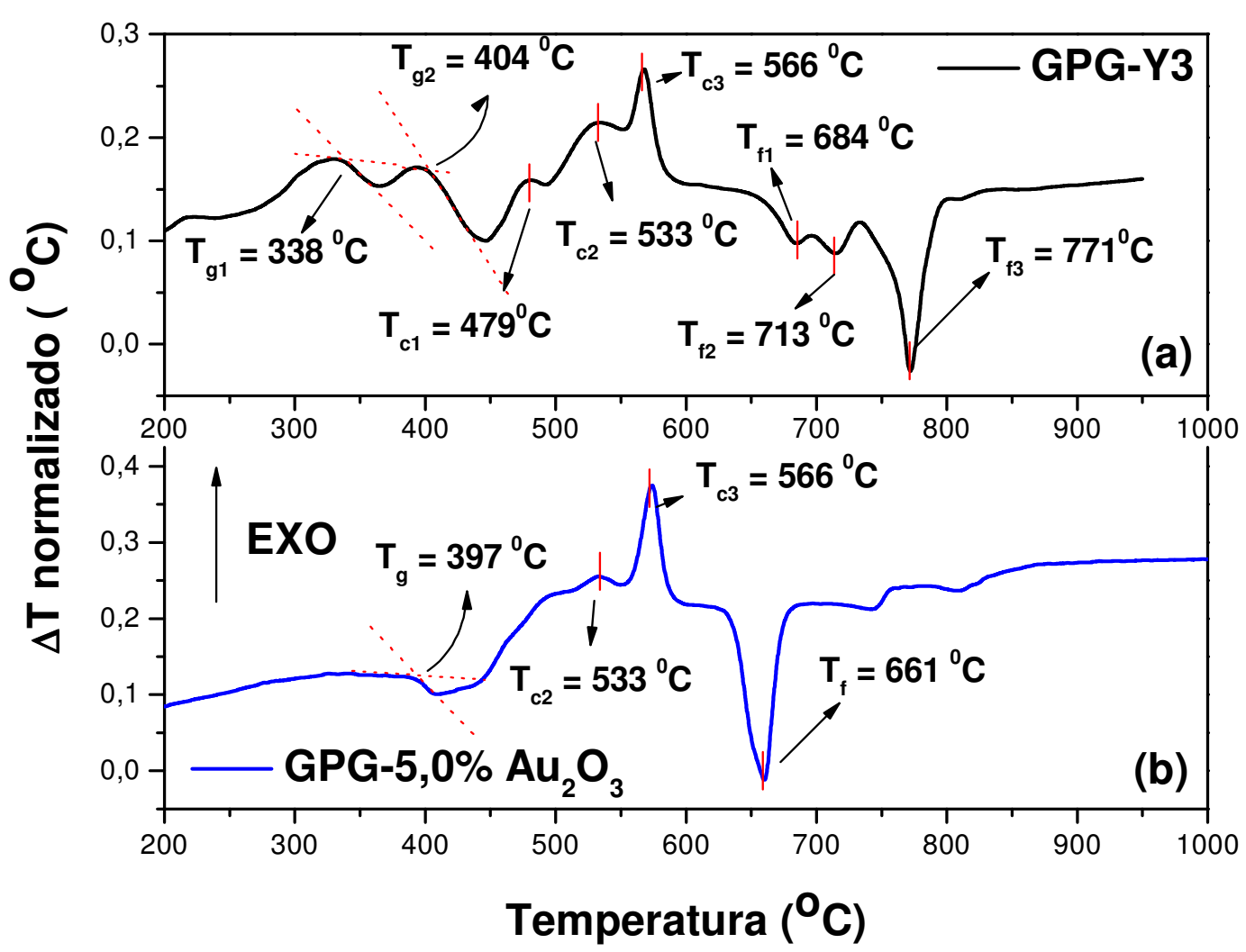

Figura 27 - Curvas de ATD do vidro GPG-Y3 (a) e do vidro GP dopado com 5,0\% de $\mathrm{Au}_{2} \mathrm{O}_{3}(\mathrm{~b})$. 
O vidro GPG-Y3, é um sistema vítreo mais complexo, possuindo duas $\mathrm{Tg}$ $\left(T_{g 1}=338^{\circ} \mathrm{C}\right.$ e $\left.T_{g 2}=404^{\circ} \mathrm{C}\right)$ e três $T c\left(T_{c 1}=479^{\circ} \mathrm{C}, T_{c 2}=553^{\circ} \mathrm{C}\right.$ e $\left.T_{c 3}=566^{\circ} \mathrm{C}\right)$ e respectivas temperaturas de fusão das fases cristalinas $T_{f}\left(T_{f 1}=683^{\circ} \mathrm{C}, T_{f 2}=713^{\circ} \mathrm{C} e\right.$ $\mathrm{T}_{\mathrm{f} 3}=771^{\circ} \mathrm{C}$ ). Cabe acrescentar que a temperatura de tratamento térmico utilizada para nucleação das NPs foi superior a temperatura de transição vítrea.

\subsection{Difração de Raios X}

Na Figura 28 (a) e (b) são mostrados os difratogramas de raios $X$ (DRX) dos vidros GP e GPG dopados com 3,0\% de $\mathrm{AgNO}_{3}$ e 5,0\% $\mathrm{Au}_{2} \mathrm{O}$, respectivamente. As amostras foram tratadas termicamente por $1 \mathrm{~h}$ e $48 \mathrm{~h}$ a fim de se verificar a manutenção do estado amorfo para os diferentes tempos de tratamento térmico.
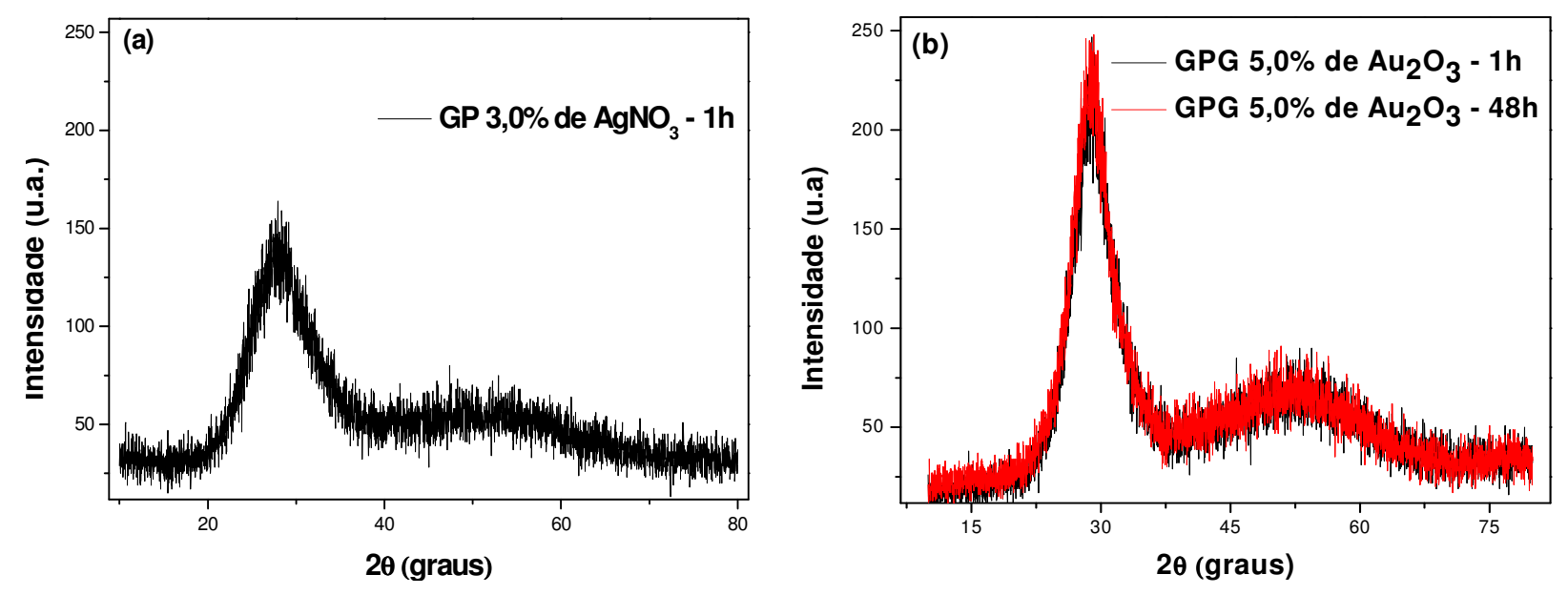

Figura 28 - Difratogramas de Raios X dos vidros GP (a) e GPG (b) com 3,0\% de $\mathrm{AgNO}_{3}$ e $5,0 \% \mathrm{Au}_{2} \mathrm{O}_{3}$, respectivamente.

Como pode ser visto, não é observada a formação de nenhum pico característico de fase cristalina em ambos os vidros. É observado apenas o halo amorfo característico de sistemas vítreos. Entretanto, será mostrada posteriormente por meio das observações em MET que há formação de NPs cristalinas em escala nanométrica em ambos os sistemas. 
Nas Figuras 29 e 30 são mostrados os DRX dos vidros GPG $\left(5,0 \% \mathrm{Au}_{2} \mathrm{O}_{3}\right)$ e GPG-Y3, respectivamente, tratados termicamente nas temperaturas de cristalização determinadas por meio da ATD. Este tratamento térmico foi realizado com intuito de se determinar a formação de fases cristalinas distintas, relacionadas com uma tendência de separação de fase dos vidros do sistema GPG.

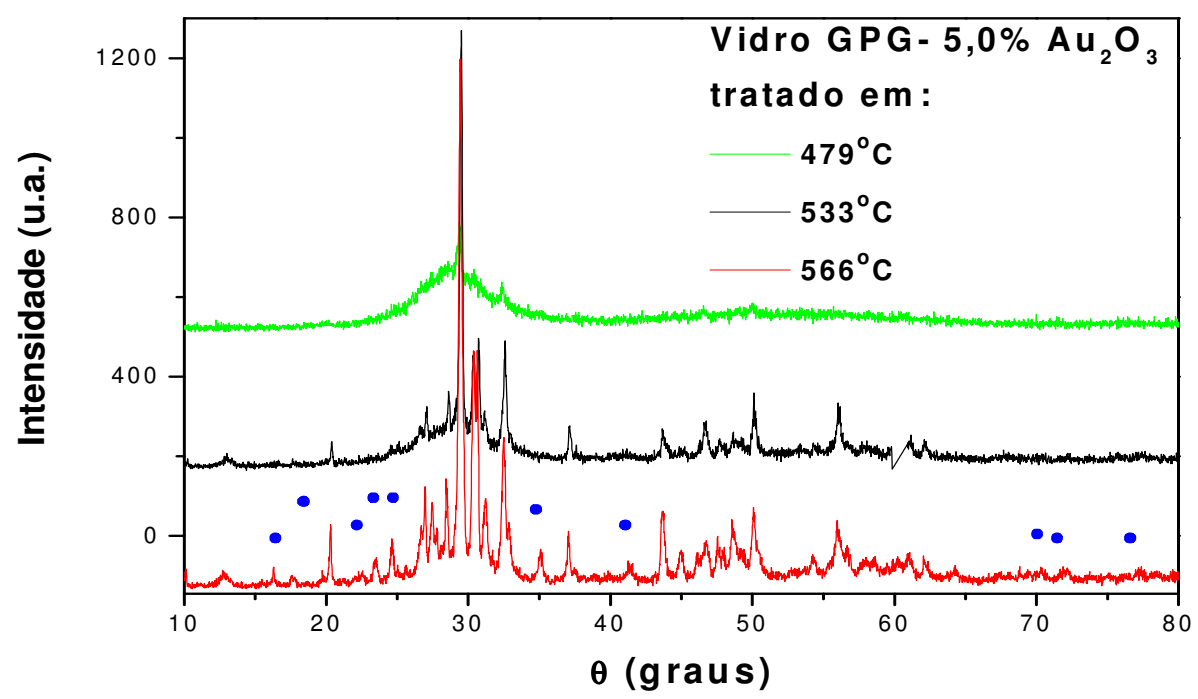

Figura 29 - Difratogramas de Raios X do vidro GPG dopado com 5,0\% de $\mathrm{Au}_{2} \mathrm{O}_{3}$ tratados termicamente a 479,533 e $566^{\circ} \mathrm{C}$.

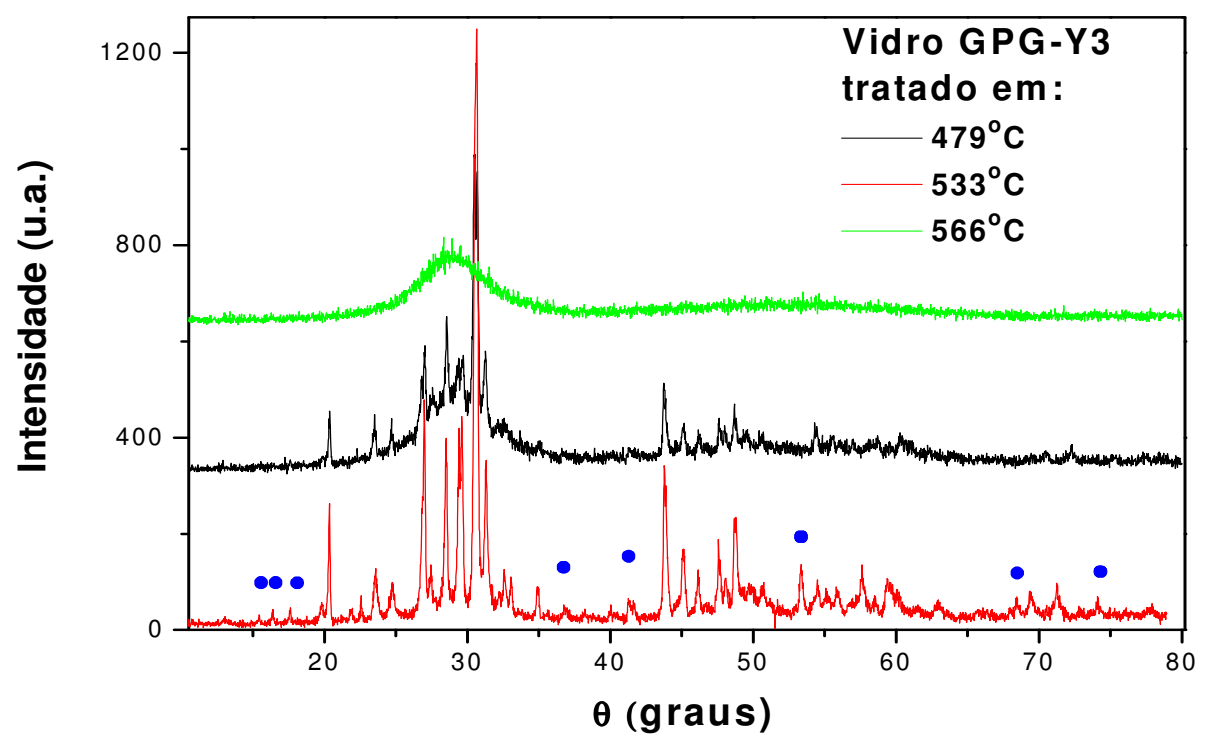

Figura 30 - Difratogramas de Raios $X$ do vidro GPG-Y3 tratados termicamente a 479,533 e $566^{\circ} \mathrm{C}$. 
Observa-se por meio dos DRX tanto do vidro GPG-Y3 quanto GPG dopado com $5,0 \%$ de $\mathrm{Au}_{2} \mathrm{O}_{3}$, que há a formação de picos (assinalados pelas esferas azuis) nos DRXs dos vidros tratados a $566^{\circ} \mathrm{C}$ que não estão presentes nos DRXs dos vidros tratados por 479 e $533^{\circ} \mathrm{C}$. Apesar das fases cristalinas não serem identificadas, atribui-se o surgimento desses picos à formação de fases cristalinas distintas. Essa constatação experimental associado com os resultados de ATD indica que há separação de fase nos vidros do sistema GPG.

\subsection{Espectroscopia Raman nos vidros GP e GPG}

Na Figura 31 (a) e (b) são mostrados os espectros de vibração Raman das matrizes vítreas GP e GPG sem dopante, respectivamente.
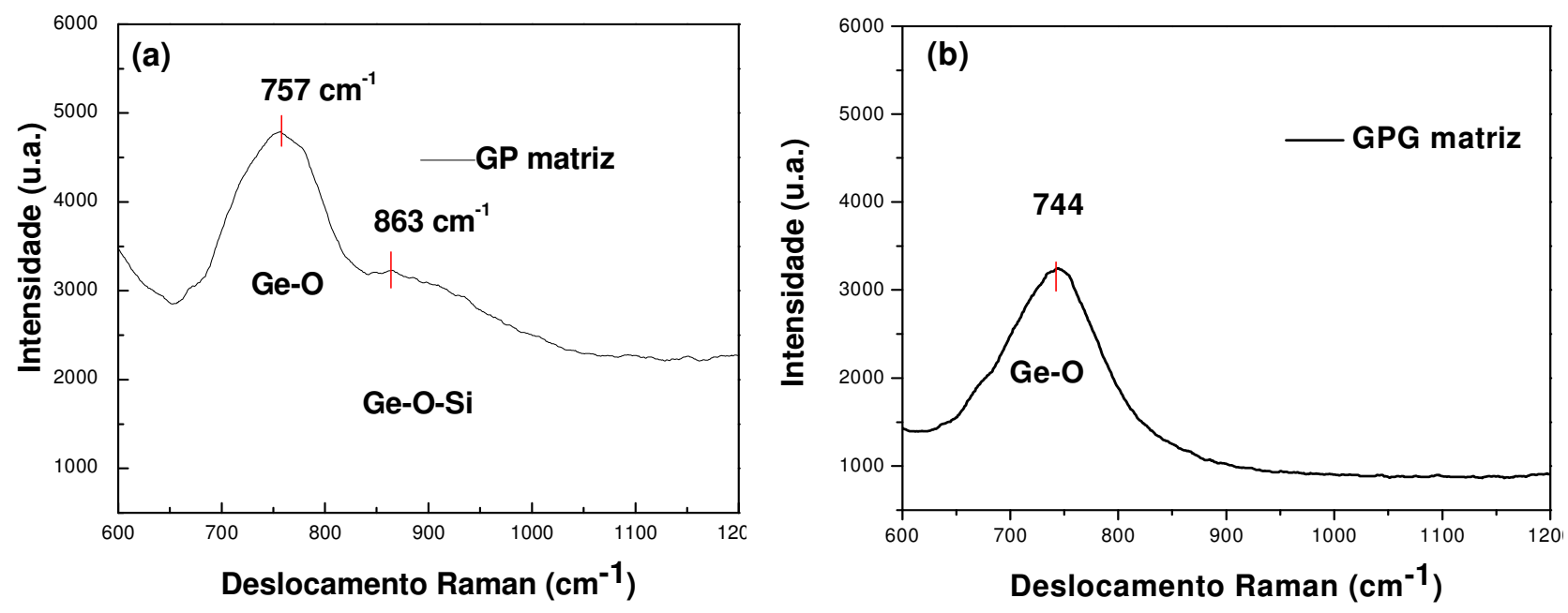

Figura 31 - Espectro de espalhamento Raman dos vidros GP (a) e GPG (b).

Por meio da determinação do espalhamento Raman é possível identificar a máxima energia de fônon, que pode ser associada com a vibração da ligação Ge-O [56] com picos centrados em 757 e $744 \mathrm{~cm}^{-1}$ para os vidros GP e GPG, respectivamente. A maior intensidade de espalhamento Raman observada no vidro 
GP está relaciona com a maior concentração de germânio contida neste vidro em comparação ao vidro GPG. Além da banda característica da ligação Ge-O também é encontrada um fraca banda em $863 \mathrm{~cm}^{-1}$ no vidro GP, que de acordo com a literatura pode ser relacionada com a vibração da ligação Si-O-Ge [57], já que nesse vidro há um pequena teor de $\mathrm{SiO}_{2}$ proveniente do cadinho de $\mathrm{Al}_{2} \mathrm{O}_{3}-\mathrm{SiO}_{2}$ usado para a preparação desses vidros.

A localização da máxima energia de fônon é importante, pois o decaimento multifônon do íon $\mathrm{Er}^{3+}$ depende fundamentalmente da máxima energia de fônon da matriz; quanto maior a energia de fônon de um material, maior será a perda de energia, e por conseqüência, menor será a eficiência das emissões de CAF [58].

\subsection{Transmissão óptica}

As Figuras 32 (a) e (b) mostram os espectros de transmitância das matrizes GP e GPG sem dopante, assim como os espectros de transmissão dos vidros GP e GPG contendo diferentes concentrações de prata (Figura 32 (a)) e ouro (Figura 32(b)).
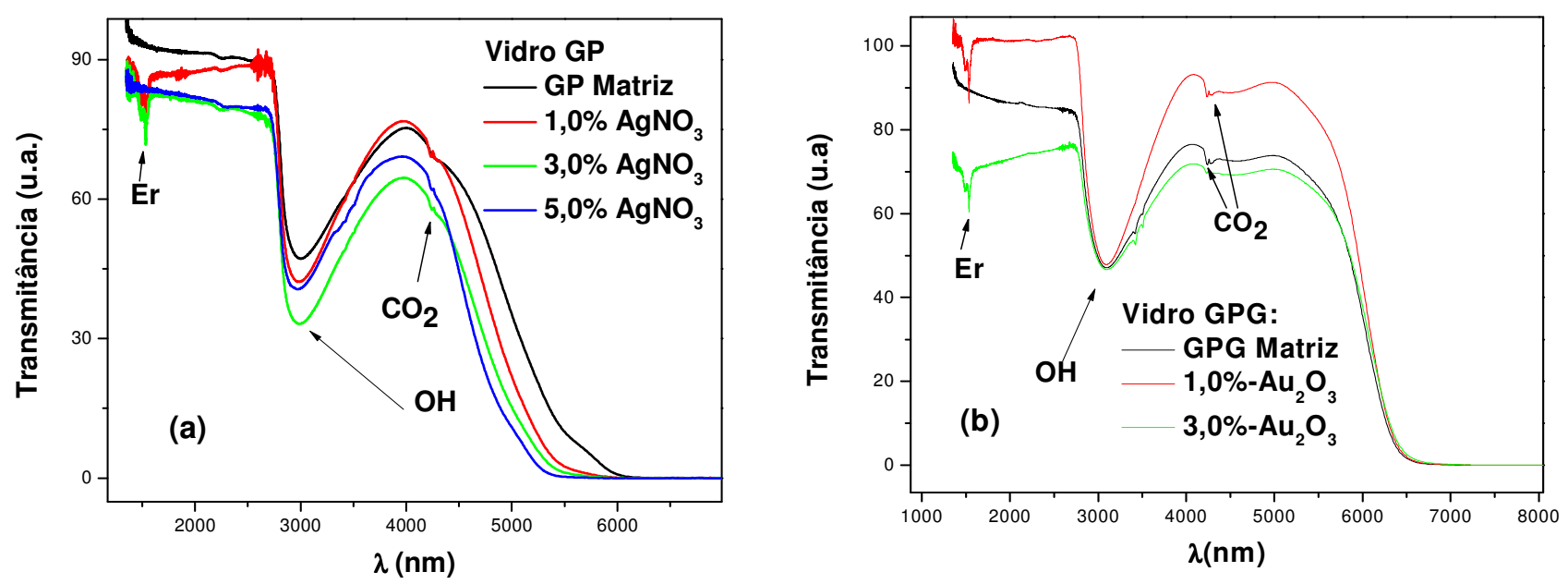

Figura 32 - (a) transmitância do vidro GP sem dopante e co-dopados com diferentes concentrações de prata; (b) transmitância do vidro GPG sem dopante e co-dopados com diferentes concentrações de ouro. 
O vidro GP apresenta transmissão óptica no infravermelho até $4500 \mathrm{~nm}$, e o vidro GPG possui transmissão óptica até 6000 nm, Figura 32 (a). No caso dos vidros do sistema GP é observada uma diminuição na janela de transmissão quando a concentração de prata é aumentada de zero a 5,0\%. Com relação ao vidro GPG, não é observada alterações na janela de transmissão na presença de NPs. A maior janela de transmissão do vidro GPG, em comparação ao vidro GP, está relacionada com o maior teor de chumbo em sua composição, que possui baixa freqüência de vibração, ou seja, vidros que possuem maior concentração de cátions com grande massa atômica apresentaram uma janela de transmissão no infravermelho [59].

\subsection{Caracterização óptica dos vidros co-dopados}

\subsubsection{Absorção óptica do vidro GPG}

Na Figura 33 é mostrado o espectro de absorção óptica na região do visível e infravermelho dos vidros GPG co-dopados com concentração de 0,5\% de $\mathrm{Er}_{2} \mathrm{O}_{3}$ e diferentes concentrações de $\mathrm{Yb}_{2} \mathrm{O}_{3}(1,0 \%$ a 5,0\%, \% em peso). O início da janela de transmissão desse vidro ocorre em torno de $450 \mathrm{~nm}$.

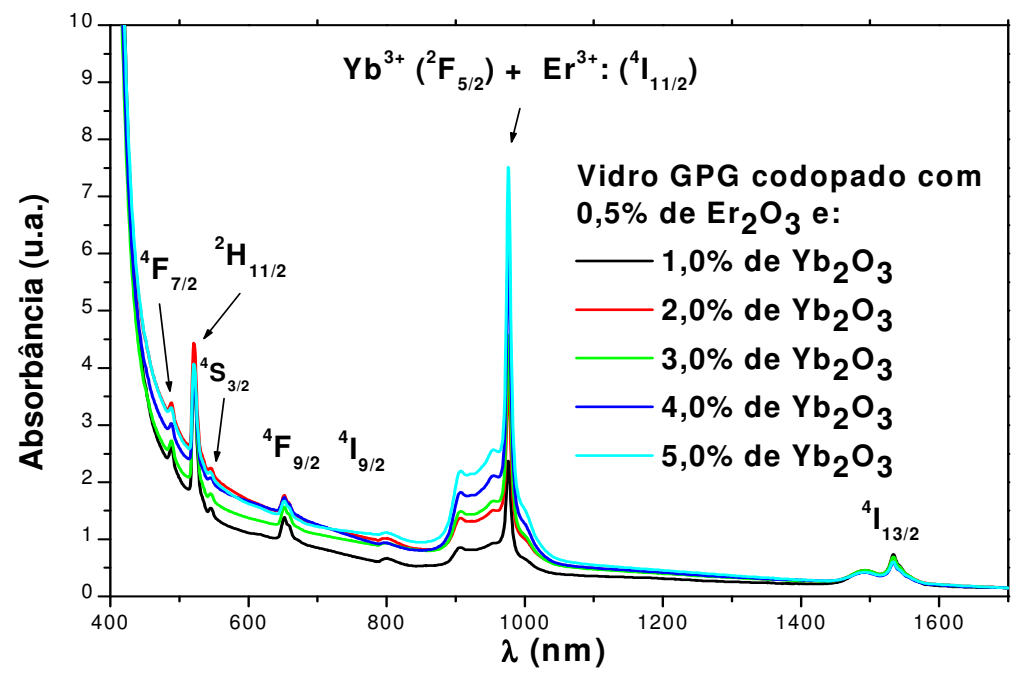

Figura 33 - Espectros de absorção óptica na região do visível e infravermelho do vidro GPG co-dopado com $0,5 \% \mathrm{Er}_{2} \mathrm{O}_{3}$ e diferentes concentrações de $\mathrm{Yb}_{2} \mathrm{O}_{3}$. 
As bandas de absorção são atribuídas às transições $4 \mathrm{f}-4 \mathrm{f}$ do $E r^{3+}$ do estado fundamental ${ }^{4} \mathrm{I}_{15 / 2}$ para $\mathrm{o}$ estado excitado. Observa-se dez picos relacionados às absorções do $\mathrm{Er}^{3+}$ em 490, 522, 545, 654, 800, 980 e 1532 nm do vidro GP, devido às transições a partir do estado fundamental ${ }^{4} I_{15 / 2}$ para os estados excitados ${ }^{4} \mathrm{~F}_{7 / 2}$, ${ }^{2} \mathrm{H}_{1 / 2},{ }^{4} \mathrm{~S}_{3 / 2},{ }^{4} \mathrm{~F}_{9 / 2},{ }^{4} \mathrm{I}_{9 / 2},{ }^{4} \mathrm{I}_{1 / 2}$ e ${ }^{4} \mathrm{I}_{13 / 2}$. Observa-se também o aumento da banda de absorção em torno de 980nm em função da concentração de $\mathrm{Yb}_{2} \mathrm{O}_{3}$.

\subsubsection{Emissão óptica dos vidros GPG}

A Figura 34 mostra o espectro de CAF do vidro GPG co-dopado com $\mathrm{Er}_{2} \mathrm{O}_{3}$ e diferentes concentrações de $\mathrm{Yb}_{2} \mathrm{O}_{3}$. As bandas de emissão centradas em 523, 545, $657 \mathrm{~nm}$ correspondem às transições ${ }^{2} \mathrm{H}_{11 / 2} \rightarrow{ }^{4} \mathrm{I}_{15 / 2},{ }^{4} \mathrm{~S}_{3 / 2} \rightarrow{ }^{4} \mathrm{I}_{15 / 2}$, e ${ }^{4} \mathrm{~F}_{9 / 2} \rightarrow{ }^{4} \mathrm{I}_{15 / 2}$ do $\mathrm{Er}^{3+}$, respectivamente.

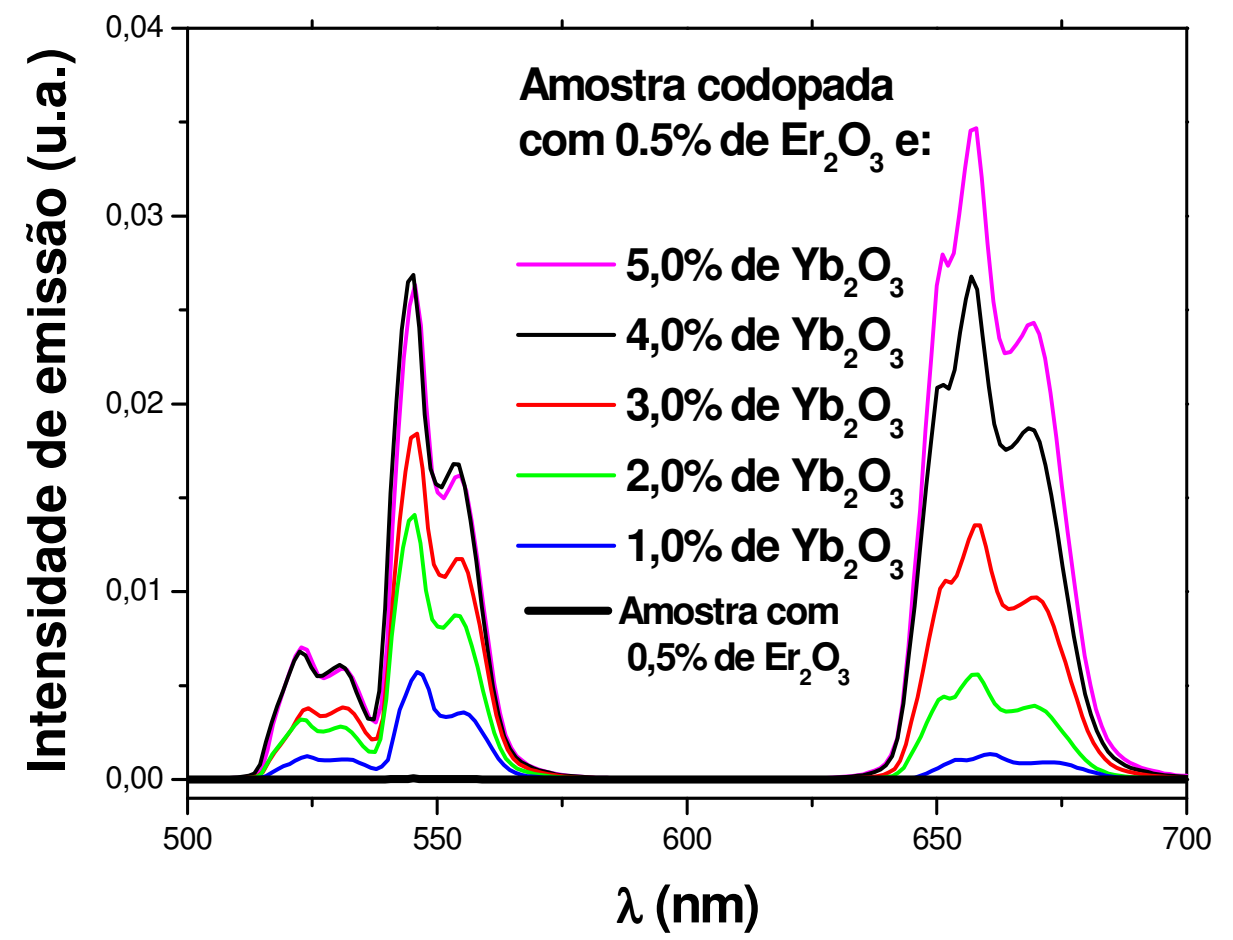

Figura 34 - Espectro de emissão de CAF do vidro GPG com diferentes concentrações de $\mathrm{Yb}_{2} \mathrm{O}_{3}$ excitado em $980 \mathrm{~nm}$. 
Pode-se observar que 0 aumento da concentração de $\mathrm{Yb}_{2} \mathrm{O}_{3}$ causa um aumento da emissão de CAF do $\mathrm{Er}^{3+}$. Para concentrações superiores a 4,0\% de $\mathrm{Yb}_{2} \mathrm{O}_{3}$ a emissão vermelha supera a verde. Com o intuito de avaliar a influência do itérbio nas emissões do érbio, foram realizadas comparações entre as bandas integradas das emissões do érbio como mostrado na Figura 35.

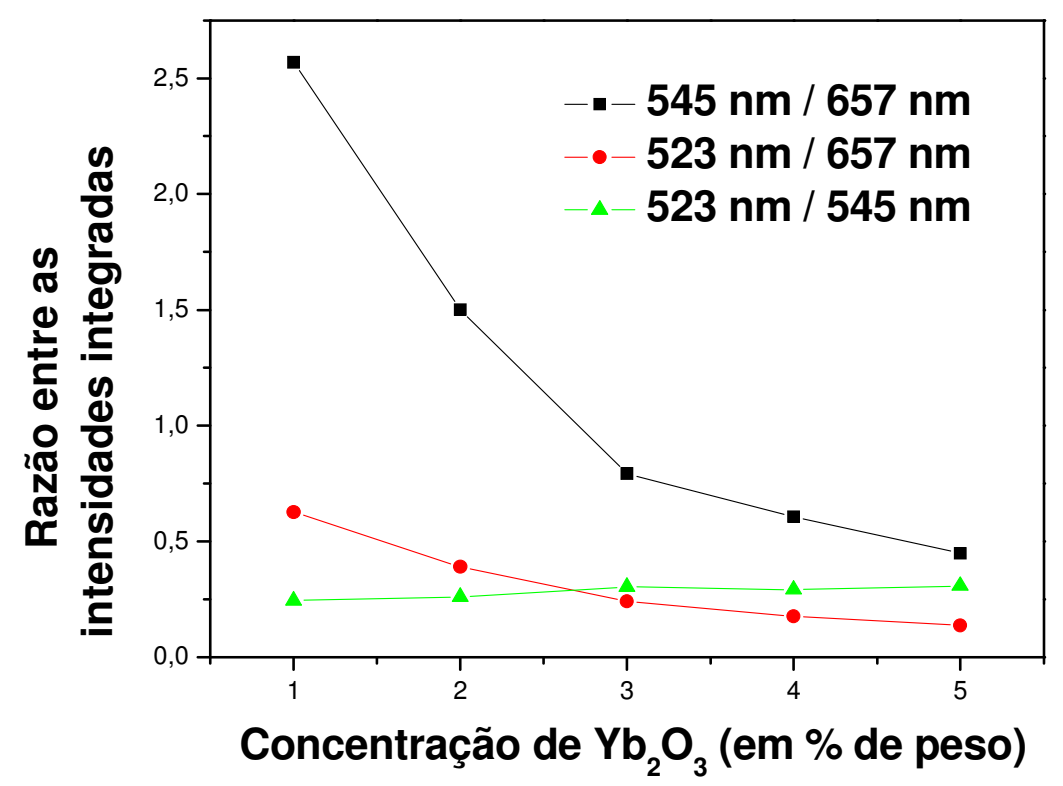

Figura 35 - Razão das intensidades integradas em função da concentração de $\mathrm{Yb}_{2} \mathrm{O}_{3}$ do vidro GPG.

A intensidade de luminescência de CAF é aumentada com a concentração do íon $\mathrm{Yb}^{3+}$ que absorve, de forma eficiente, a radiação eletromagnética em $980 \mathrm{~nm}$. A emissão mais afetada com o aumento da concentração de $\mathrm{Yb}_{2} \mathrm{O}_{3}$ é a vermelha, seguida da verde em $545 \mathrm{~nm}$. Estes resultados demonstram o papel dos íons $\mathrm{Yb}^{3+}$ no processo de CAF, que ocorre fundamentalmente por meio da transferência de energia, tendo em vista a baixa concentração de érbio na composição do vidro

As razões entre as integrais das bandas de emissão nas regiões do vermelho (657 nm) e do verde (545 nm) mostram que o crescimento da primeira é mais acentuado com o aumento da concentração de $\mathrm{Yb}_{2} \mathrm{O}_{3}$, como mostrado na Figura 35. 
O mesmo comportamento é observado para a razão entre as emissões do vermelho (657 nm) e do verde em 523 nm também mostrado na Figura 35.

A evidência experimental do aumento da emissão em torno de $660 \mathrm{~nm}$ quando comparada com a emissão verde pode ser explicada pelo processo 3 mostrado na Figura 36. A quantidade de íons de $\mathrm{Er}^{3+}$ no nível ${ }^{4} \mathrm{I}_{11 / 2}$ que relaxa não radiativamente para o nível inferior ${ }^{4} I_{13 / 2}$ é muito maior do que a dos íons que são excitados para o nível ${ }^{4} \mathrm{~F}_{7 / 2}$ (pelos processos 1 e 2). O longo tempo de vida do nível ${ }^{4} \mathrm{I}_{13 / 2}$ quando comparado com o tempo de vida do nível ${ }^{4} \mathrm{I}_{11 / 2}[41,60-61]$ faz com que 0 processo 3 seja dominante favorecendo a emissão em $660 \mathrm{~nm}$. Cabe acrescentar que o nível emissor da luz verde não pode ser populado pelo processo 3 . Além disso, a energia de fônon também tem um papel importante e influencia a intensidade de CAF; quanto maior for a energia de fônon em vidros co-dopados com $\mathrm{Er}^{3+}$ e $\mathrm{Yb}^{3+}$ mais afetada será a emissão na região do vermelho [39].

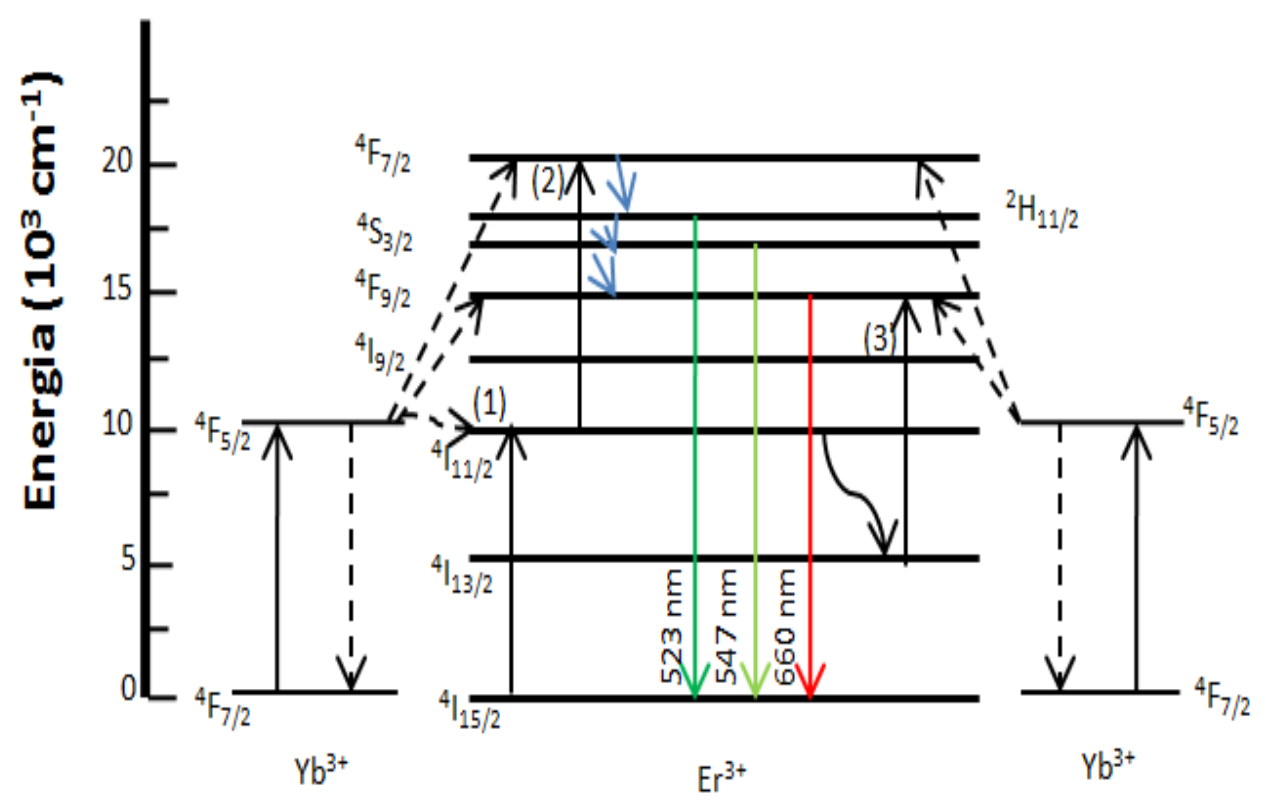

Figura 36 - Diagrama de energia dos íons $\mathrm{Er}^{3+} / \mathrm{Yb}^{3+}$ e os mecanismos de CAF no vidro GPG. As linhas sólidas indicam o comprimento de onda de bombeio, as transições de CAF, e as transições radiativas, respectivamente. As linhas pontilhadas e em azul estão relacionadas aos processos de transferência de energia e relaxação não radiativa, respectivamente. 
Na Figura 37 são apresentados os resultados das intensidades de emissão em $545 \mathrm{~nm}$ e $660 \mathrm{~nm}$ dos vidros GP em função da potência de bombeio em 980nm, em escala logarítmica.
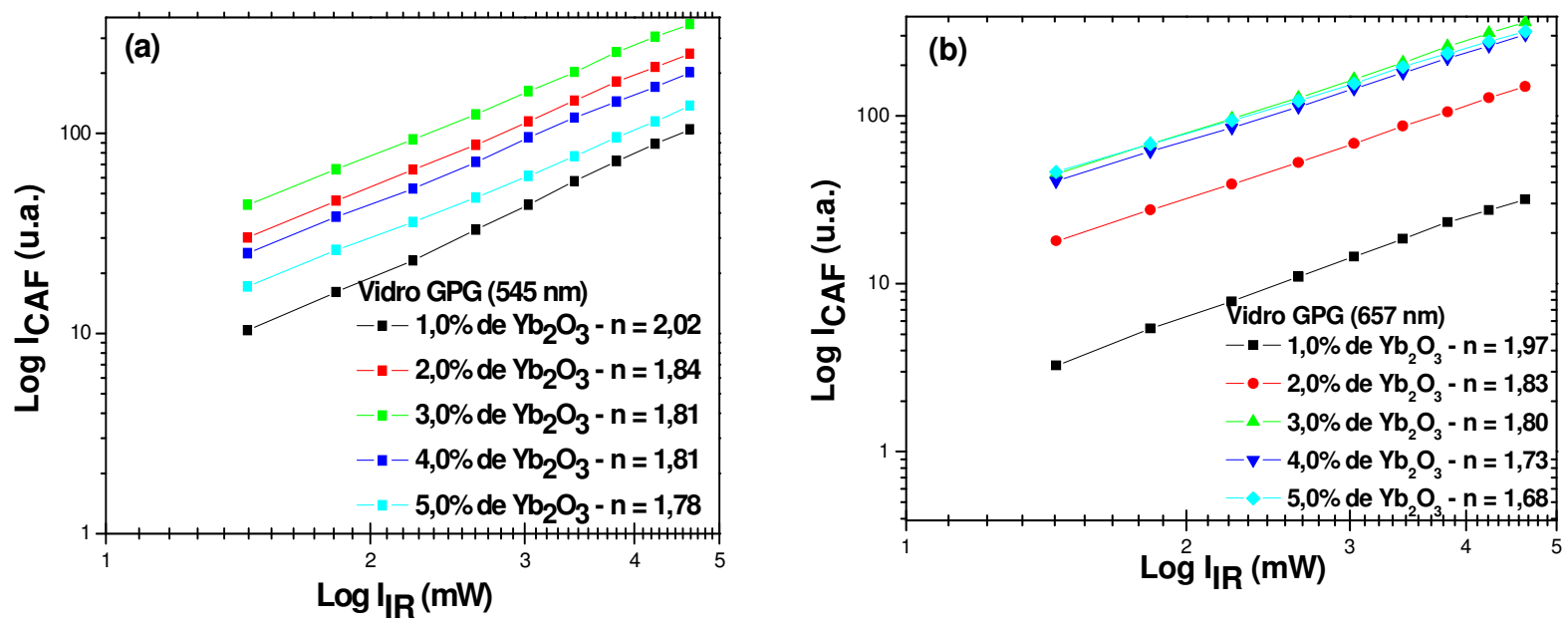

Figura 37 - Intensidade de emissão de CAF em 545 nm (a) e em 657 nm (b), respectivamente em função da potência de bombeio do vidro GPG.

Em todos os casos o coeficiente da reta (n) está em torno de 2, indicando que dois fótons participam do processo de conversão ascendente. Processos não radiativos podem ocorrer levando a redução do coeficiente da reta.

\subsubsection{Absorção óptica dos vidros GP}

Na Figura 38 são mostrados os espectros de absorção óptica na região do visível e infravermelho dos vidros GP co-dopados com concentração fixa de $0,5 \%$ de $\mathrm{Er}_{2} \mathrm{O}_{3}$ e diferentes concentrações de $\mathrm{Yb}_{2} \mathrm{O}_{3}$ (1,0\% a 3,0\%, \% em peso). O início da janela de transmissão desse vidro ocorre em $370 \mathrm{~nm}$, comprimento de onda inferior a do vidro GPG, possibilitando a observação de mais bandas de absorção. 


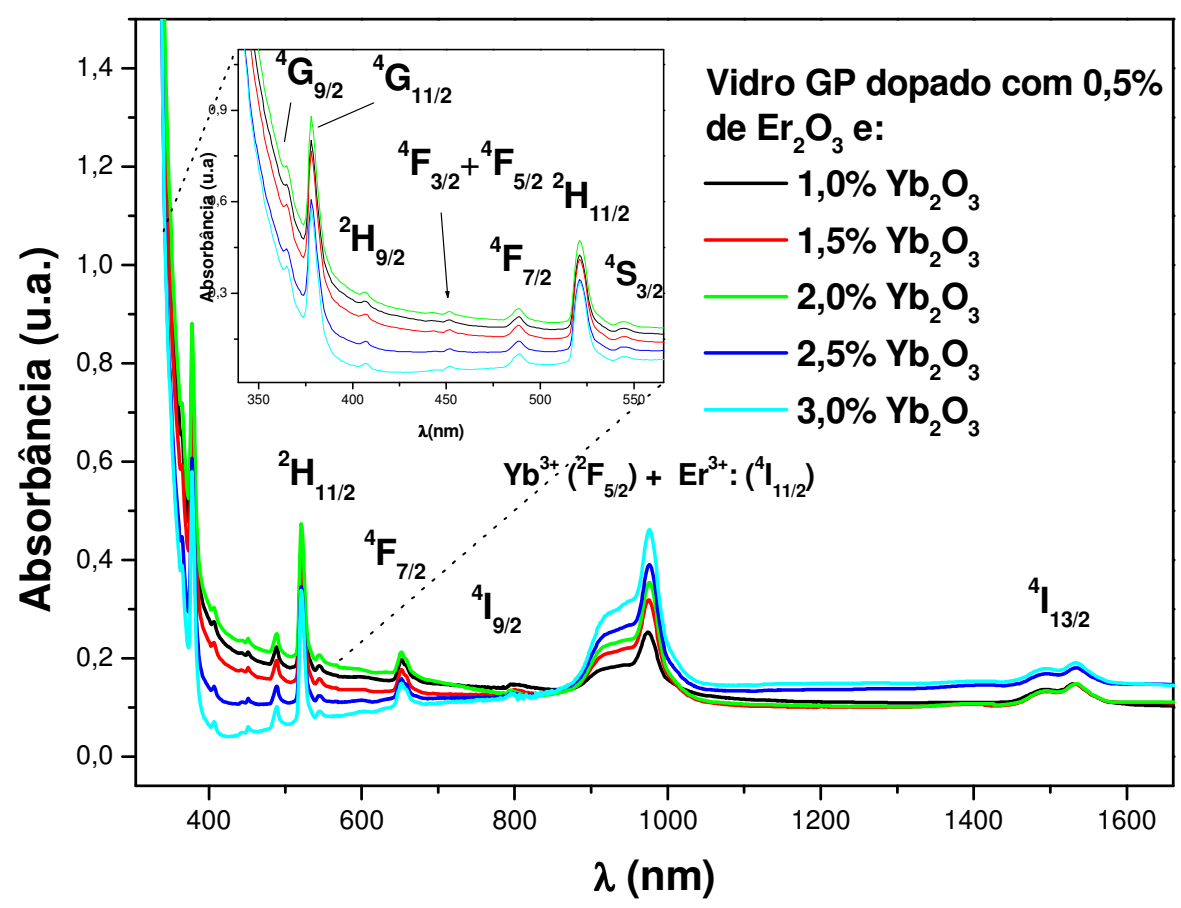

Figura 38 - Espectros de absorção óptica na região do visível e infravermelho do vidro GP co-dopado com $0,5 \% \mathrm{Er}_{2} \mathrm{O}_{3}$ e diferentes concentrações de $\mathrm{Yb}_{2} \mathrm{O}_{3}$.

Além dos picos encontrados no vidro GPG foram também observados os picos relacionados com as transições do estado fundamental para os estados excitados ${ }^{4} G_{11 / 2},{ }^{2} G_{9 / 2}$ e ${ }^{4} F_{3 / 2}+{ }^{4} F_{5 / 2}$, situados em 380,410 e $450 \mathrm{~nm}$. Assim como no vidro GPG observa-se o aumento da banda em torno de $980 \mathrm{~nm}$, associada com a sobreposição espectral das transições ${ }^{4} \mathrm{I}_{15 / 2} \rightarrow{ }^{4} \mathrm{I}_{11 / 2}$ do íon $\mathrm{Er}^{3+}$ e ${ }^{4} \mathrm{~F}_{7 / 2} \rightarrow{ }^{4} \mathrm{~F}_{5 / 2}$ do íon $\mathrm{Yb}^{3+}$.

\subsubsection{Emissão óptica do vidro GP co-dopado}

A Figura 39 mostra os espectros de CAF do vidro GP co-dopado com $\mathrm{Er}_{2} \mathrm{O}_{3} \mathrm{e}$ $\mathrm{Yb}_{2} \mathrm{O}_{3}$. As bandas de emissão centradas em 523, 547, $659 \mathrm{~nm}$ correspondem às transições ${ }^{2} \mathrm{H}_{11 / 2} \rightarrow{ }^{4} \mathrm{I}_{15 / 2},{ }^{4} \mathrm{~S}_{3 / 2} \rightarrow{ }^{4} \mathrm{I}_{15 / 2}$, e ${ }^{4} \mathrm{~F}_{9 / 2} \rightarrow{ }^{4} \mathrm{I}_{15 / 2}$ do $\mathrm{Er}^{3+}$, respectivamente. 


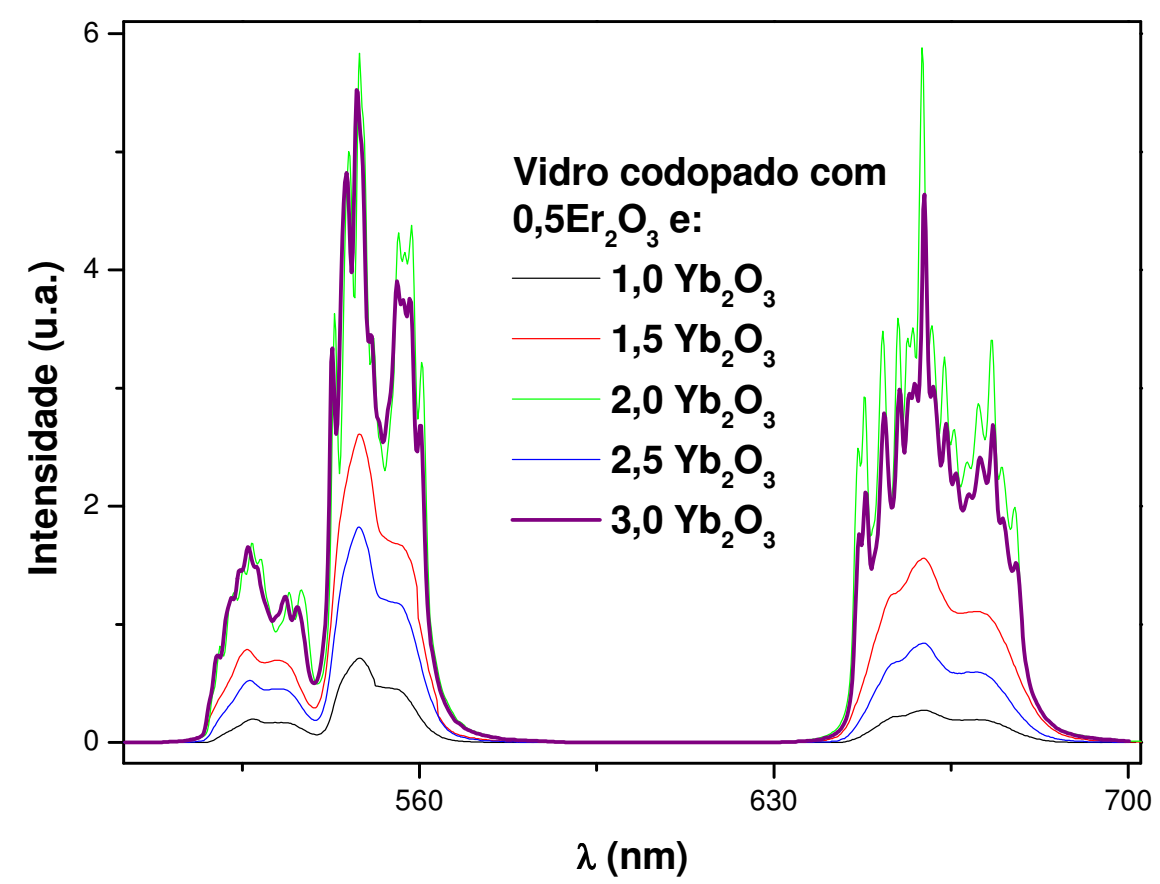

Figura 39 - Espectro de emissão de conversão ascendente do vidro GP com diferentes concentrações de $\mathrm{Yb}_{2} \mathrm{O}_{3}$ excitado, em $980 \mathrm{~nm}$.

O mesmo comportamento da luminescência de CAF em função da concentração de $\mathrm{Yb}_{2} \mathrm{O}_{3}$ observada no vidro GPG é também observada nesse sistema, demonstrando mais uma vez o papel fundamental do íon $\mathrm{Yb}^{3+}$ na transferência de energia que influencia as emissões do íon $\mathrm{Er}^{3+}$. Cabe acrescentar que para concentrações de $\mathrm{Yb}_{2} \mathrm{O}_{3}$ superiores a 2,0\%, os vidros tornam-se gradualmente opacas, provocando uma distorção no espectro. Propõe-se que essa distorção no espectro é ocasionada pela saturação do vidro provocada pela grande quantidade de impurezas provenientes do cadinho e também pela maior concentração de $\mathrm{Yb}_{2} \mathrm{O}_{3}$.

As razões entre as bandas de emissão integradas em função da concentração de $\mathrm{Yb}_{2} \mathrm{O}_{3}$ do vidro GP são mostradas na Figura 40. 


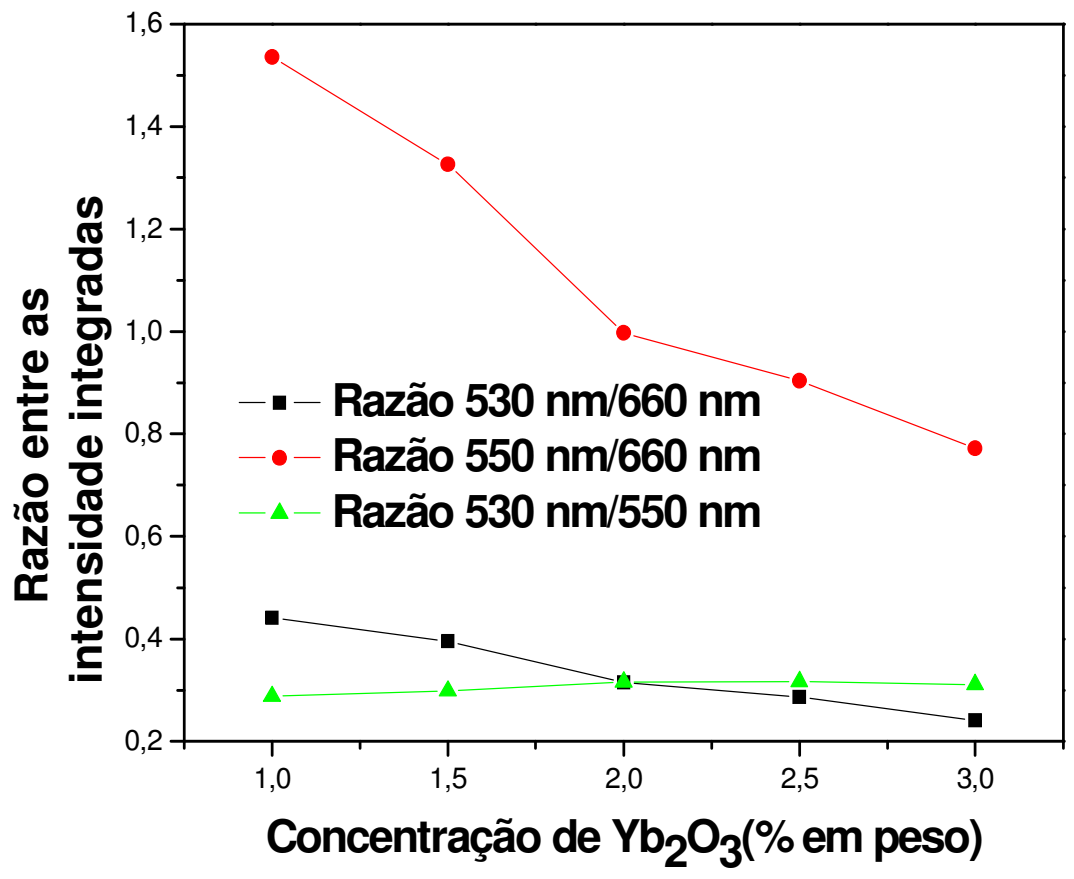

Figura 40 - Razão das intensidades integradas em função da concentração de $\mathrm{Yb}_{2} \mathrm{O}_{3}$.

As razões entre as integrais das bandas de emissão nas regiões do vermelho (659 nm) e do verde (547 e $523 \mathrm{~nm}$ ) do vidro GP apresentam o mesmo comportamento em relação ao vidro GPG. Entretanto, o crescimento da emissão vermelha em relação ao verde é quase que linear. Cabe acrescentar que não foi possível a co-dopagem para concentrações superiores a 2,0\%.

$\mathrm{Na}$ Figura 41 (a) e (b) são apresentados os resultados das intensidades de emissão em torno de $545 \mathrm{~nm}$ e $660 \mathrm{~nm}$ dos vidros GP em função da potência de bombeio, em escala logarítmica, e na Figura 42 é apresentado o diagrama

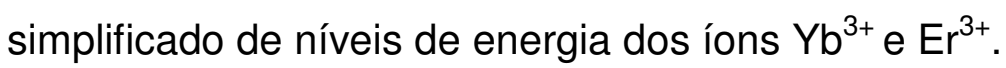



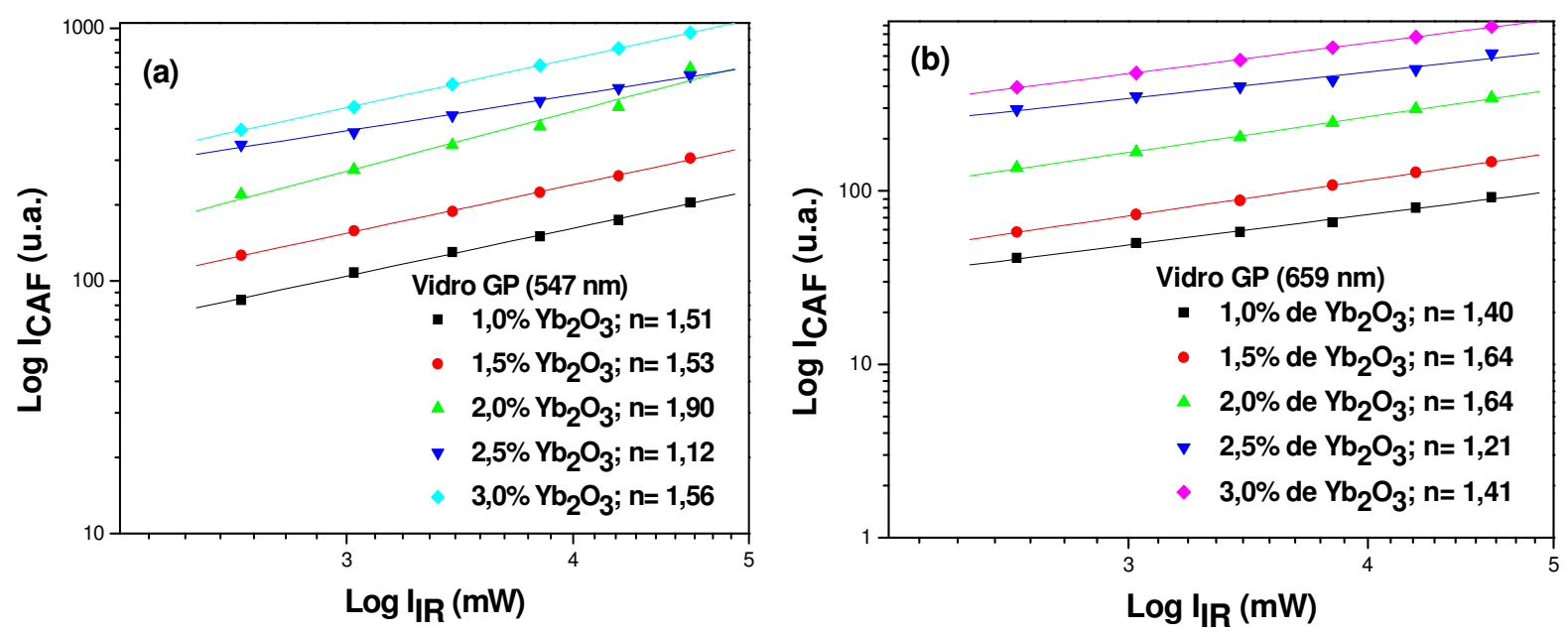

Figura 41 - Intensidade de emissão de CAF em 547 nm (a) e em 659 nm (b), respectivamente em função da potência de bombeio em $980 \mathrm{~nm}$.

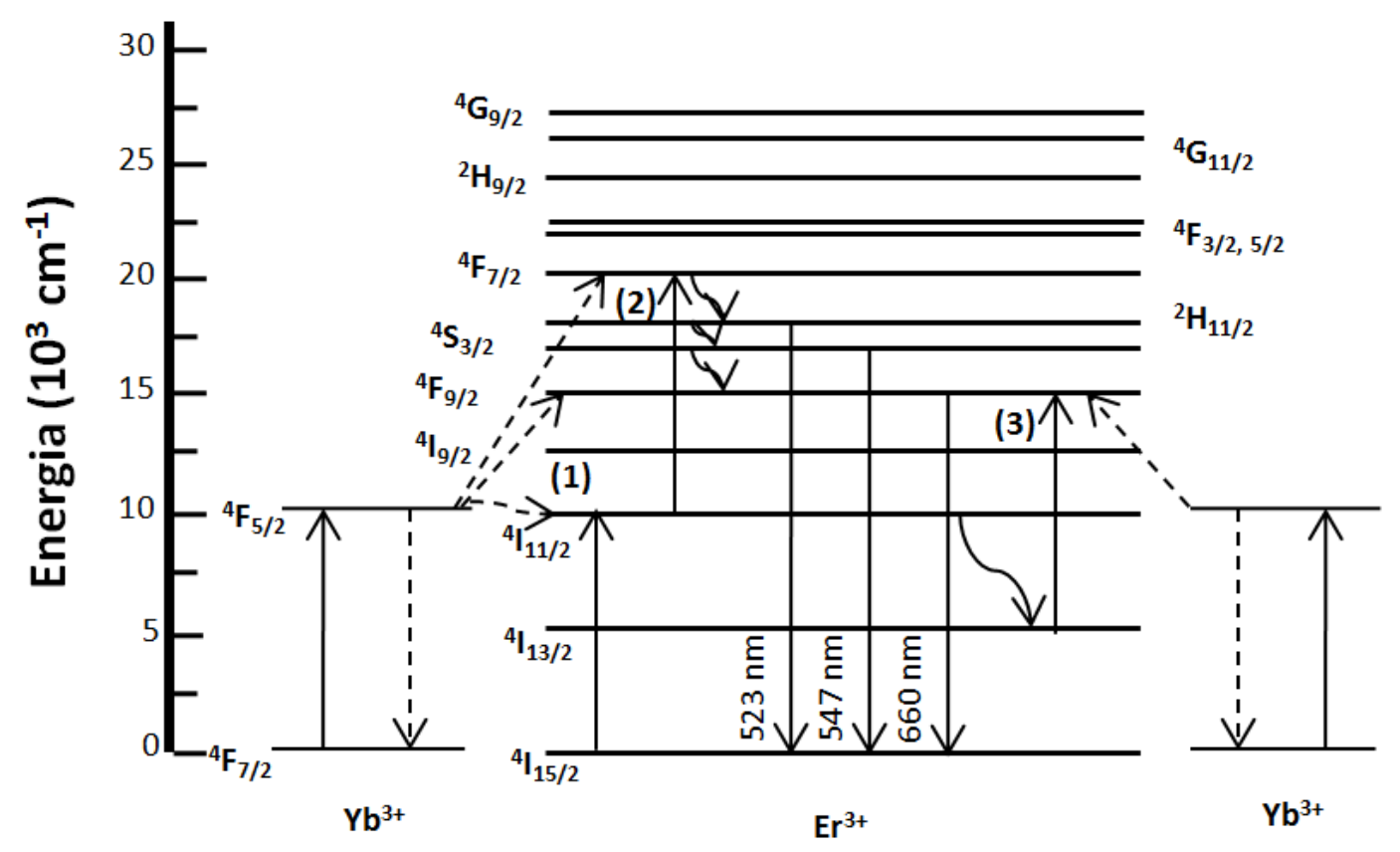

Figura 42 - Diagrama de energia dos íons $\mathrm{Er}^{3+} / \mathrm{Yb}^{3+}$ e os mecanismos de CAF no vidro GP. As linhas sólidas indicam o comprimento de onda de bombeio, as transições de CAF, e as transições radiativas, respectivamente. As linhas pontilhadas e onduladas estão relacionadas aos processos de transferência de energia e relaxação não radiativa, respectivamente. 
Em todos os casos o coeficiente das retas (n) na Figura 41 está em torno de 2, indicando que dois fótons participam do processo de conversão ascendente. Entretanto há uma redução dos coeficientes das retas (n) para valores próximos a 1,5 , provocado por processos não-radiativos, devido a maior intensidade da vibração Ge-O e também pela presença de uma fraca banda associada a vibração Si-O-Ge, observadas através da espectroscopia Raman.

Na Figura 42 são mostrados os níveis de energia ${ }^{4} G_{11 / 2},{ }^{2} G_{9 / 2}$ e ${ }^{4} F_{3 / 2}+{ }^{4} F_{5 / 2}$ não observados no vidro GPG. Entretanto, os mesmos processos de CAF são observados em ambos os tipos de vidro.

\subsection{Resultados dos vidros GP co-dopados com NPs prata}

\subsubsection{Análise de MET do vidro GP-Y3 e GP-A3}

Foram realizadas observações em microscopia eletrônica de transmissão com o intuito de determinar o tamanho das NPs em função do tratamento térmico. As Figuras 43 e 44 mostram as micrografias e distribuição do tamanho de partícula para o vidro GP-Y3 tratado termicamente por 2 (Figura 43) e 48h (Figura 44), respectivamente. Nas Figuras 43 e 44 são mostradas as micrografias e a distribuição de tamanho de partículas do vidro GP-A3 tratado termicamente por $2 \mathrm{~h}$ e $48 \mathrm{~h}$, respectivamente. 

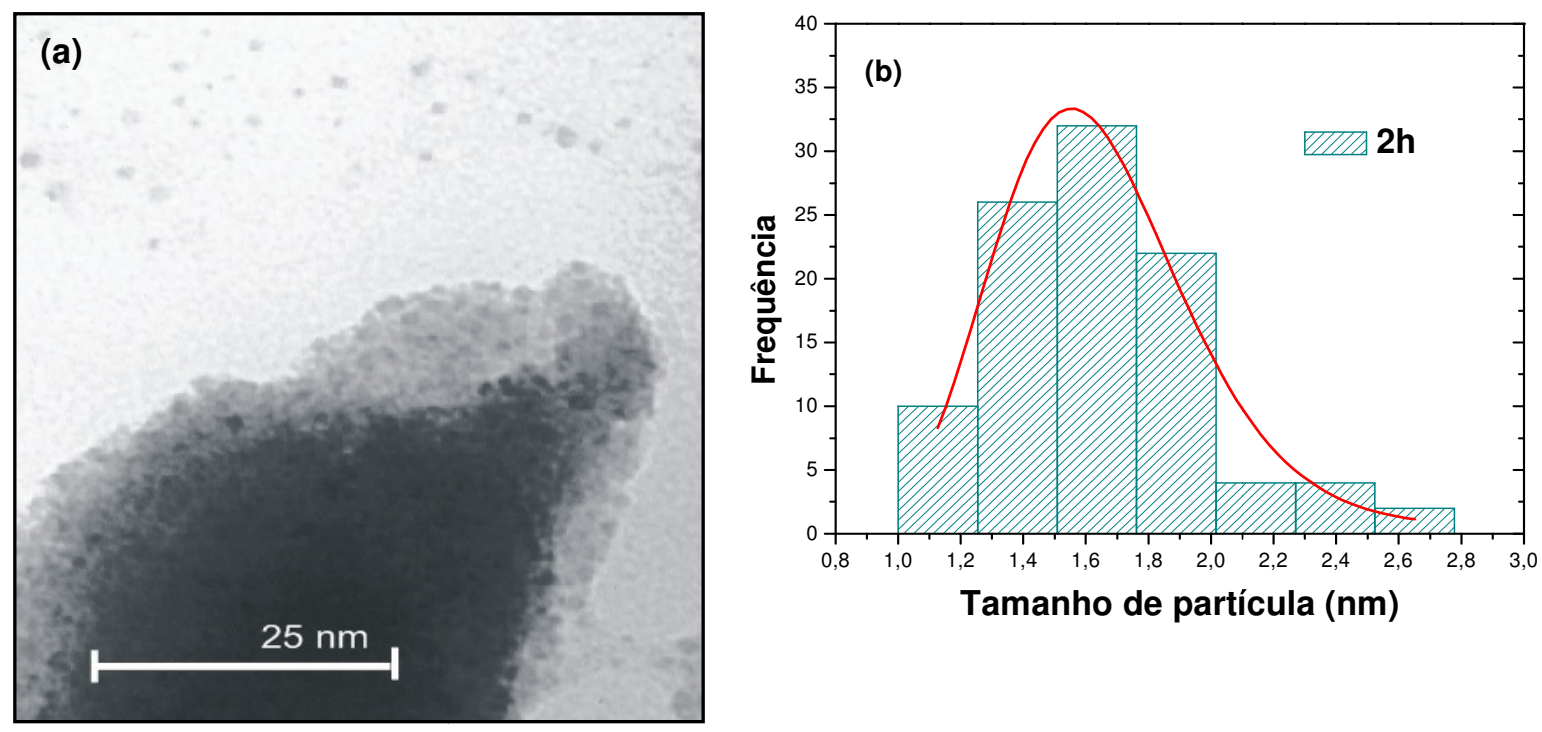

Figura 43 - Micrografia (a) e distribuição do tamanho de partícula (b) do vidro GP-Y3 tratado por $2 \mathrm{~h}$.
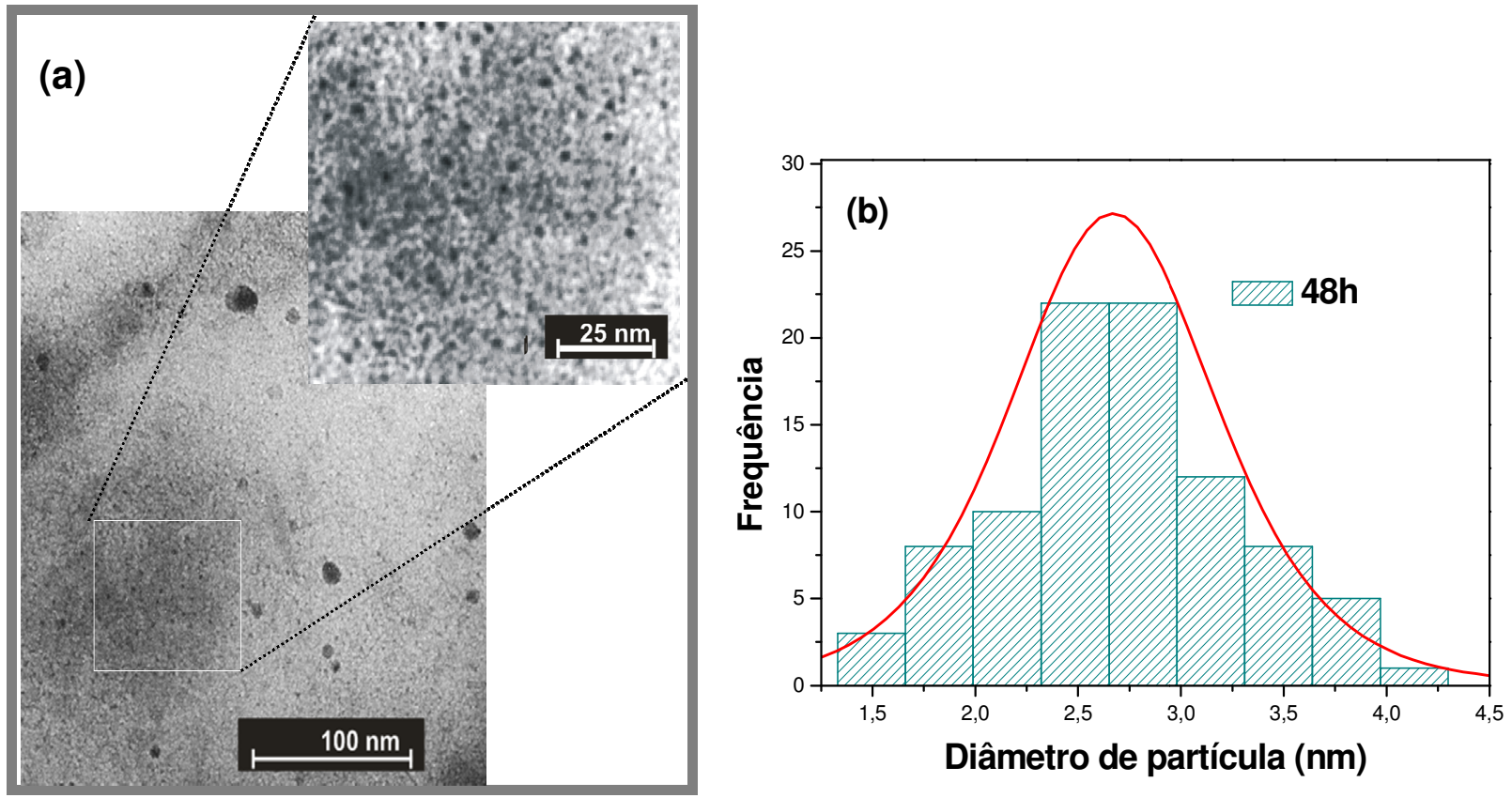

Figura 44 - Micrografia (a) e distribuição do tamanho de partícula (b) do vidro GP-Y3 tratado por $48 \mathrm{~h}$. 

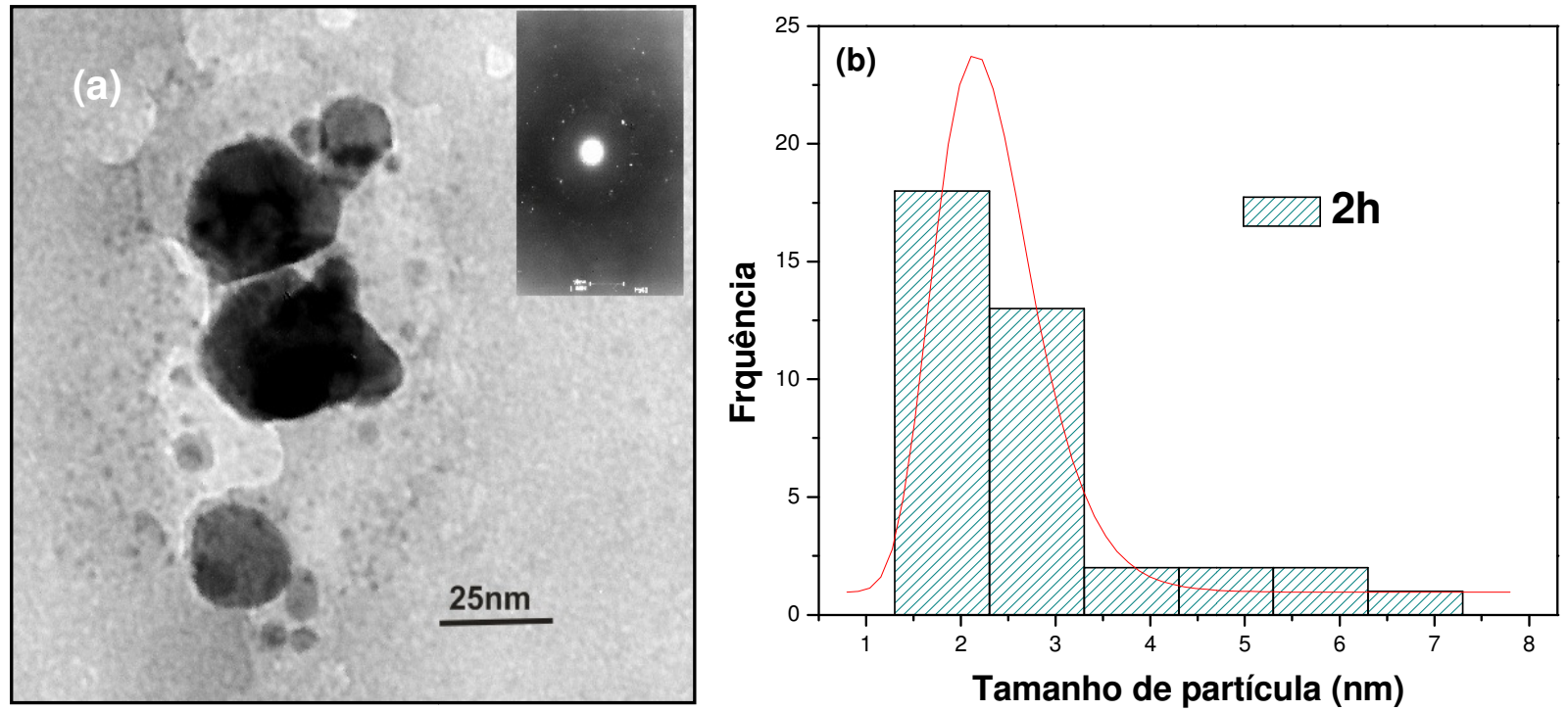

Figura 45 - Micrografia (a) e distribuição do tamanho de partícula (b) do vidro GP-A3 tratado por $2 \mathrm{~h}$.
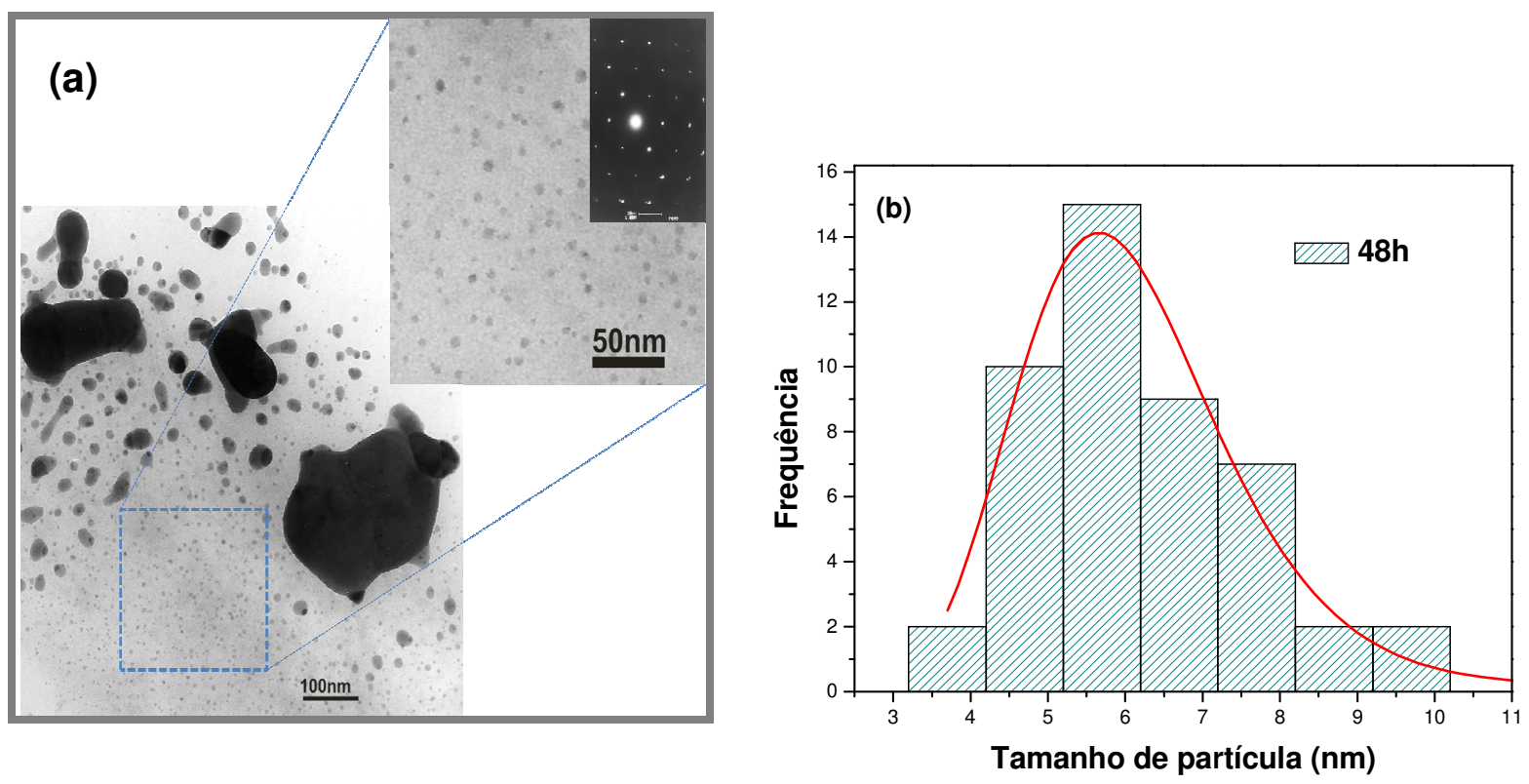

Figura 46 - Micrografia (a) e distribuição do tamanho de partícula (b) do vidro GP-A3 tratado por $48 \mathrm{~h}$. 
Observa-se por meio das análises das micrografias do vidro GP-Y3 tratado por $2 \mathrm{~h}$ e $48 \mathrm{~h}$ que o tamanho médio das NPs é 1,6 e 2,6 nm, respectivamente, possuindo formato mais próximo do esférico (Figura 43 e 44). Além disso, pode-se observar o aumento no número de NPs na amostra tratada por $48 \mathrm{~h}$ em comparação com a amostra tratada durante $2 \mathrm{~h}$. Cabe acrescentar que não há uma homogeneidade na distribuição das NPs, e também é observada a formação de aglomerados com tamanho médio aproximado de 10nm.

Por meio das análises de MET dos vidros GP-A3 tratados termicamente por 2 e 48h, apresentados na Figura 45 e 46, observa-se que há um aumento considerável no tamanho médio das NPs em função do tratamento térmico, sendo 2,5 e 5,5 nm, respectivamente e que também apresentam um formato aproximadamente esférico. Em ambos os casos é possível notar a presença de alguns aglomerados de NPs, com tamanhos ainda maiores do que aqueles encontrados no vidro GP-Y3, de 20 nm, no caso do vidro tratado por $2 \mathrm{~h}$, e NPs de até $300 \mathrm{~nm}$, como mostrado na micrografia do vidro GP-A3 tratado por 48h (Figura 46).

A formação de aglomerados pode afetar negativamente a luminescência, fazendo com que haja uma diminuição do campo local e o alargamento da banda de ressonância plasmônica, assim como o deslocamento dessa banda para comprimentos de onda maiores. Com isso, aumenta a probabilidade de que haja a transferência de energia dos íons de terras-raras para as NPs, tendo em vista que a distância entre o íon e a NPs provavelmente é inferior a $5 \mathrm{~nm}$, levando a uma redução da luminescência [1] como será visto posteriormente pelas medidas de emissão óptica desses vidros.

Os padrões de difração eletrônica mostradas nas inserções de todas as micrografias apresentadas anteriormente confirmam estrutura cristalina das NPs precipitadas na matriz vítrea.

As análises de espectroscopia de fluorescência de raios $\mathrm{x}$ por energia dispersiva acoplado ao MET (EDS), realizadas com um equipamento acoplado ao microscópio eletrônico de transmissão do vidro GP-A3 tratados por $2 \mathrm{~h}$ e $48 \mathrm{~h}$ são 
mostradas nas Figuras 47 e 48, respectivamente. A análise de EDS do vidro GP-Y3 não foi realizada devido a problemas no equipamento EDS.

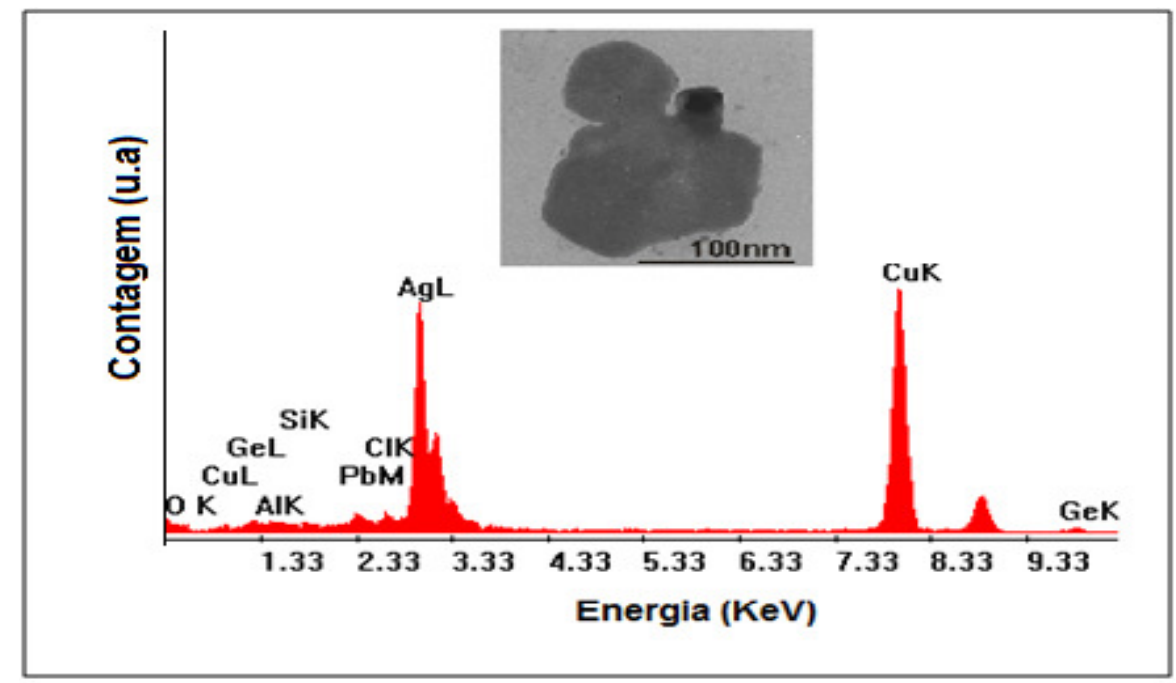

Figura 47 - Espectro de EDS da NP do vidro GP-A3 tratado termicamente por $2 \mathrm{~h}$.

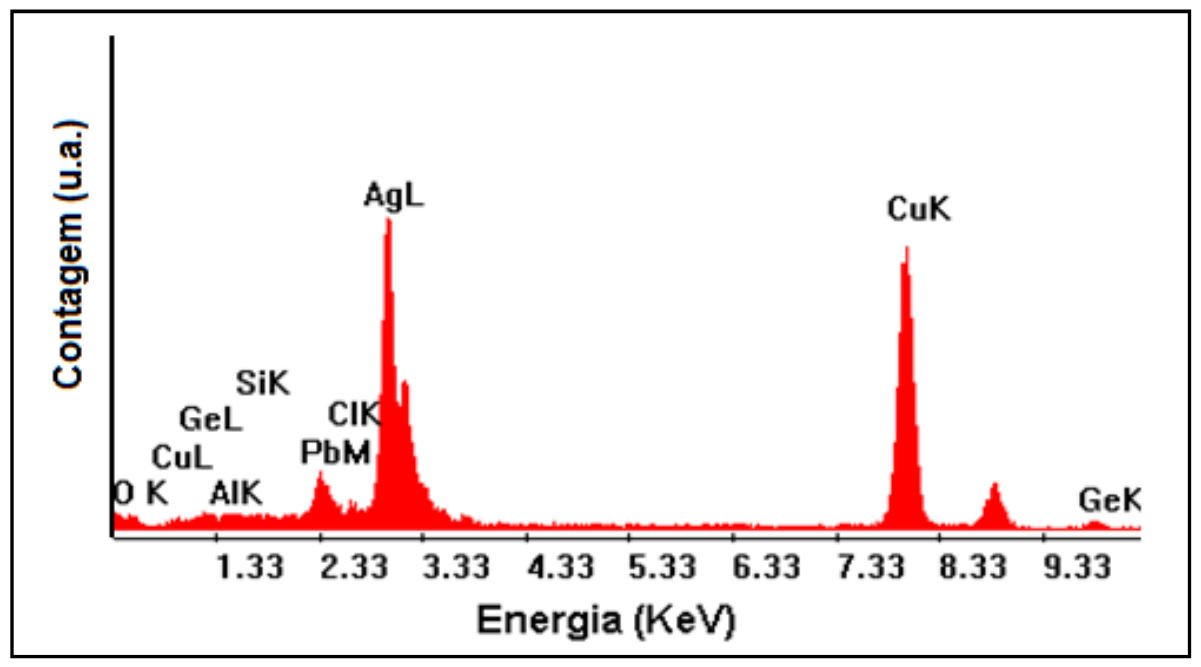

Figura 48 - Espectro de EDS da NP do vidro GP-A3 tratado termicamente por 48h.

Os resultados das análises de EDS mostram que as NPs são formadas fundamentalmente por prata, caracterizada pelo pico em $\sim 2,6 \mathrm{KeV}$, mas como pode ser notado, também são encontrados picos de menor intensidade relacionados aos 
constituintes da matriz vítrea ( $\mathrm{Ge}$ e $\mathrm{Pb}$ ) e contaminantes ( $\mathrm{Si}$ e $\mathrm{Al}$ ). Isso se deve a iteração do feixe eletrônico com regiões vizinhas das NPs. Cabe acrescentar que o pico de cobre encontrado é atribuído a grade de suporte da amostra.

Apesar de não ter sido possível realizar as medidas de EDS do vidro GP-Y3, pode-se assumir que a composição das NPs desses vidros é semelhante a do vidro GP-A3, visto que, a única diferença entre esses vidros é a concentração de prata (1,0\% e 3,0\%) para os vidros GP-Y3 e GP-A3, respectivamente.

\subsubsection{Absorção óptica do vidro GP-Y3 e GP-A3}

Nas Figuras 49 e 50 são mostrados os espectros de absorção óptica na região do visível e infravermelho dos vidros GP-Y3 e GP-A3, respectivamente, tratados termicamente por 2, 24, 48 e $72 \mathrm{~h}$.

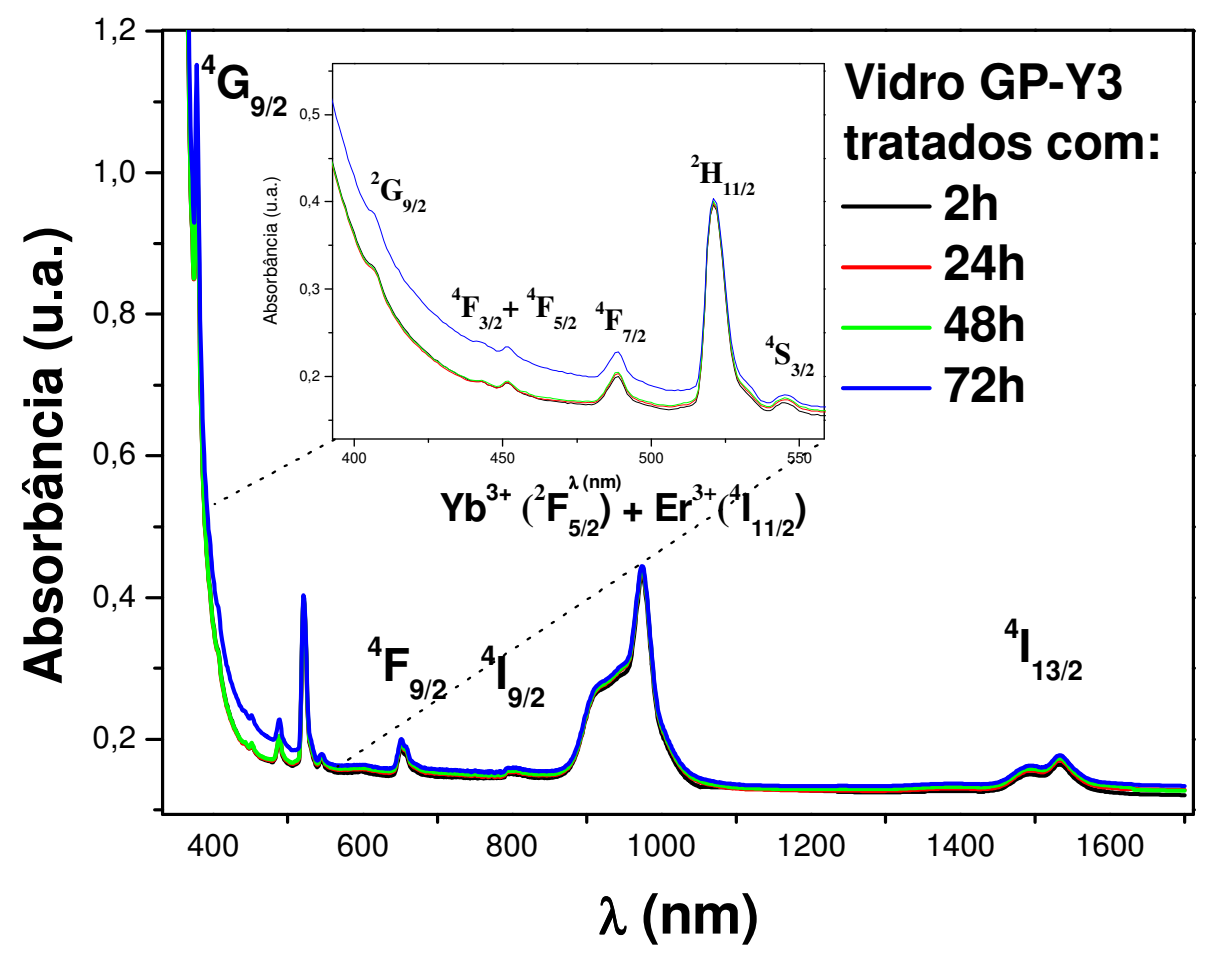

Figura 49 - Espectros de absorção óptica na região do visível e infravermelho dos vidros GP-Y3 tratados termicamente por 2, 24, 48 e 72h. 


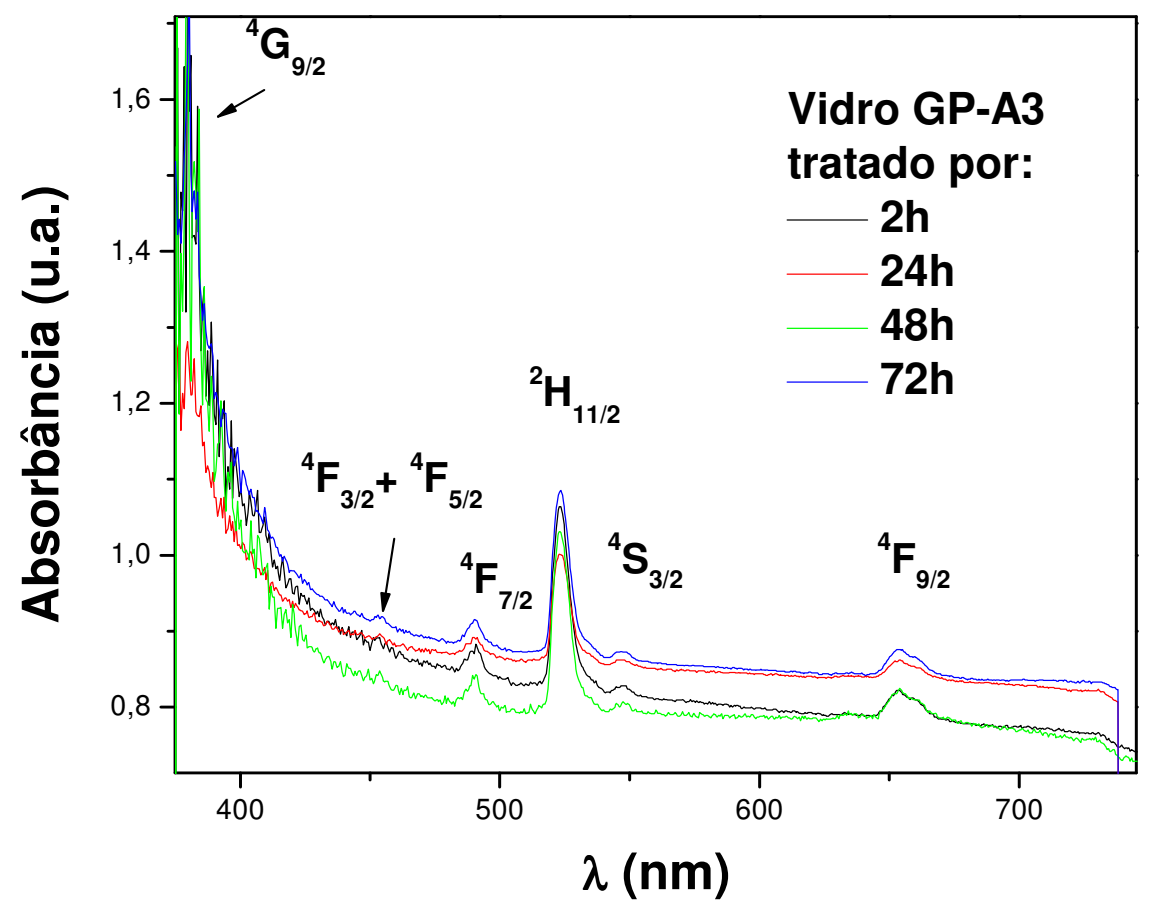

Figura 50 - Espectros de absorção óptica na região do visível dos vidros GP-A3 tratados termicamente por 2, 24, 48 e $72 \mathrm{~h}$.

Em ambos os vidros, as bandas de absorção são atribuídas às transições 4f4f do $\mathrm{Er}^{3+}$ do estado fundamental ${ }^{4} \mathrm{I}_{15 / 2}$ para o estado do íon $\mathrm{Er}^{3+}$ em 490, 522, 545, $654,800,980$ e $1532 \mathrm{~nm}$ do vidro GP, devido às transições do estado fundamental ${ }^{4} \mathrm{I}_{15 / 2}$ para os estados excitados ${ }^{4} \mathrm{~F}_{7 / 2},{ }^{2} \mathrm{H}_{11 / 2},{ }^{4} \mathrm{~S}_{3 / 2},{ }^{4} \mathrm{~F}_{9 / 2},{ }^{4} \mathrm{I}_{9 / 2},{ }^{4} \mathrm{I}_{11 / 2}$ e ${ }^{4} \mathrm{I}_{13 / 2}$.

Diferentemente de outros estudos [46,52], a banda de ressonância plasmônica não é observada nos vidros GP-Y3 e GP-A3. Isto pode estar relacionado com a pequena quantidade de NPs encontras no vidro e também pela formação de aglomerados, que pode provocar o alargamento da banda de ressonância plasmônica para comprimentos de onda maiores. Por meio da função dielétrica da prata e do índice de refração do vidro GP ( 2), estima-se que a banda de ressonância plasmônica esteja localizada entre 420 e 500 nm [54]. 


\subsubsection{Emissão óptica do vidro GP-Y3 e GP-A3}

Nas Figuras 51 e 52 são mostrados os espectros de emissão na região do visível do vidro GP-Y3 e as razões entre as áreas integradas das bandas de emissão do mesmo vidro, respectivamente; nas Figuras 53 e 54 são mostrados os espectros de CAF do vidro GP-A3 e a razão entre as bandas de emissão integradas, respectivamente. Todos os vidros, como já citado anteriormente, foram tratados por 2, 24, 48 e 72h e as emissões apresentadas nas Figuras 51 e 53 correspondem às transições ${ }^{2} \mathrm{H}_{11 / 2} \rightarrow{ }^{4} \mathrm{I}_{15 / 2},{ }^{4} \mathrm{~S}_{3 / 2} \rightarrow{ }^{4} \mathrm{I}_{15 / 2}, \mathrm{e}^{4} \mathrm{~F}_{9 / 2} \rightarrow{ }^{4} \mathrm{I}_{15 / 2}$ do íon $\mathrm{Er}^{3+}$.

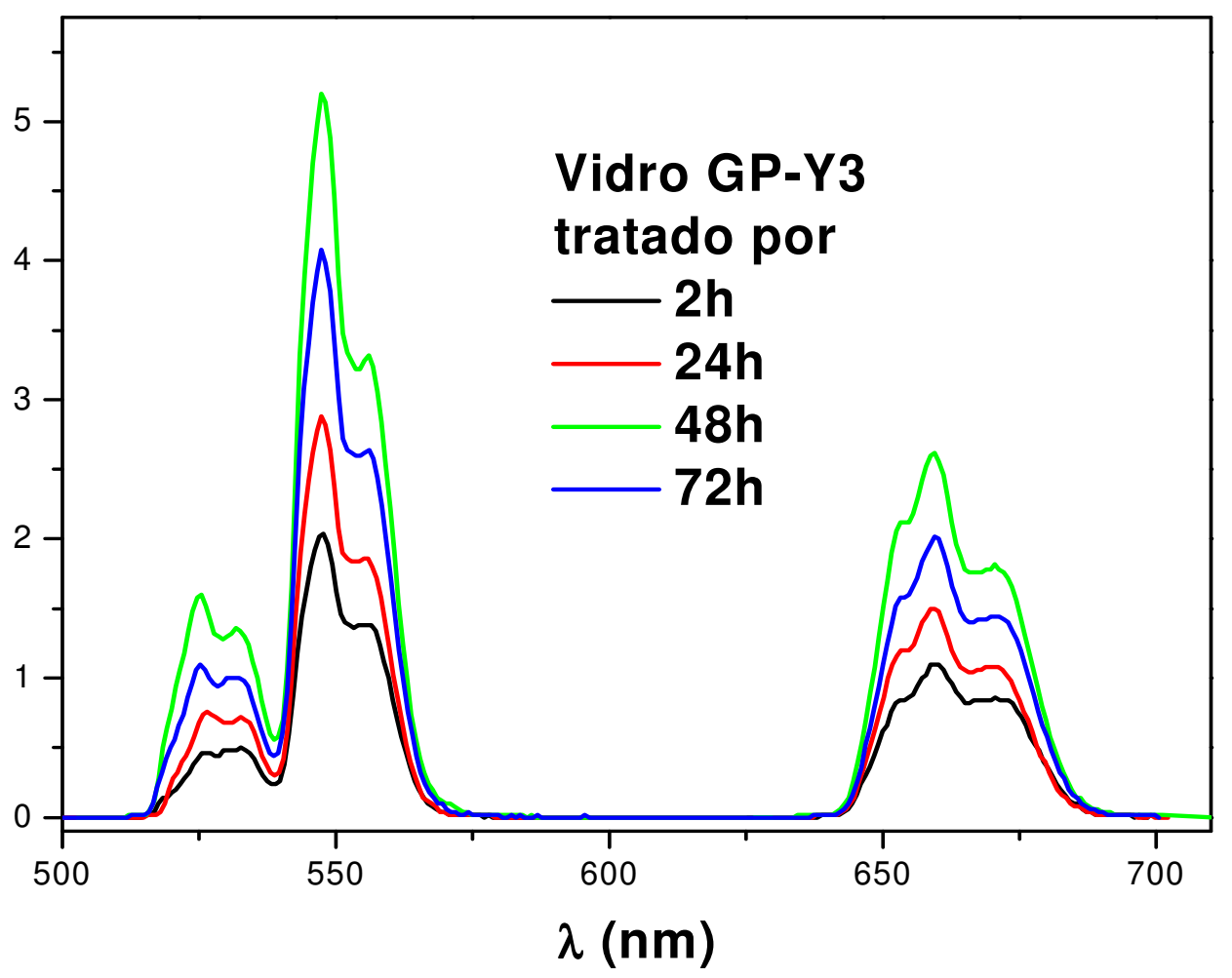

Figura 51 - Espectros de emissão óptica na região do visível do vidro GP-Y3 tratado termicamente por 1, 12, 28, 40 e $72 \mathrm{~h}$. 


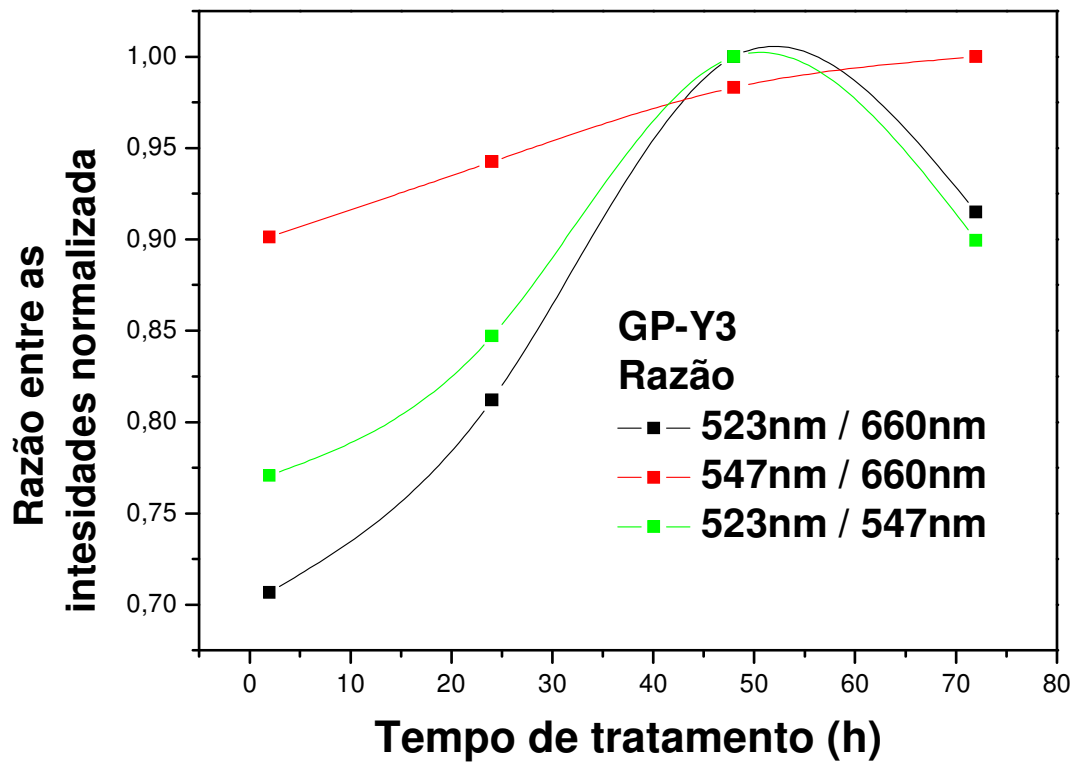

Figura 52 - Razão entre as áreas das bandas de emissão do vidro GP-Y3 em função do tempo de tratamento térmico. A curva foi ajustada para auxiliar na orientação e não está relacionada com nenhum modelo teórico.

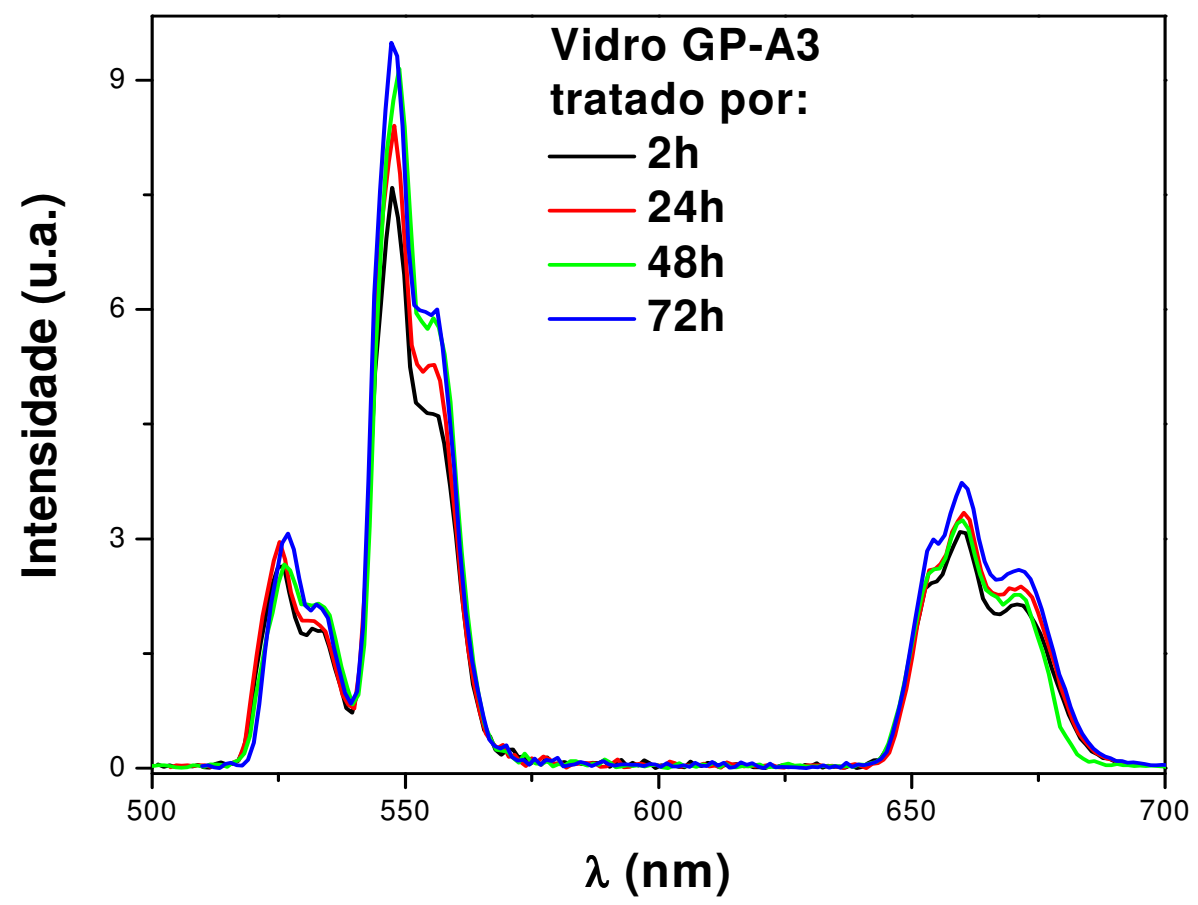

Figura 53 - Espectros de emissão óptica na região do visível do vidro GP-A3 tratado termicamente por 2, 24, 48 e $72 \mathrm{~h}$. 


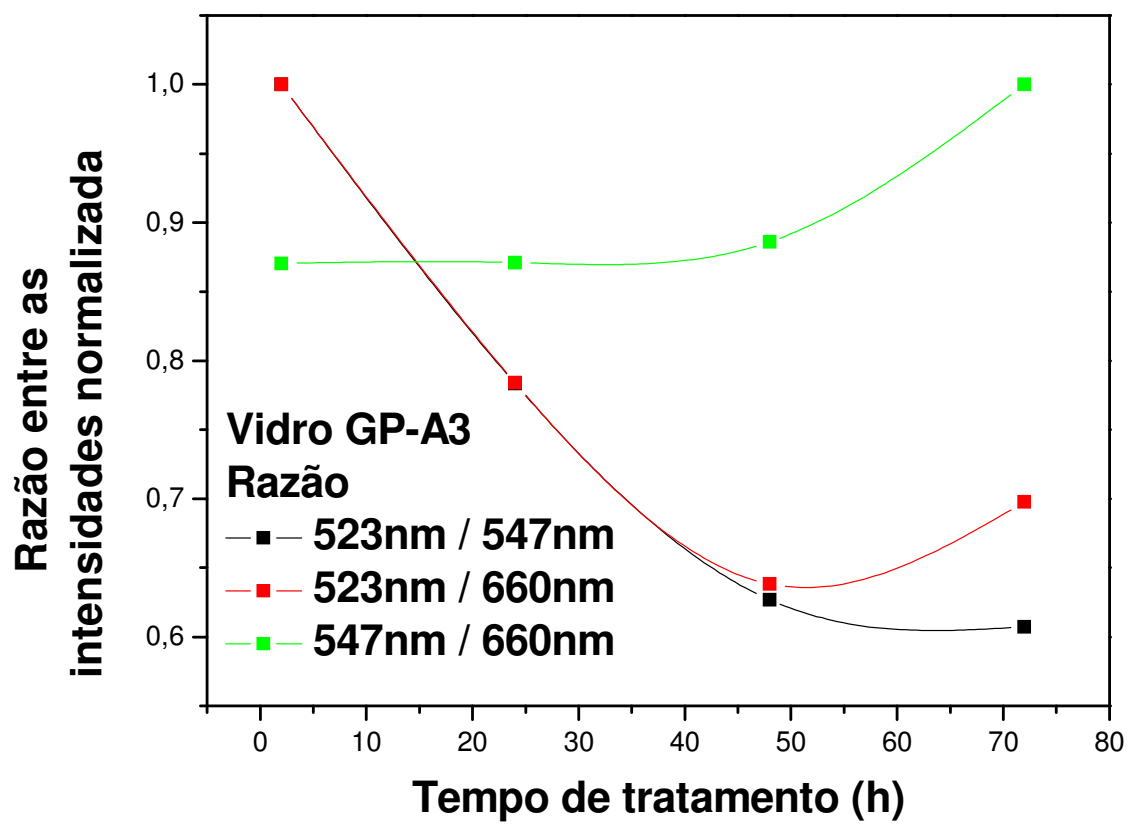

Figura 54 - Razão entre as áreas das bandas de emissão do vidro GP-A3 em função do tempo de tratamento térmico. A curva foi ajustada para auxiliar na orientação e não está relacionada com nenhum modelo teórico.

Mesmo com a ausência da banda de ressonância plasmônica no vidro GP-Y3, há um aumento significativo de todas as emissões de CAF em função do tratamento térmico (até $48 \mathrm{~h})$ e uma redução na seqüência $(72 \mathrm{~h})$, como mostrado na Figura 51. Além disso, pode-se observar que não há distorção no espectro, como observado no vidro GP sem $\mathrm{AgNO}_{3}$, com concentrações superiores a 2,0\% de $\mathrm{Yb}_{2} \mathrm{O}_{3}$ (Figura 39).

A proximidade das transições da emissão do verde do íon $\mathrm{Er}^{3+}\left({ }^{2} \mathrm{H}_{11 / 2} \rightarrow{ }^{4} \mathrm{I}_{15 / 2}\right.$ $\mathrm{e}^{4} \mathrm{~S}_{3 / 2} \rightarrow{ }^{4} \mathrm{I}_{15 / 2}$ ) com a banda de ressonância plasmônica favorece o aumento dessas emissões, que é resultado do aumento do campo local na vizinhança das NPs. Por outro lado, a emissão do vermelho associadas com a transição ${ }^{4} \mathrm{~F}_{9 / 2} \rightarrow{ }^{4} \mathrm{I}_{15 / 2} \mathrm{do}_{\mathrm{Er}}{ }^{3+}$ é influenciada pela formação de aglomerados de NPs de prata como observado para vidro dopado com $\mathrm{Pr}^{3+}$ [39-40], fazendo com que a banda de ressonância se desloque em direção ao infravermelho. A emissão em $523 \mathrm{~nm}$ é mais afetada do que a emissão em $547 \mathrm{~nm}$ devido à proximidade com o plasmon da prata. 
Por meio dos espectros da Figura 53 pode-se observar que há um aumento da luminescência de CAF do érbio do vidro GP-A3, mas com um aumento na intensidade de emissão menor do que aquela observada para o vidro GP-Y3. Nesse caso, ocorre uma competição nos processos de transferência de energia entre as NPs e os íons de érbio, com leve favorecimento da transferência de energia das NPs para os íons de érbio.

Analisando-se as razões entre as bandas de emissão observa-se que a emissão em $660 \mathrm{~nm}$ é mais influenciada pela presença das NPs. Isso pode estar associado com a formação de NPs em maior número e com maiores tamanhos, além da formação de aglomerados, já que a concentração de prata nesse vidro é consideravelmente maior do que a do vidro GP-Y3 como observado por MET que desloca a banda de ressonância para comprimentos de onda maiores.

Nas Figuras 55 e 56 são apresentados os resultados de intensidade de emissão em torno de $545 \mathrm{~nm}$ e $660 \mathrm{~nm}$ dos vidros GP-Y3 e GP-A3 em função da potência de bombeio em $980 \mathrm{~nm}$ (em escala logarítmica).

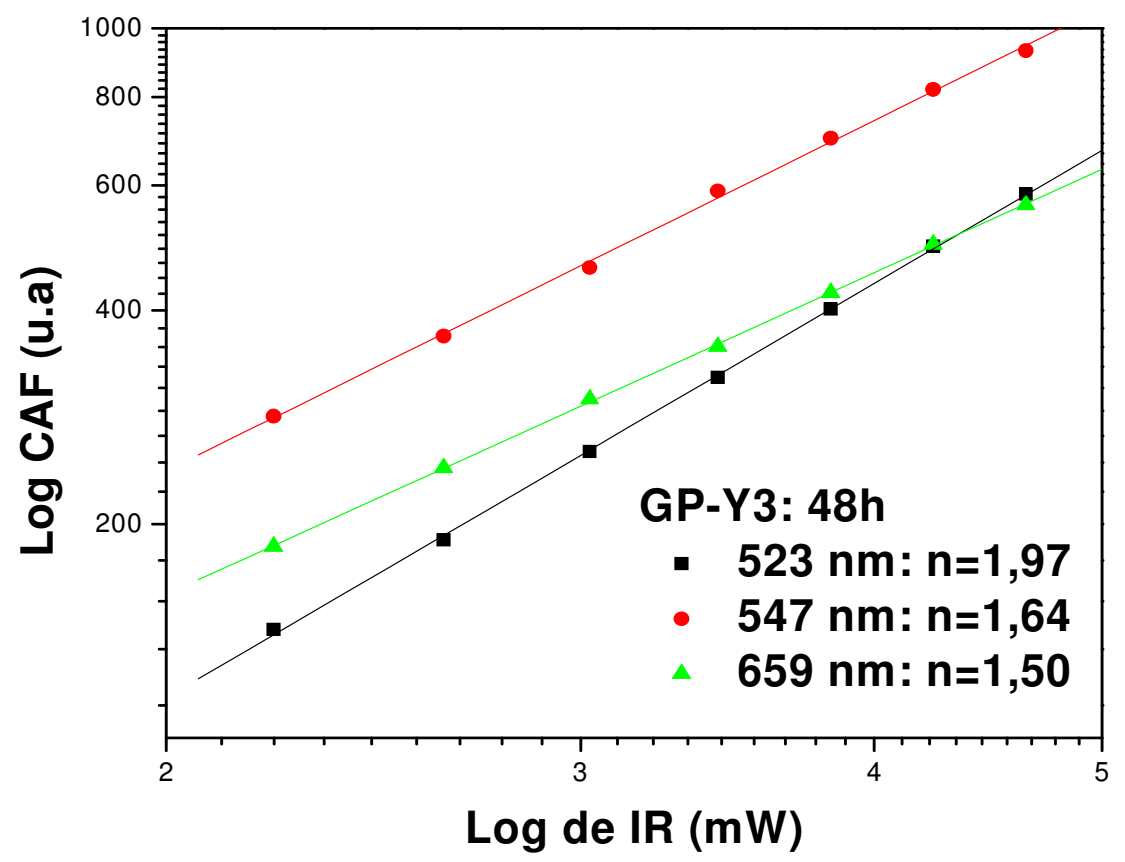

Figura 55 - Intensidade de emissão de CAF em 523, 547 e 659 nm do vidro GP-Y3 em função da potência de bombeio em $980 \mathrm{~nm}$. 


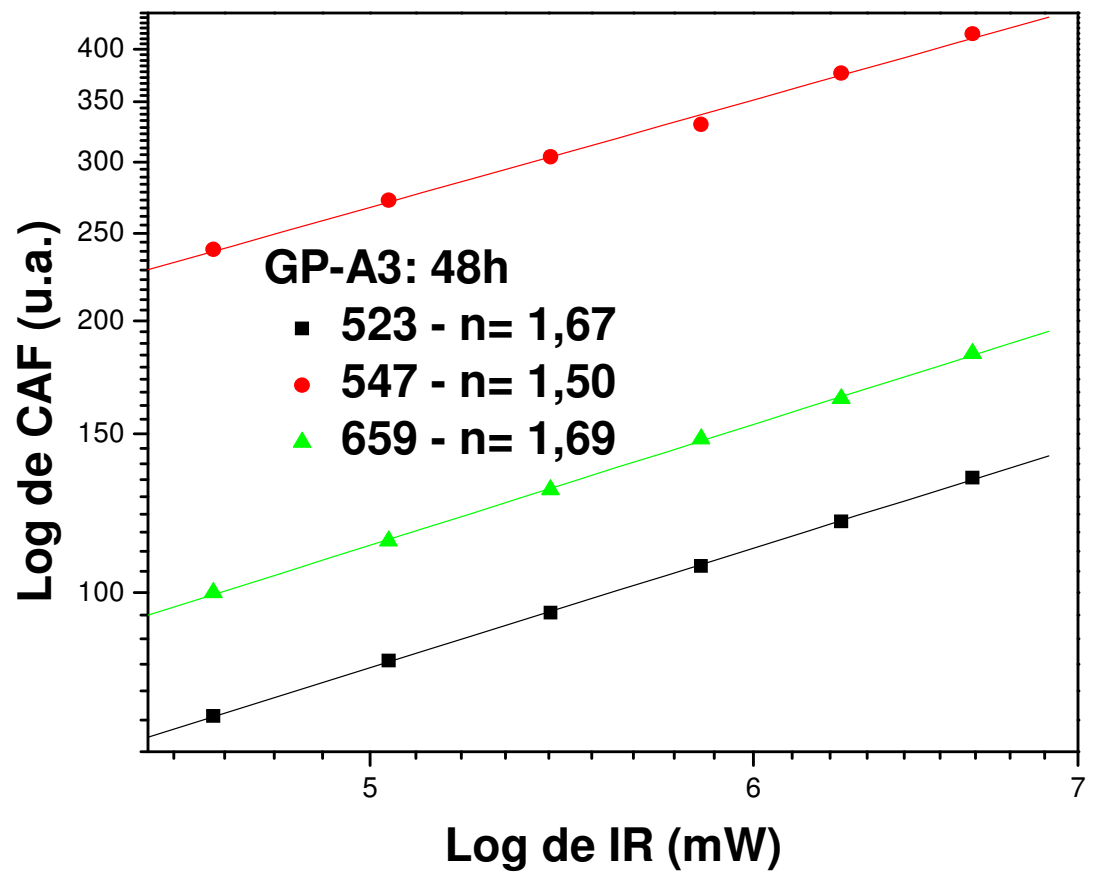

Figura 56 - Intensidade de emissão de CAF em 523, 547 e 659 nm do vidro GP-A3 em função da potência de bombeio em $980 \mathrm{~nm}$.

Em todos os casos os coeficientes das retas (n) estão em torno de 2, indicando que dois fótons participam do processo de conversão ascendente e que a presença das NPs de prata não contribui para alterar tal mecanismo. Processos não radiativos podem ocorrer com uma maior probabilidade neste vidro, tendo em vista que a intensidade da vibração da ligação Ge-O é maior para este sistema. Cabe acrescentar que os mecanismos responsáveis pelos processos de CAF são os mesmo já discutidos anteriormente para o vidro GP co-dopados sem prata e mostrados na Figura 42. 


\subsubsection{Resultados do vidro GP-Y3N em cadinho de alumina}

A Figura 57 mostra os espectros de absorção óptica na região do visível dos vidros GP-Y3N tratados termicamente por 2, 24, 48 e 72h. O início da janela de transmissão desse vidro ocorre em torno de $400 \mathrm{~nm}$.

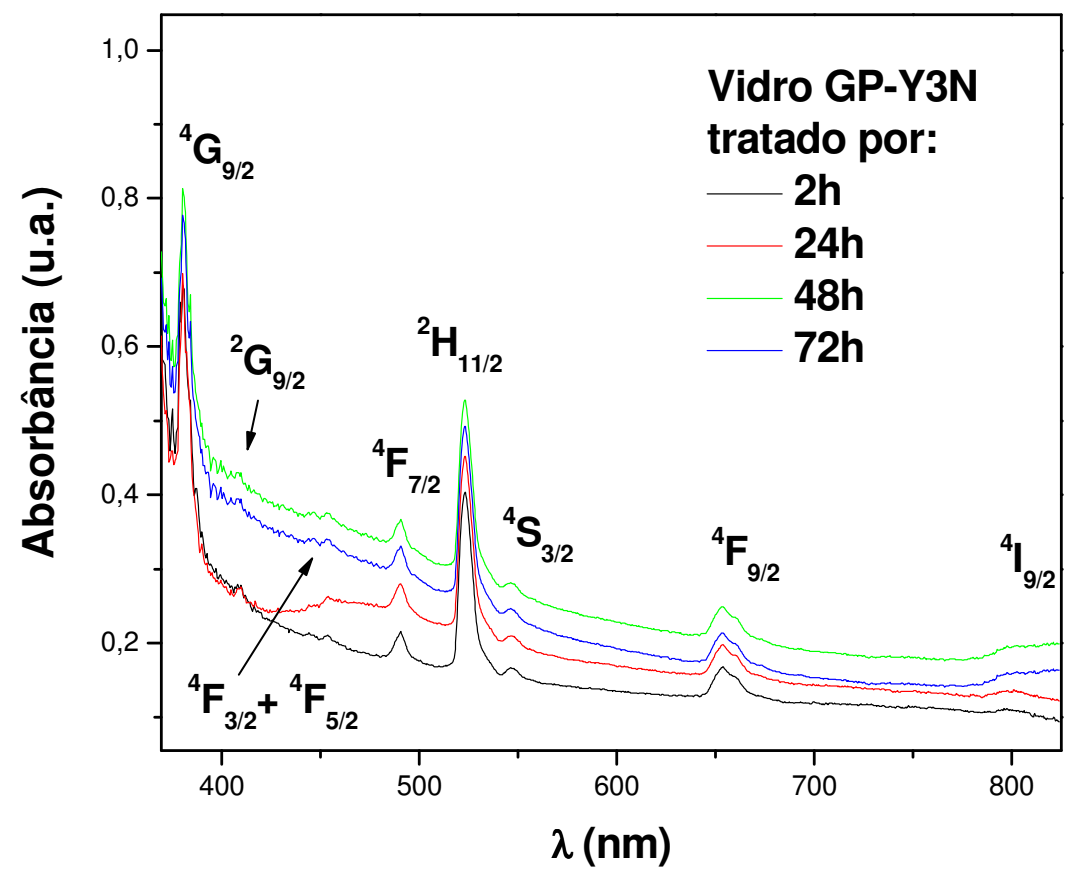

Figura 57 - Espectros de absorção óptica na região do visível dos vidros GP-Y3N tratados termicamente por 2, 24, 48 e $72 \mathrm{~h}$.

As bandas de absorção 380, 407, 490, 522, 545, 654 e 800 nm são atribuídas às transições $4 \mathrm{f}-4 \mathrm{f}$ do $\mathrm{Er}^{3+}$ do estado fundamental ${ }^{4} \mathrm{I}_{15 / 2}$ para os estado excitados ${ }^{4} \mathrm{G}_{9 / 2},{ }^{2} \mathrm{G}_{9 / 2},{ }^{4} \mathrm{~F}_{3 / 2}+{ }^{4} \mathrm{~F}_{5 / 2},{ }^{4} \mathrm{~F}_{7 / 2},{ }^{2} \mathrm{H}_{11 / 2},{ }^{4} \mathrm{~S}_{3 / 2},{ }^{4} \mathrm{~F}_{9 / 2} \mathrm{e}{ }^{4} \mathrm{I}_{9 / 2}$. Diferentemente do resultado do mesmo vidro obtido em cadinho de $\mathrm{Al}_{2} \mathrm{O}_{3}-\mathrm{SiO}_{2}$, é observada uma fraca banda centrada em $480 \mathrm{~nm}$ sobreposta a transição ${ }^{4} \mathrm{~F}_{3 / 2}+{ }^{4} \mathrm{~F}_{5 / 2}$, que é atribuída a banda de ressonância plasmônica da prata. O aparecimento dessa banda nessa região do espectro, já foi reportado anteriormente para a mesma matriz vítrea contendo apenas prata [52], e seu surgimento nesse caso pode estar relacionado com a maior nucleação de NPs de prata. 


\subsubsection{Emissão óptica do vidro GP-Y3N}

A Figura 58 mostra os espectros de CAF do íon $\operatorname{Er}^{3+}(523,547$ e $659 \mathrm{~nm})$ e também a emissão cooperativa do íon $\mathrm{Yb}^{3+}$ em $480 \mathrm{~nm}$ dos vidros contendo prata tratados por 2 e $24 \mathrm{~h}$ e do vidro co-dopado com 0,5\% de $\mathrm{Er}_{2} \mathrm{O}_{3}$ e $3,0 \%$ de $\mathrm{Yb}_{2} \mathrm{O}_{3}$ sem prata. Os espectros de emissão de CAF dos vidros tratados por 48 e $72 \mathrm{~h}$ não são mostrados, mas cabe acrescentar que há uma redução nas emissões de CAF para esses tratamentos térmicos; a razão entre as bandas são mostradas na Figuras 58 (a) (razão entre 523 nm/408 nm, 547 nm/408 nm e 659 nm/408 nm) e Figura 56 (b) (razão entre $523 \mathrm{~nm} / 547 \mathrm{~nm}, 547 \mathrm{~nm} / 659 \mathrm{~nm}$ e $523 \mathrm{~nm} / 659 \mathrm{~nm}$.

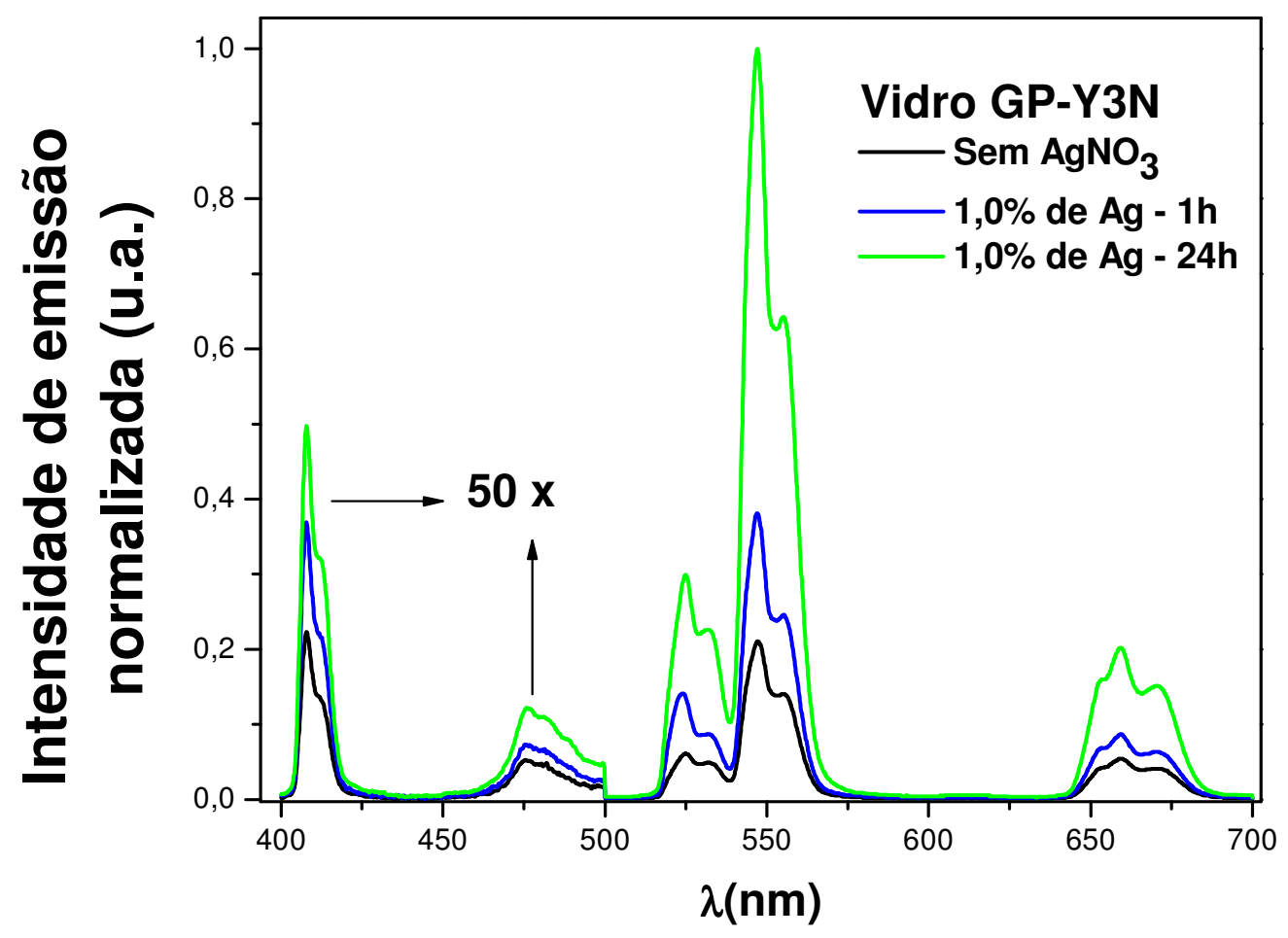

Figura 58 - Espectros de emissão óptica na região do visível do vidro GP-Y3N tratado termicamente por $1 \mathrm{~h}, 24 \mathrm{~h}$ e do vidro sem prata. 

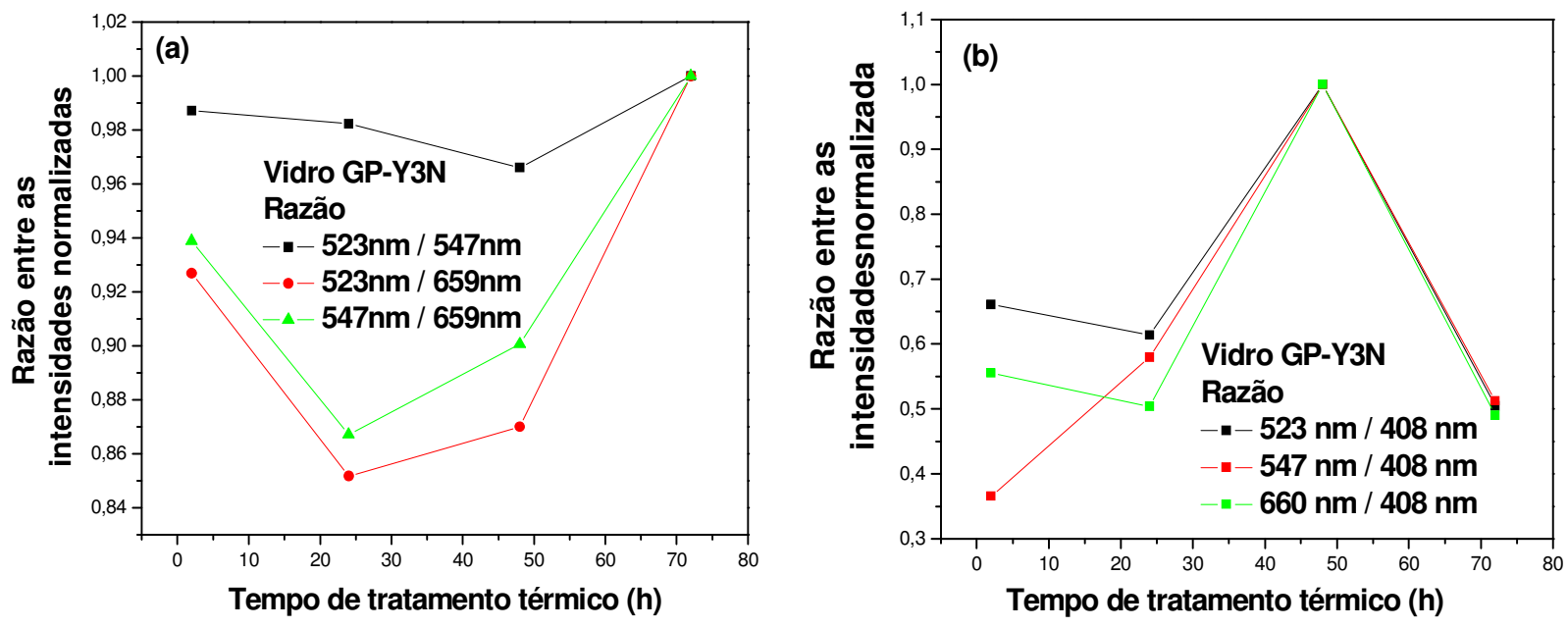

Figura 59 - (a) razão entre as bandas $523 \mathrm{~nm} / 408 \mathrm{~nm}, 547 \mathrm{~nm} / 408 \mathrm{~nm}$ e 659 $\mathrm{nm} / 408 \mathrm{~nm}$ e (b) razão entre $523 \mathrm{~nm} / 547 \mathrm{~nm}, 547 \mathrm{~nm} / 659 \mathrm{~nm}$ e $523 \mathrm{~nm} / 659 \mathrm{~nm}$.

As bandas de emissão centradas em 408, 580, 523, 547, 659nm correspondem às transições dos estados ${ }^{2} \mathrm{H}_{9 / 2},{ }^{2} \mathrm{H}_{11 / 2},{ }^{4} \mathrm{I}_{15 / 2}$ e ${ }^{4} \mathrm{~F}_{9 / 2}$ para $\mathrm{o}$ estado fundamental do $\mathrm{Er}^{3+}$, respectivamente. Uma emissão centrada em 480nm também é observada e é atribuída ao efeito cooperativo dos íons $\mathrm{Yb}^{3+}$, onde dois íons $\mathrm{Yb}^{3+}$ decaem simultaneamente gerando dois fótons de $\sim 980 \mathrm{~nm}$, que se recombinam em um nível virtual para na seqüência emitir um fóton de $\sim 480 \mathrm{~nm}$.

Por meio dos espectros de emissão da Figura 58, observa-se um aumento ainda maior na emissão em $\sim 547 \mathrm{~nm}$ em relação a emissão ao $659 \mathrm{~nm}$, quando se compara a razão entres as intensidades dos picos dessas emissões com a dos vidros GP-Y3. No caso do vidro GP-Y3, a razão entre as intensidades é de aproximadamente 2, e para o vidro GP-Y3N está razão é aumentada para 5.

O aumento da emissão em $547 \mathrm{~nm}$ ocorre através de dois fatores: primeiro, há um aumento do campo local ainda maior ao redor dos íons $\mathrm{Er}^{3+}$, evidenciado pelo surgimento da banda de ressonância plasmônica observada nas medidas de absorção óptica; por outro lado, evitando-se a introdução $\mathrm{SiO}_{2}$ proveniente do cadinho, há formação de um vidro com melhor qualidade óptica e sem a existência da banda de vibração Raman em 863 nm atribuída a ligação Si-O-Ge, a qual causa 
uma maior taxa de decaimento não radiativo e por conseqüência, a redução da luminescência de CAF do íon $\mathrm{Er}^{3+}$ observada no vidro GP-Y3.

Ao se comparar as emissões de CAF em 523, 547 e 659 nm com a emissão em $408 \mathrm{~nm}$ por meio das razões mostradas na Figura 58 (b), observa-se que as emissões mais influenciadas são as de 523, 547 e 659 nm, com um aumento superior a duas vezes em relação à emissão em $408 \mathrm{~nm}$ na presença da prata. Isso se deve ao posicionamento da banda de ressonância plasmônica com comprimento de onda superior a emissão em $408 \mathrm{~nm}$, que está situada em $\sim 480 \mathrm{~nm}$, e por isso, a transferência de energia é mais efetiva para as outras emissões.

$\mathrm{Na}$ Figuras 60 são mostrados os resultados de intensidade de emissão em torno de 408 e $480 \mathrm{~nm}$ em função da potência de bombeio em $980 \mathrm{~nm}$ (em escala logarítmica). As intensidades de emissão de CAF em 523, 547 e 559 nm não estão incluídas, mas os processos são os mesmos já apresentados anteriormente para o vidro GP-Y3. Cabe acrescentar que estas medidas foram feitas através de filtros com transmitância de 40, 80, 90\%.

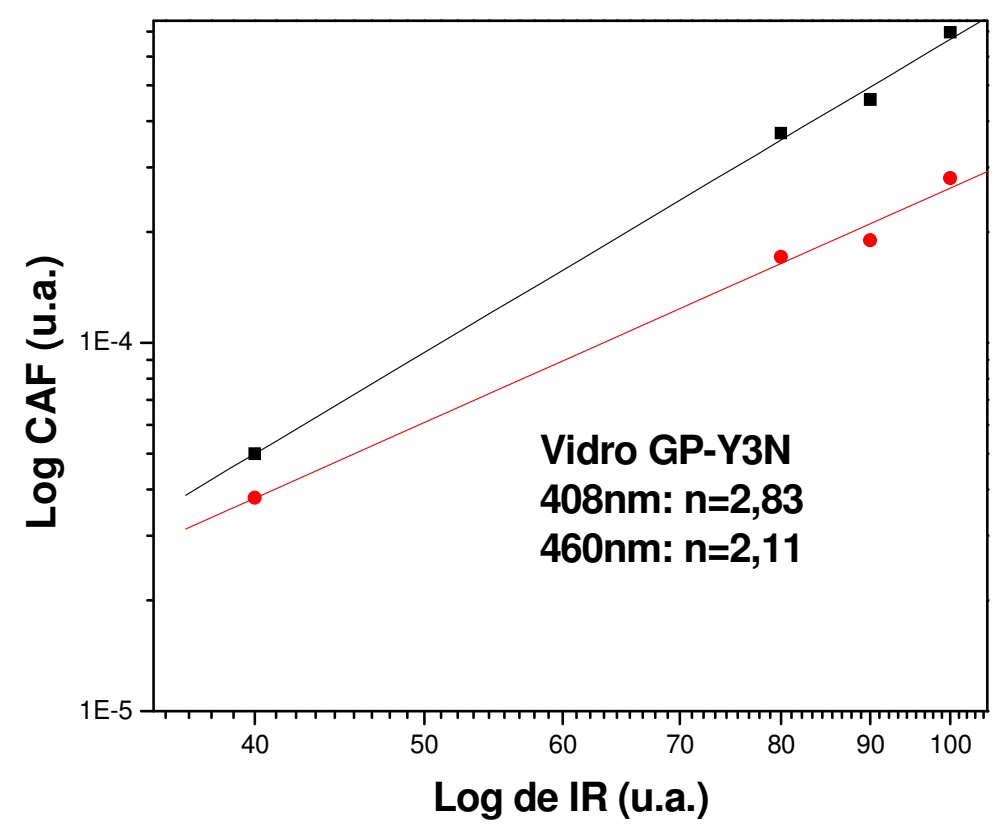

Figura 60 - Intensidade de emissão de CAF em 408 e 480 nm do vidro GP-Y3N em função da potência de bombeio em $980 \mathrm{~nm}$. 
As novas emissões observadas em 408 e $480 \mathrm{~nm}$ ocorrem a partir da absorção de 3 e 2 fótons, respectivamente, como indicado pelos coeficientes das retas mostrado na Figura 60 (2,83 e 2,11 para as emissões em 408 e 460nm, respectivamente). A seqüência de absorção multifóton para população do nível emissor do 408nm ( $\left({ }^{2} \mathrm{H}_{9 / 2}\right)$ do íon $\mathrm{Er}^{3+}$ é mostrada na Figura 61 e na mesma figura é mostrado o processo para emissão em $480 \mathrm{~nm}$ (efeito cooperativo do íon $\mathrm{Yb}^{3+}$ ).

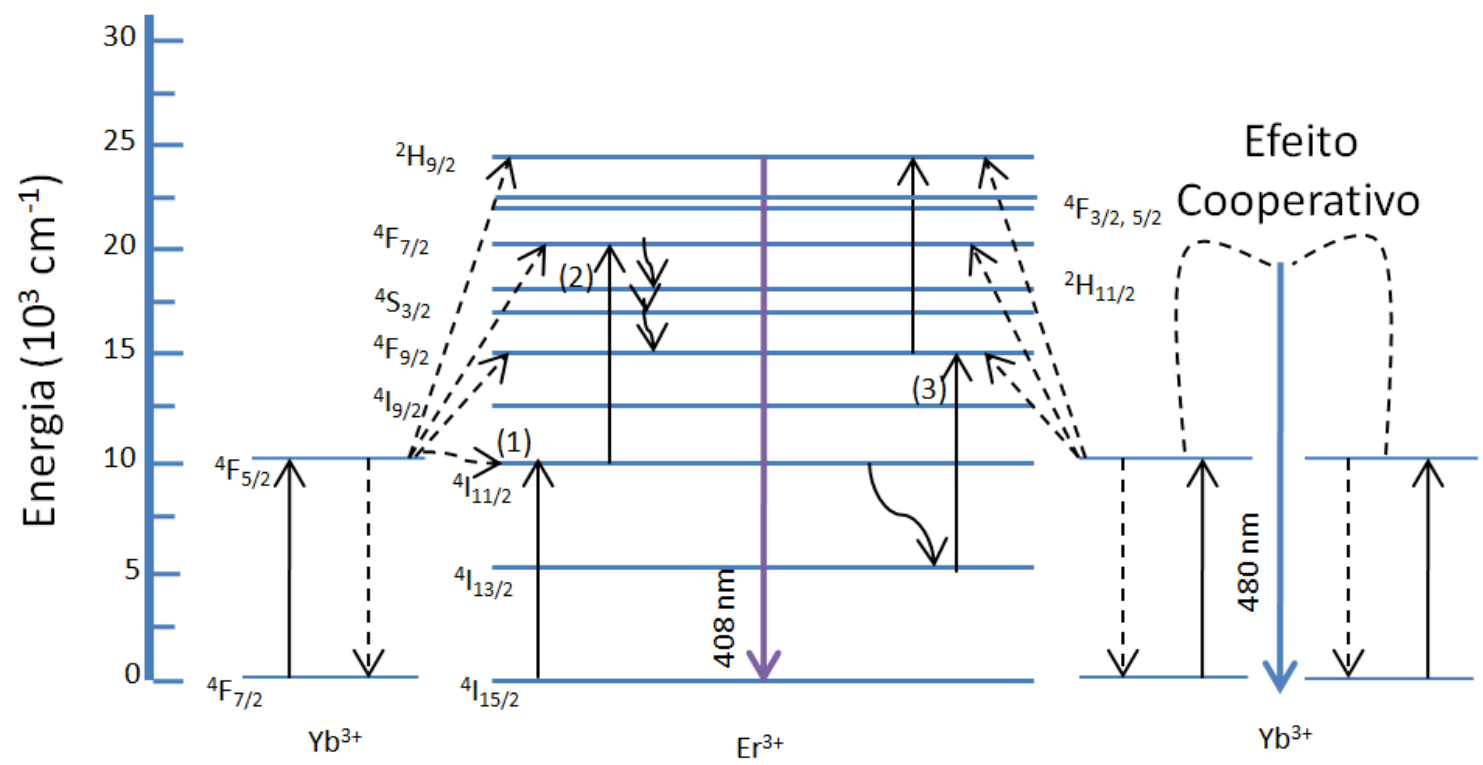

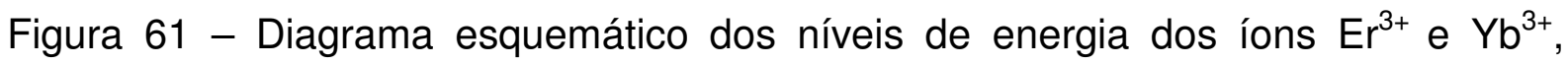
evidenciando os processos responsáveis pelas emissões em $408 \mathrm{~nm}$ e o processo cooperativo responsável pela emissão em 480nm.

Para que a emissão em 408 nm ocorra é necessário que haja a população do nível ${ }^{4} \mathrm{~F}_{9 / 2}$ do íon $\mathrm{Er}^{3+}$, e na seqüência, um fóton é absorvido levando o íon $\mathrm{Er}^{3+}$ ao estado excitado ${ }^{2} \mathrm{H}_{9 / 2}$. Existem dois possíveis caminhos para que isso ocorra: primeiro é necessário que haja a absorção de dois fótons com comprimento de onda de $980 \mathrm{~nm}$, como mostrado pelos processos 1 e 2 da Figura 61, levando o íon $\mathrm{Er}^{3+}$ para o estado excitado ${ }^{4} \mathrm{~F}_{7 / 2}$; deste nível, processos não-radiativos ocorrem para popular o nível ${ }^{4} \mathrm{~F}_{9 / 2}$,e assim que este nível esteja populado, um terceiro fóton é absorvido, excitando o íon $\mathrm{Er}^{3+}$ para o estado emissor do $408 \mathrm{~nm}\left({ }^{2} \mathrm{H}_{9 / 2}\right)$. O segundo 
mecanismo ocorre por meio da população do nível ${ }^{4} \mathrm{I}_{13 / 2}$ do íon $\mathrm{Er}^{3+}$, após ocorrer um decaimento não-radiativo a partir do nível ${ }^{4} \mathrm{I}_{13 / 2}$. Na seqüência, um segundo fóton é absorvido, o que provoca a população do estado ${ }^{4} \mathrm{~F}_{7 / 2}$ (processo 3 ) e na seqüência 0 terceiro fótons é absorvido para popular o estado emissor $408 \mathrm{~nm}\left({ }^{2} \mathrm{H}_{9 / 2}\right)$. Todos esses processos ocorrem considerando a transferência de energia do íon $\mathrm{Yb}^{3+}$ para o $\mathrm{Er}^{3+}$.

A observação da emissão em $408 \mathrm{~nm}$ não é muito comum, e foram reportadas em alguns poucos trabalhos na literatura [62-64], mas a intensificação dessa emissão na presença de prata é demonstrada pela primeira vez neste trabalho.

O processo responsável pela emissão em $\sim 480 \mathrm{~nm}$ ocorre por meio da emissão de dois fótons com comprimento de onda de $\sim 980 \mathrm{~nm}$ provenientes de dois íons $\mathrm{Yb}^{3+}$ que decaem do nível ${ }^{4} \mathrm{~F}_{5 / 2}$ e se recombinam em nível virtual, para, na seqüência, emitir um único fóton de 480nm.

\subsection{Resultados do vidro GP-CY3}

\subsubsection{Resultados de MET do vidro GP-CY3}

As Figuras 62 (a) e (b) mostram a micrografia e a distribuição de tamanho de partícula do vidro GP-CY3 tratado termicamente por $2 \mathrm{~h}$, respectivamente. Não foi possível determinar a distribuição de tamanho de partícula para o vidro tratado por 48h, como pode ser observado pela micrografia da Figura 63. 

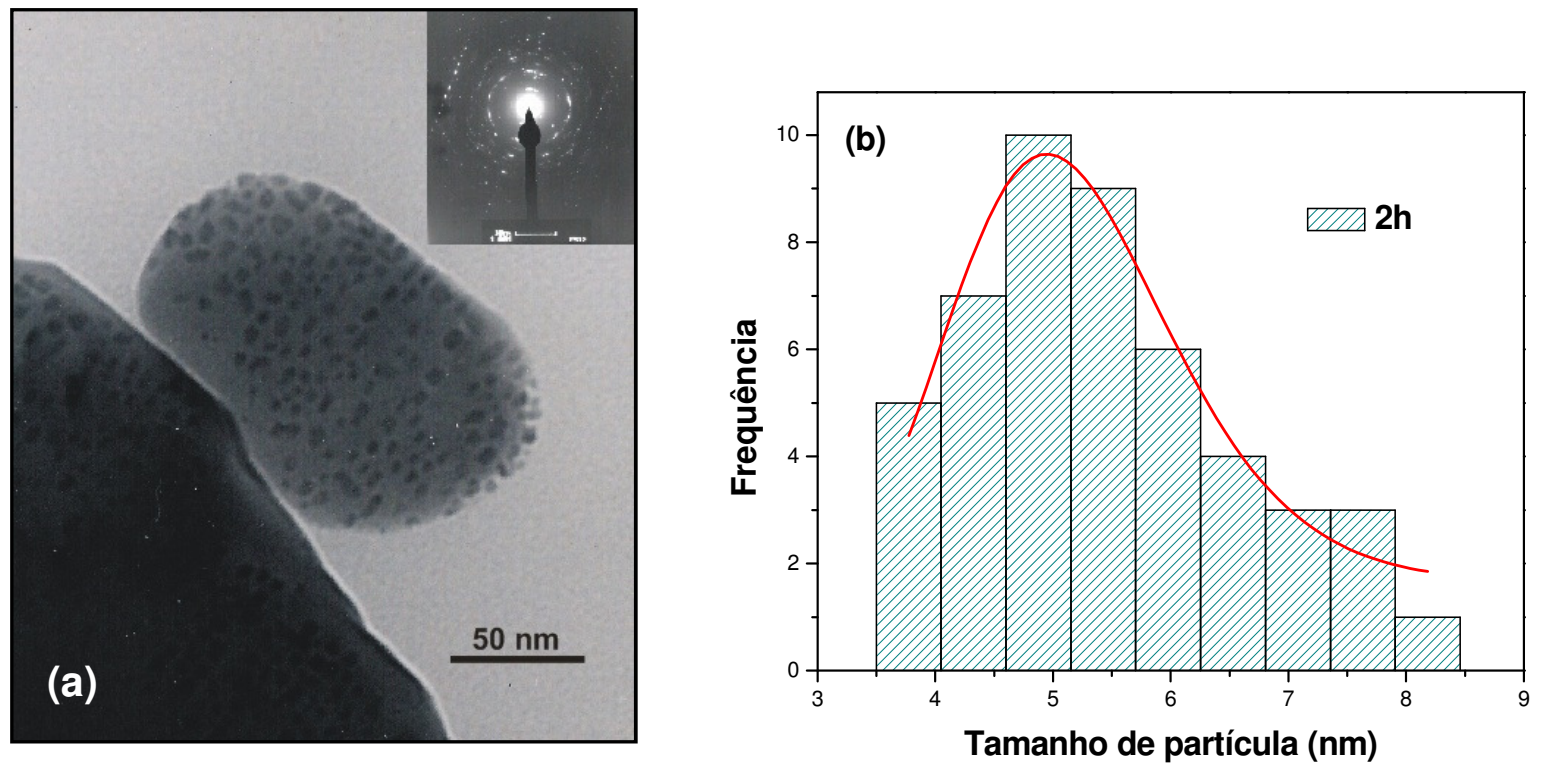

Figura 62 - Micrografia (a) e distribuição do tamanho de partícula (b) do vidro GPCY3 tratado por $2 \mathrm{~h}$.

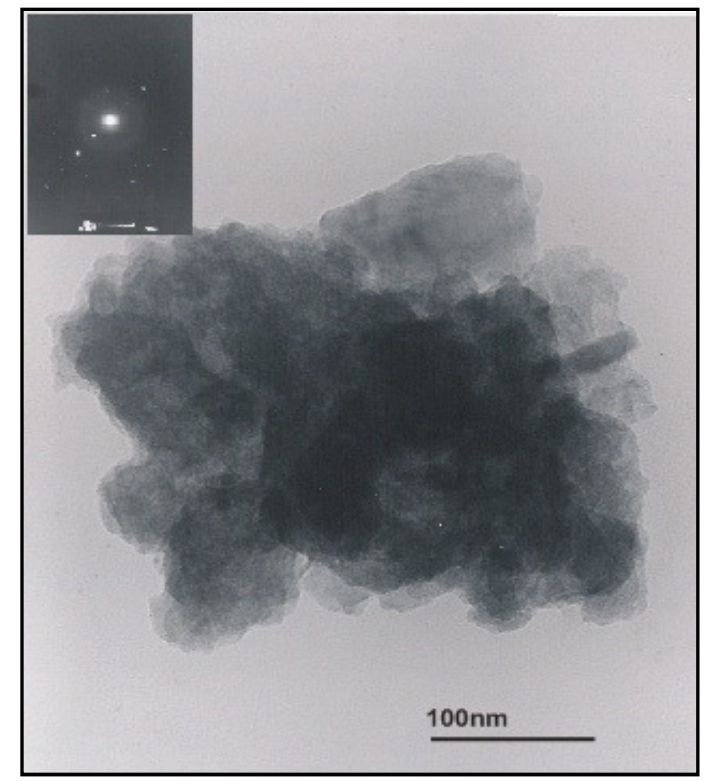

Figura 63 - Micrografia do vidro GP-CY3 tratado por $48 \mathrm{~h}$. 
Por meio da micrografia da Figura 62 (a), observa-se que as NPs têm formato aproximadamente esférico e são cristalinas, como pode ser observado pelo padrão de difração eletrônica mostrado na inserção da Figura 62 (a). O tamanho médio das NPs tratadas por $2 \mathrm{~h}$ é de $5,0 \mathrm{~nm}$. Na Figura 63 observa-se apenas a formação de aglomerados de NPs. Como não foi possível determinar a composição dessas NPs não se sabe qual é a real origem dessas NPs e se elas são constituídas de cobre.

\subsubsection{Absorção óptica do vidro GP-CY3}

Na Figura 64 são mostrados os espectros de absorção na região do visível e infravermelho do vidro GP-CY3 tratados termicamente por 2, 24, 48 e 72h.

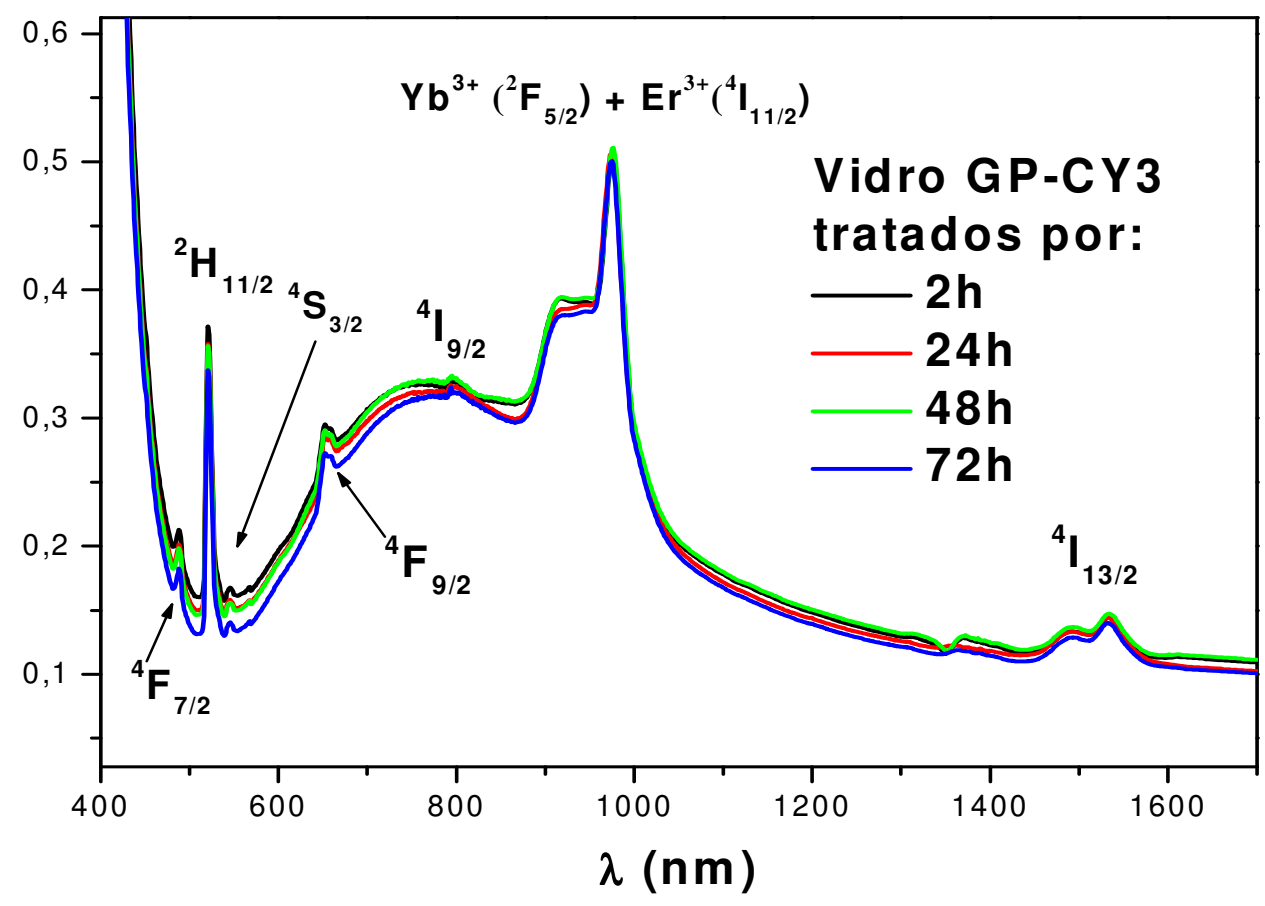

Figura 64 - Espectros de absorção óptica na região do visível dos vidros GP-CY3 tratados termicamente por 2, 24, 48 e $72 \mathrm{~h}$. 
A observação das bandas relacionadas com as transições do $\mathrm{Er}^{3+} \mathrm{e} \mathrm{Yb}^{3+}$ mostram que esses íons foram incorporados na matriz vítrea na sua forma trivalente. Diferentemente dos outros vidros do sistema GP, é observada uma banda que se estende de $550 \mathrm{~nm}$ a $1400 \mathrm{~nm}$, com pico centrado em $800 \mathrm{~nm}$. Essa banda é atribuída à formação de cobre iônico no vidro e não à banda de ressonância plasmônica. Entretanto, é possível que a banda de ressonância plasmônica do cobre esteja presente, sobreposta à banda do cobre iônico, sendo que há relatos na literatura no qual se observa a formação da banda de ressonância do cobre em torno de $600 \mathrm{~nm}$ [65]. Uma constatação experimental que reforça a hipótese que essa banda é atribuída ao cobre iônico, é a ausência do deslocamento e nem o aumento da intensidade da banda em função do tratamento térmico.

A coloração esverdeada é observada nas amostras mostradas na Figura 18, é devido à transmissão apenas do verde e da absorção dos outros comprimentos de onda do visível pela banda do cobre iônico.

\subsubsection{Emissão óptica do vidro GP-CY3}

$\mathrm{Na}$ Figura 65 são mostrados os espectros de emissão com picos centrados em 523, 547 e $659 \mathrm{~nm}$, que correspondem, respectivamente, às transições ${ }^{2} \mathrm{H}_{11 / 2}$, ${ }^{4} S_{3 / 2}$ e ${ }^{4} F_{9 / 2}$ para o estado fundamental; na Figura 66 são mostradas a razões entre as áreas das bandas integradas de emissão. 


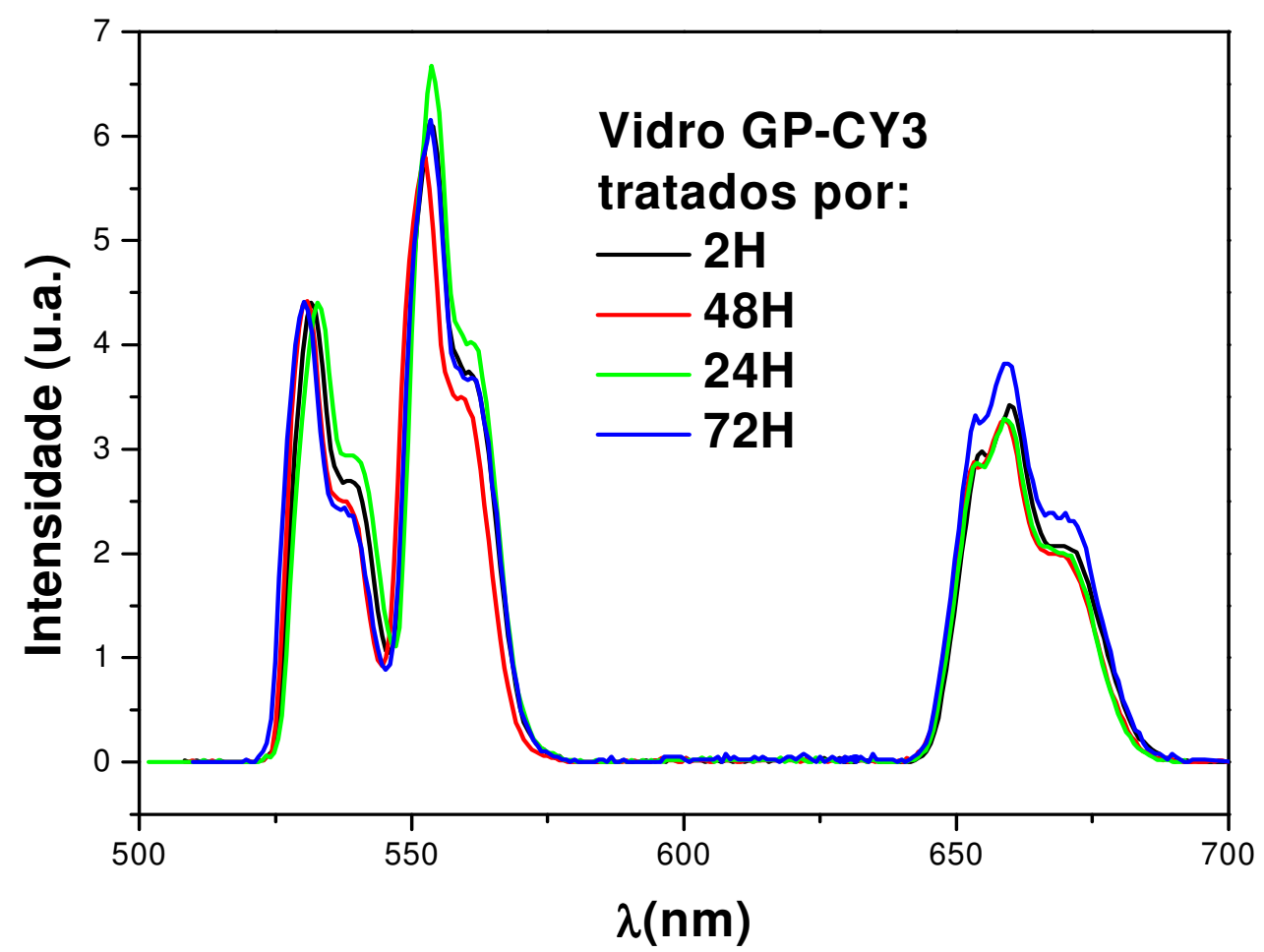

Figura 65 - Espectros de emissão óptica na região do visível do vidro GP-Y3 tratado termicamente por 1, 12, 28, 40 e $72 \mathrm{~h}$.

Por meio dos espectros mostrados na Figura 65, é possível notar que não há uma mudança substancial na luminescência de CAF em função do tratamento térmico. Mas as intensidades de emissão de CAF foram substancialmente afetadas pela presença de cobre, levando a redução considerável da luminescência de CAF, principalmente a relacionada a emissão em $547 \mathrm{~nm}$, quando comparados com outros vidros do tipo GP, já investigados neste trabalho, inclusive quando comparados com vidros com menor concentração de $\mathrm{Yb}_{2} \mathrm{O}_{3}$ e sem cobre. Tal redução deve-se a transferência de energia tanto do íon $\mathrm{Yb}^{3+}$ quanto do íon $\mathrm{Er}^{3+}$ para o cobre iônico, já que há a uma sobreposição espectral entre as bandas desses elementos. Além disso, pode estar ocorrendo também a transferência de energia entre os íons de terras-raras e NPs, devido a distância entre eles é menor do que 5,0 nm. 


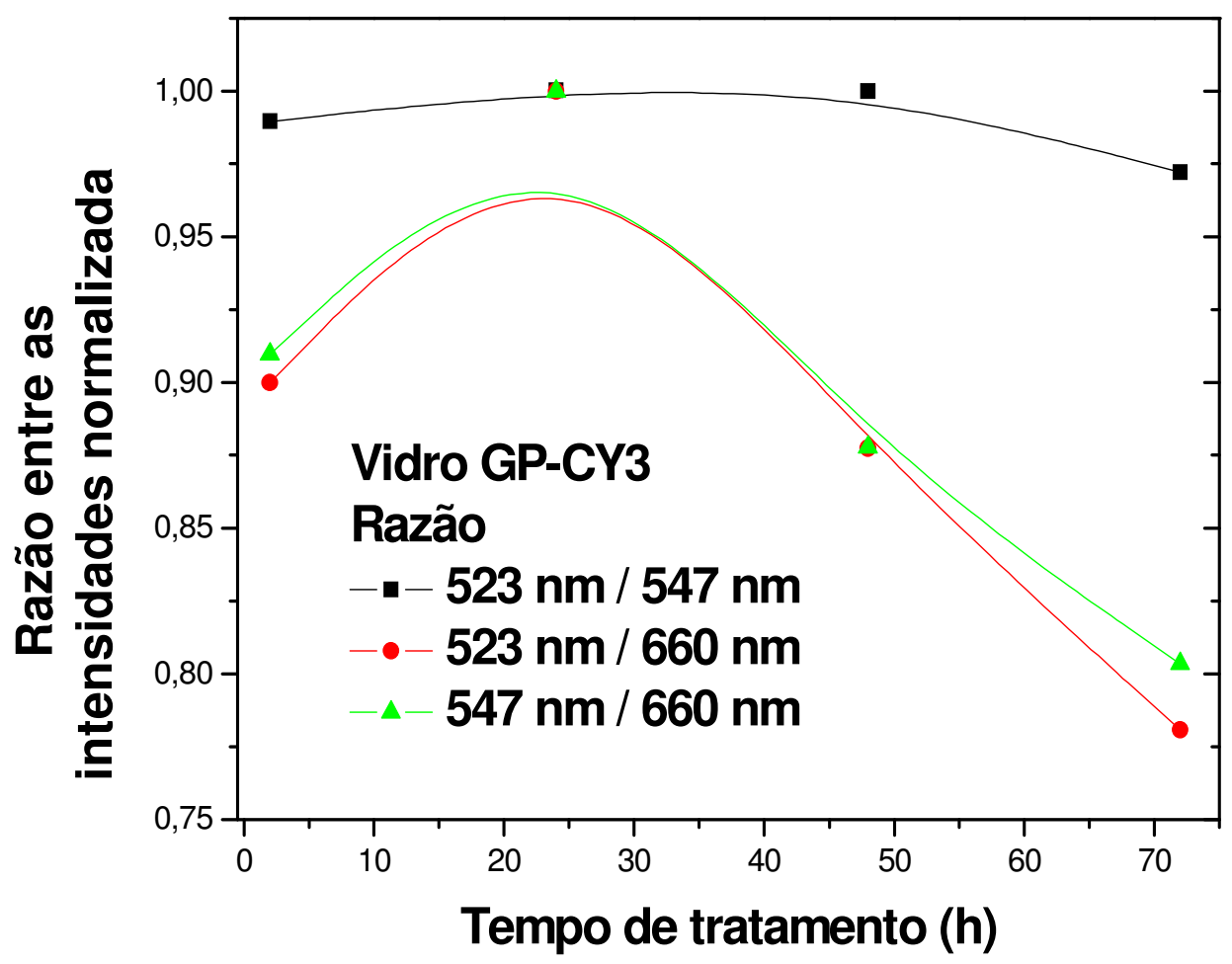

Figura 66 - Razão entre as áreas das bandas de emissão do vidro GP-CY3 em função do tempo de tratamento térmico. A curva foi ajustada para auxiliar na orientação e não está relacionada com nenhum modelo teórico.

Fica evidente observando-se as razões entre as bandas de emissão do íon $\mathrm{Er}^{3+}$ que a emissão vermelha (659 nm) é a mais influenciada pela presença do cobre em função do tratamento térmico. Este resultado indica que as NPs, que assumimos seja de cobre, possuem uma banda ressonância plamônica sobreposta à banda do cobre iônico, e por esse motivo, a emissão vermelha é a mais influenciada.

Na Figura 67 são apresentados os resultados de intensidade de emissão em torno de $545 \mathrm{~nm}$ e $660 \mathrm{~nm}$ do vidro GP-CY3 em função da potência de bombeio (em escala logarítmica). 


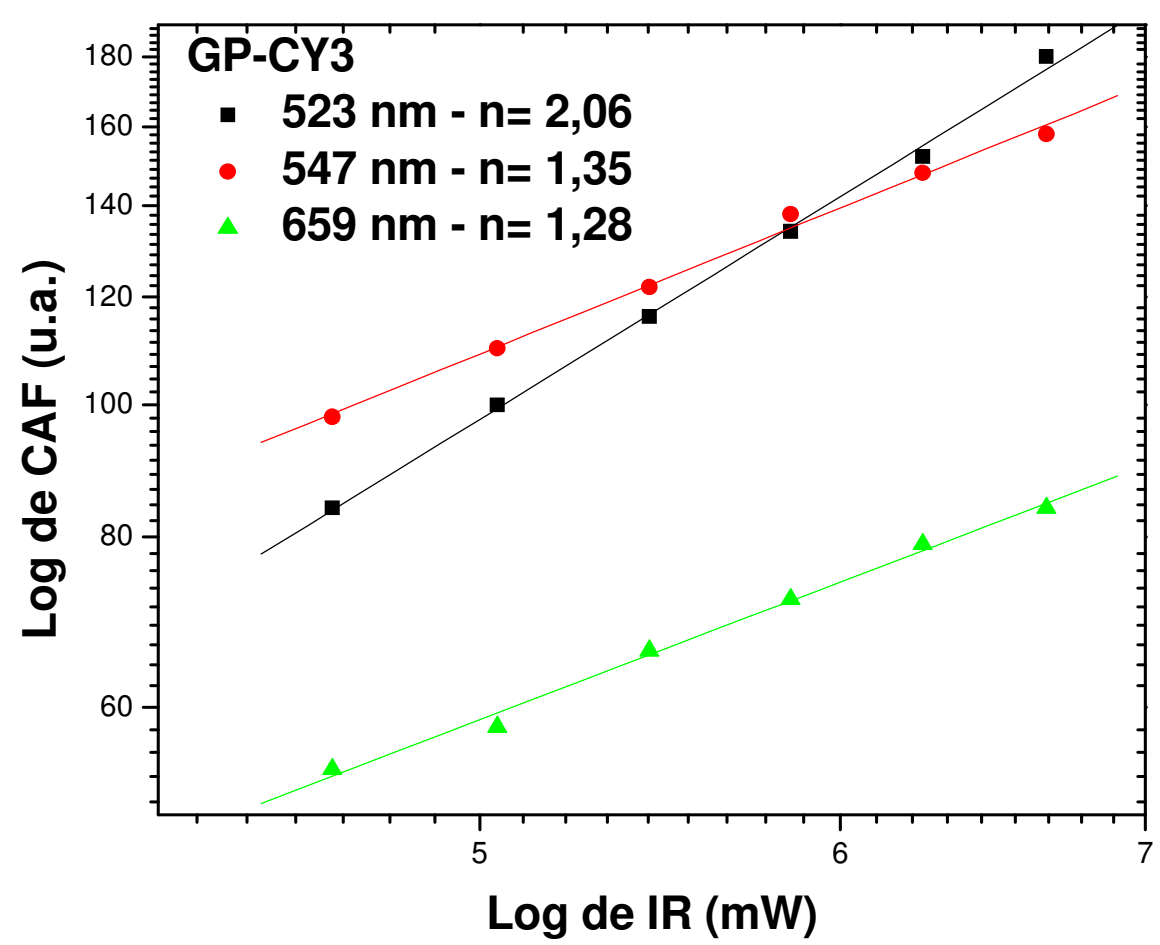

Figura 67 - Intensidade de emissão de CAF em 523, 547 e 659 nm do vidro GP-CY3 em função da potência de bombeio em $980 \mathrm{~nm}$.

Neste caso observa-se que o coeficiente angular foi reduzido para valores próximos a 1 em 547 e $659 \mathrm{~nm}$. Este resultado pode estar associado com a reabsorção dos fótons provenientes das transições dos íons $\mathrm{Er}^{3+}$ pelos íons de cobre. Entretanto, a intensidade de emissão de CAF em $523 \mathrm{~nm}$ em função da potência de excitação não é alterada, e permanece em torno de 2. Isso se deve a um distanciamento do nível emissor ${ }^{2} \mathrm{H}_{11 / 2}$ da banda de absorção do cobre iônico, que começa em aproximadamente $550 \mathrm{~nm}$ e, portanto, não afeta a luminescência em $523 \mathrm{~nm}$. 


\subsection{Resultados do vidro GPG contendo ouro}

\subsubsection{MET do vidro GPG-O3}

Nas Figuras 68 e 69 são mostradas as micrografias dos vidros GPG-O3 tratados por $28 \mathrm{~h}$ e $52 \mathrm{~h}$, respectivamente. Por apresentar NPs com tamanho intermediário em relação às anteriormente analisados, a distribuição de tamanho de partículas foi determinada apenas para as micrografias da Figura 68 (b) e 69 (b) e são mostradas nas Figuras 70 e 71 . Cabe acrescentar que essas análises foram realizadas no MET de alta resolução.
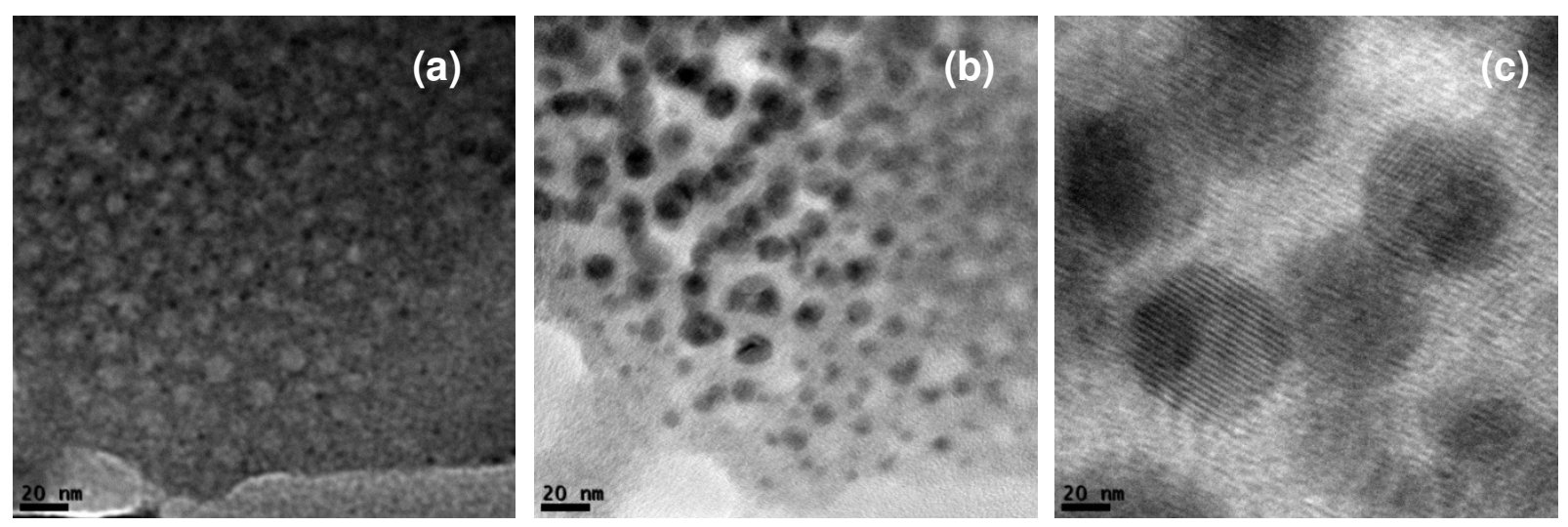

Figura 68 - Micrografias obtidas por MET dos vidros GPG-O3 tratado por 28h.
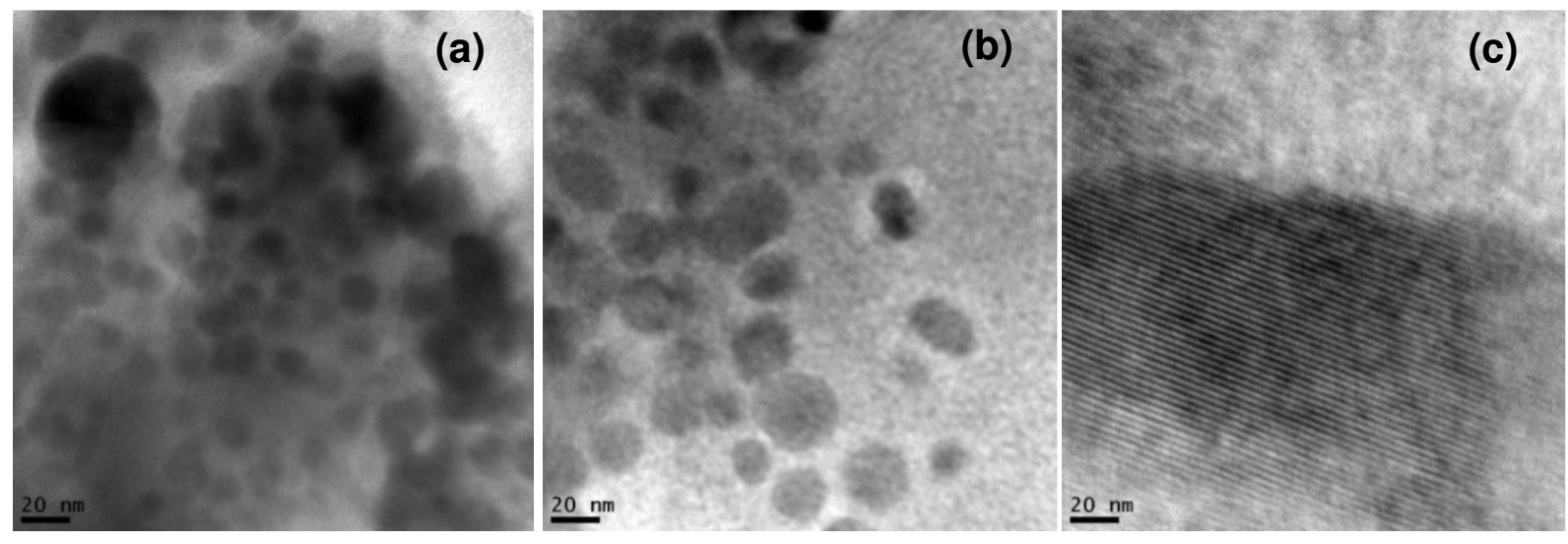

Figura 69 - Micrografias obtidas por MET dos vidros GPG-O3 tratado por 52h. 


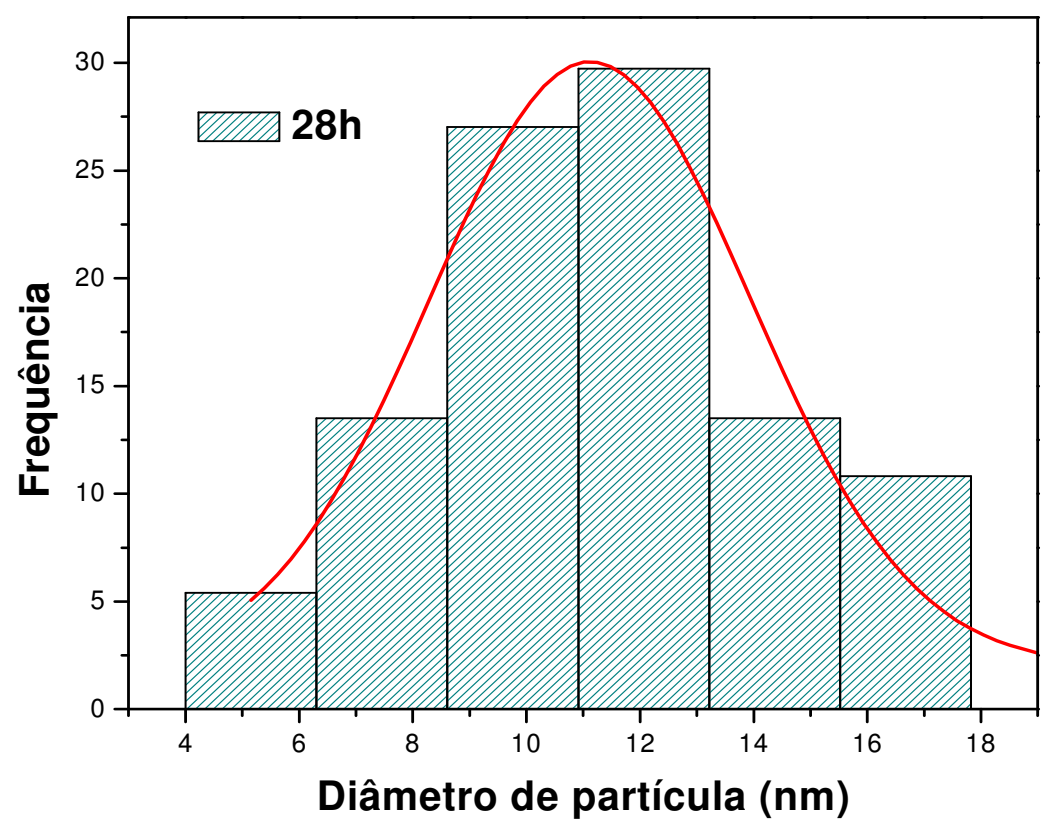

Figura 70 - Distribuição do tamanho de partícula do vidro GPG-O3 tratado por 28h.

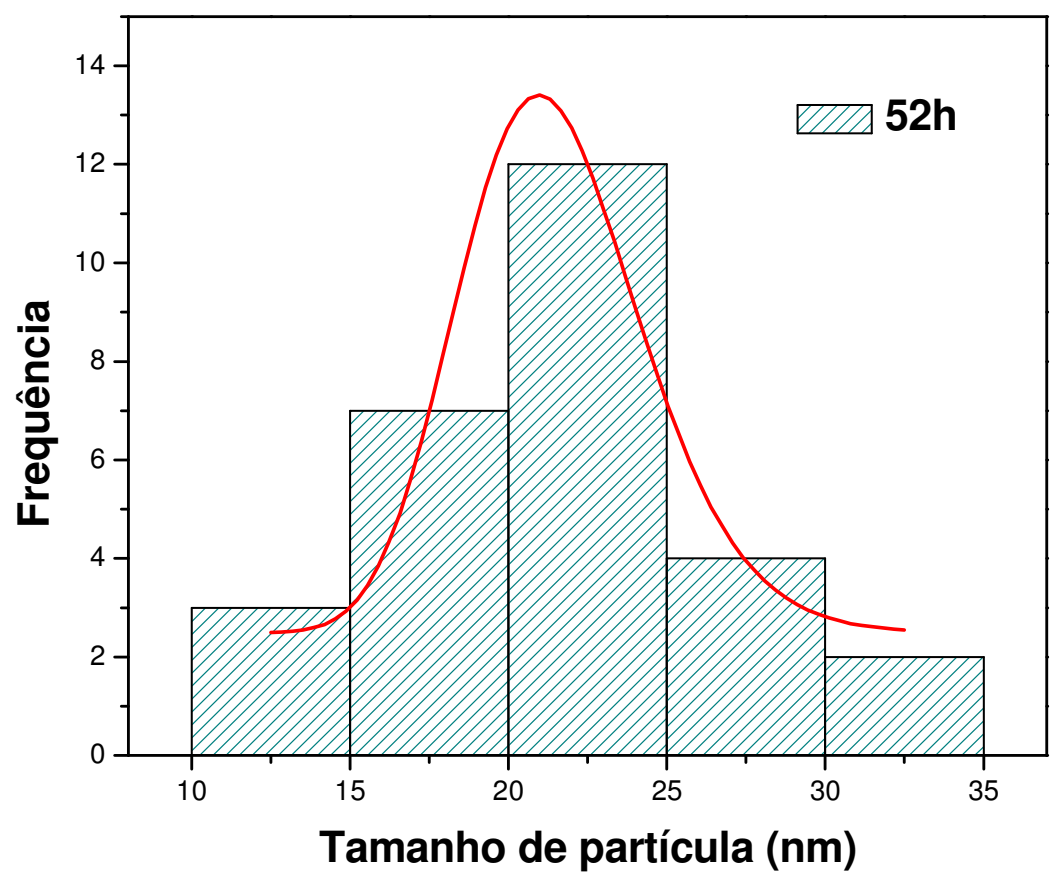

Figura 71 - Distribuição do tamanho de partícula do vidro GPG-O3 tratado por 52h. 
Nas Figuras 72 (a) é mostrada a análises de MET do vidro GPG-Y3 tratado por $48 \mathrm{~h}$ e na Figura 58 (b) é mostrada a distribuição de tamanho de partícula desse vidro.
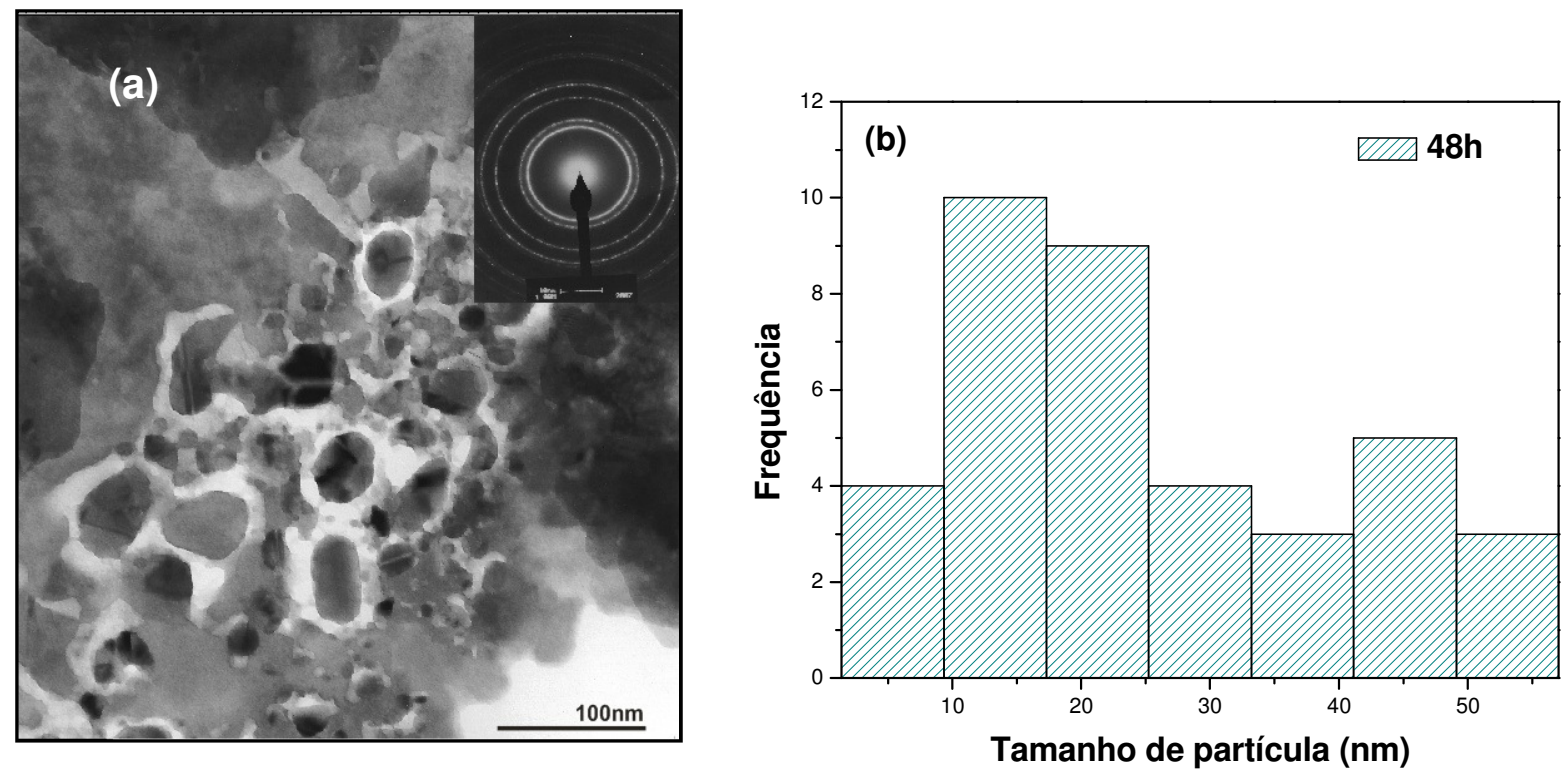

Figura 72 - Micrografia e distribuição do tamanho de partícula do vidro GPG-Y3 tratado por $48 \mathrm{~h}$.

O diâmetro das menores NPs encontradas no vidro GPG-O3 é de 2 nm (Figura 68 (a)) e as maiores possuem diâmetro máximo de 50 nm (Figura 68 (c)), com um diâmetro médio de $11 \mathrm{~nm}$ de acordo com a distribuição de tamanho de partícula apresentado na Figura 70. Além disso, é observada uma diferença de tonalidade entre as NPs, que pode estar relacionada com o surgimento de uma nucleação heterogênea. O mesmo é observado para o vidro tratado por $52 \mathrm{~h}$, entretanto, para esse vidro, o tamanho das NPs varia na faixa de $5 \mathrm{~nm}$ (Figura 69 (a)) a 120 nm Figura 69 (c)) e apresenta diâmetro médio de 21nm (Figura 71). A exata composição das NPs não foi determinada, mas será mostrado adiante que as NPs são formadas basicamente por chumbo. Cabe acrescentar que o tratamento térmico executado nesta etapa do trabalho foi a uma temperatura superior a $\mathrm{Tg}$ do 
vidro e, portanto, espera-se o surgimento de NPs com tamanhos consideravelmente maiores do que aquelas encontradas no vidro GP.

Na micrografia da Figura 72 (a), observa-se que as NPs têm formato irregular e são cristalinas, como pode ser deduzido a partir do padrão de difração eletrônica mostrado na inserção. O tamanho médio das NPs tratadas por $2 \mathrm{~h}$ é de $17 \mathrm{~nm}$, mas ocorre a formação de NPs com tamanhos superiores a $50 \mathrm{~nm}$ estão distribuídas de forma não homogênea ao longo do vidro.

A composição das NPs dos vidros GPG-O3 e GPG-Y3 foram determinadas por meio do EDS acoplado ao microscópio e são mostradas na Figura 73 e 74, respetivamente.

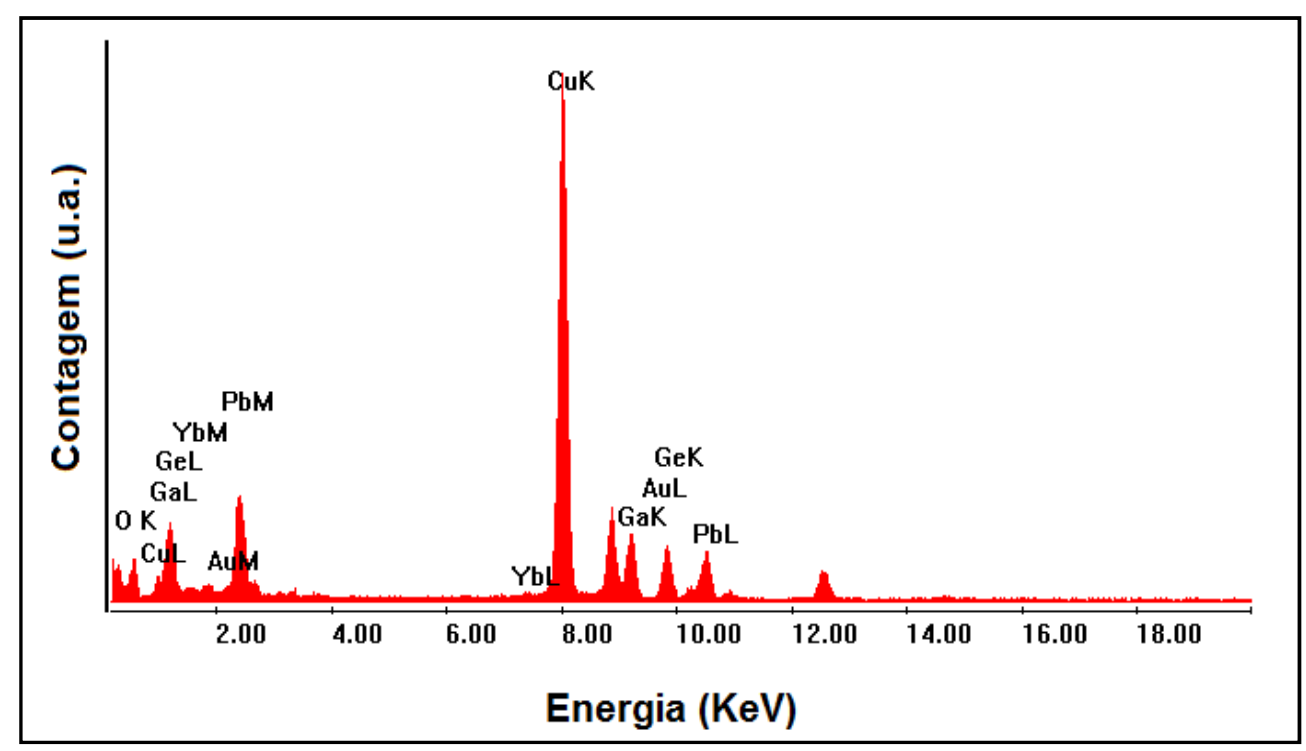

Figura 73 - Espectro de EDS das NPs do vidro GPG-Y3 tratado termicamente por 48h. 


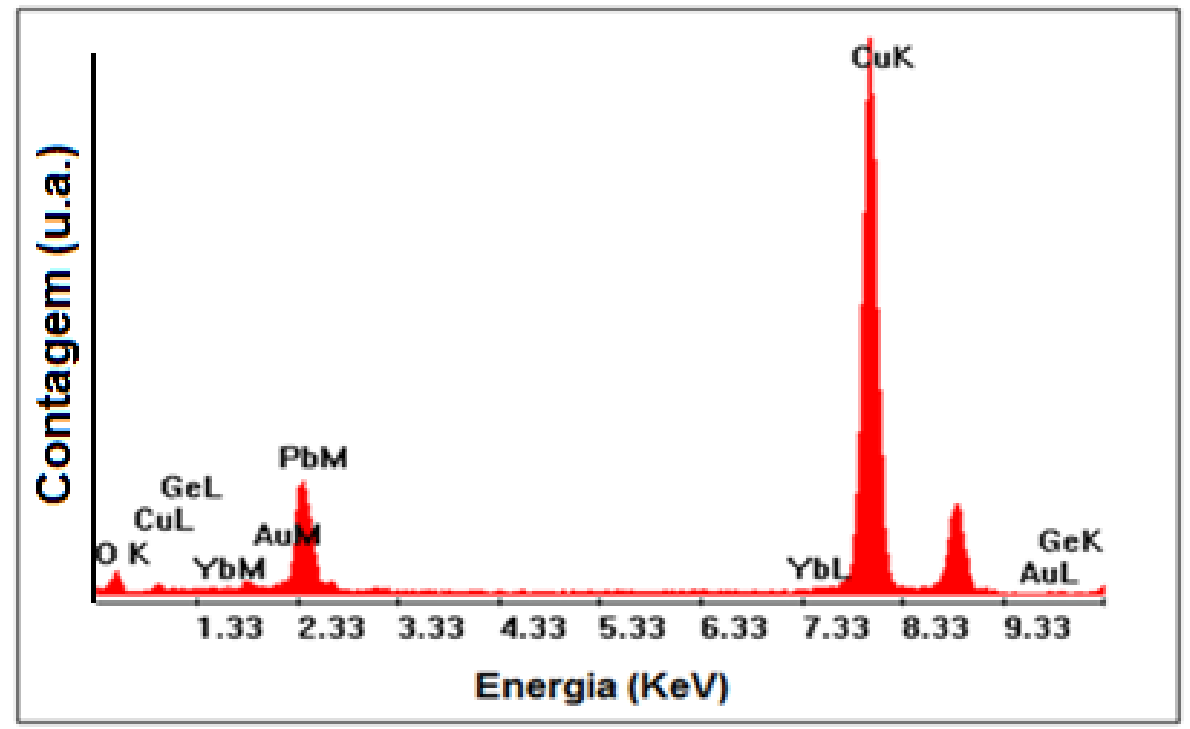

Figura 73 - Espectro de EDS das NPs do vidro GPG-Y3 tratado termicamente por $48 \mathrm{~h}$.

Por meio da análise de EDS do vidro GPG-O3 observa-se que a NP não é formada por ouro, mas apresenta basicamente os constituintes da matriz vítrea. $O$ mesmo ocorre para o vidro GPG-Y3, mas nesse caso, como pode ser observado na análise de EDS, a NP é formada basicamente por chumbo.

Esses resultados indicam, mais uma vez, que há separação de fase nesse vidro com um posterior crescimento de NPs de chumbo. O pico de cobre, como já comentado anteriormente, é devido à grade de suporte da amostra.

\subsubsection{Absorção óptica dos vidros GPG-O3 e GPG-Y3}

Na Figuras 74 e 75 são mostrados os espectros de emissão absorção na região do visível e infravermelho dos vidros GPG-O3 (tratados por 1, 12, 28, 40 e 52h) e GPG-Y3 (tratados por 1, 24, 48, 72h), respectivamente. 


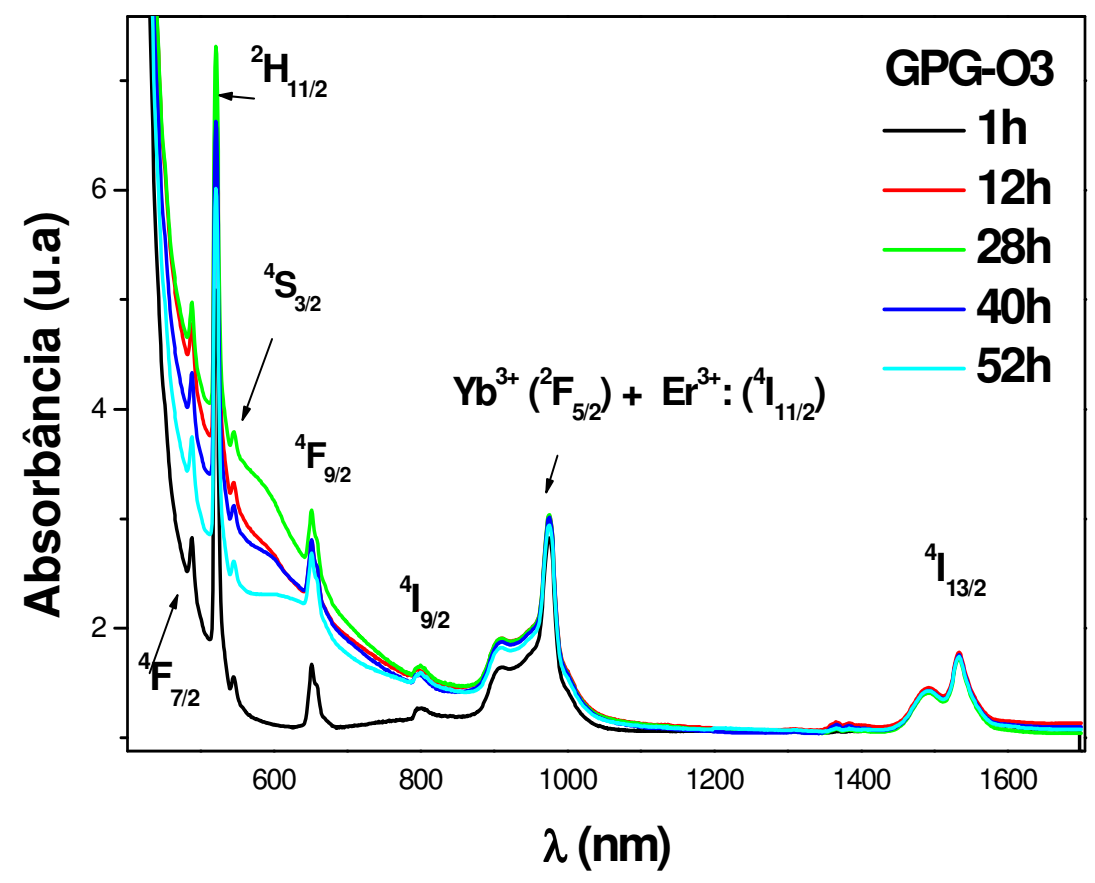

Figura 74 - Espectros de absorção óptica na região do visível e infravermelho do vidro GPG-O3 tratados termicamente por 1, 12, 28, 40 e 52h.

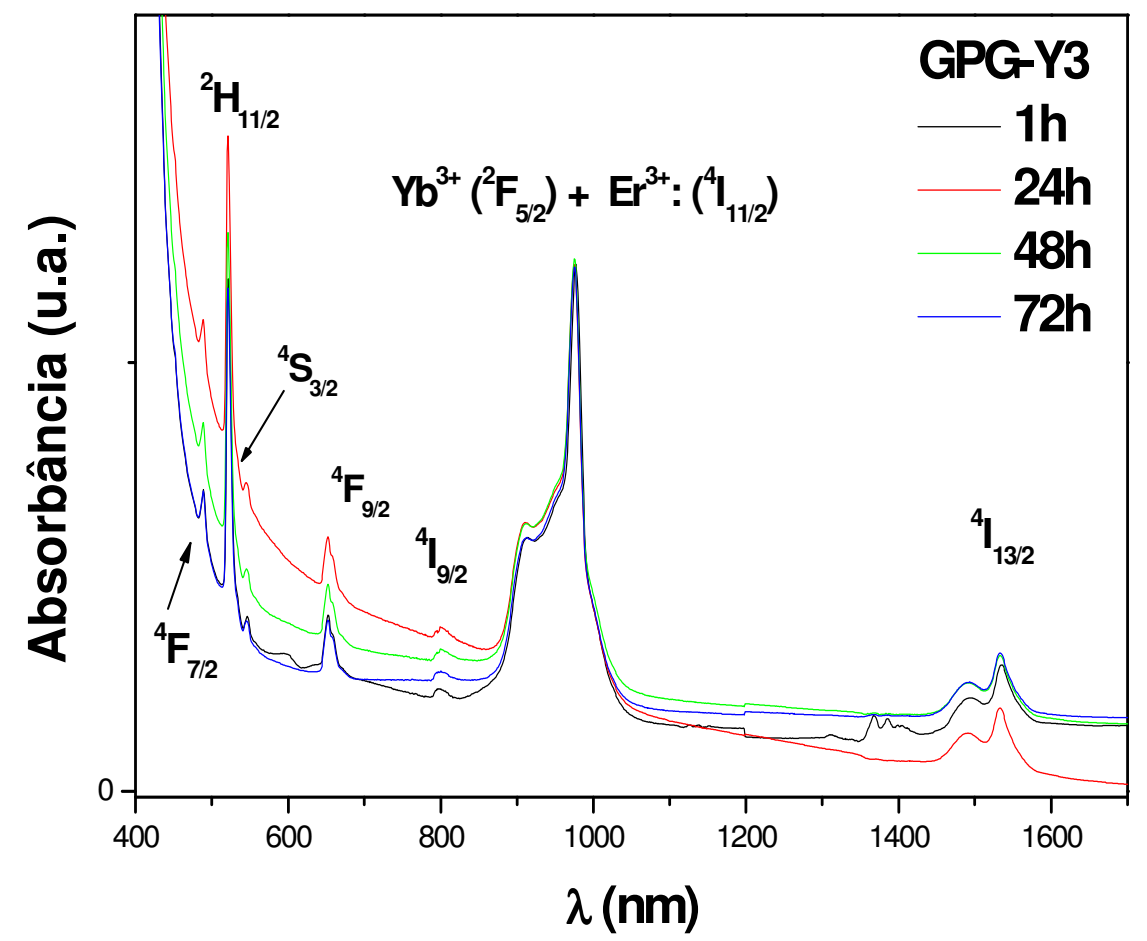

Figura 75 - Espectros de absorção óptica na região do visível e infravermelho do vidro GPG-Y3 tratados termicamente por 1, 24, 48, e 72h. 
As mesmas bandas de absorção do vidro co-dopado apenas com $\mathrm{Er}_{2} \mathrm{O}_{3} \mathrm{e}$ $\mathrm{Yb}_{2} \mathrm{O}_{3}$ são observadas para os vidros GPG-O3. Entretanto, uma banda centrada em $600 \mathrm{~nm}$, associada com a banda de ressonância dos plasmons superficiais do ouro também é observada para o vidro GPG-O3. Cabe acrescentar que há um discreto deslocamento dessa banda em direção ao infravermelho em função do tratamento térmico e um aumento da intensidade banda de absorção para o tratamentos até $28 \mathrm{~h}$ e com posterior redução para tratamentos mais prolongados.

Não é observada a formação da banda de ressonância plasmônica do ouro nos espectros da Figura 75 do vidro GPG-Y3, como encontrado no vidro GPG-O3, que pode estar relacionado com a menor concentração de $\mathrm{Au}_{2} \mathrm{O}_{3}$ presente nesse vidro.

\subsubsection{Emissão óptica do vidro GPG-O3 e GPG-Y3}

As Figura 76 e 77 mostram os espectros de CAF normalizados dos vidros GPG-O3 e GPG-Y3, respectivamente. As bandas de emissão centradas em 523, $545,657 \mathrm{~nm}$ correspondem às transições ${ }^{2} \mathrm{H}_{11 / 2} \rightarrow{ }^{4} \mathrm{I}_{15 / 2},{ }^{4} \mathrm{~S}_{3 / 2} \rightarrow{ }^{4} \mathrm{I}_{15 / 2}, \mathrm{e}^{4} \mathrm{~F}_{9 / 2} \rightarrow{ }^{4} \mathrm{I}_{15 / 2}$ do $\mathrm{Er}^{3+}$, respectivamente. As razões entre as áreas das bandas de emissão são mostradas nas Figuras 78 e 79 para os vidros GPG-O3 e GPG-Y3, respectivamente. 


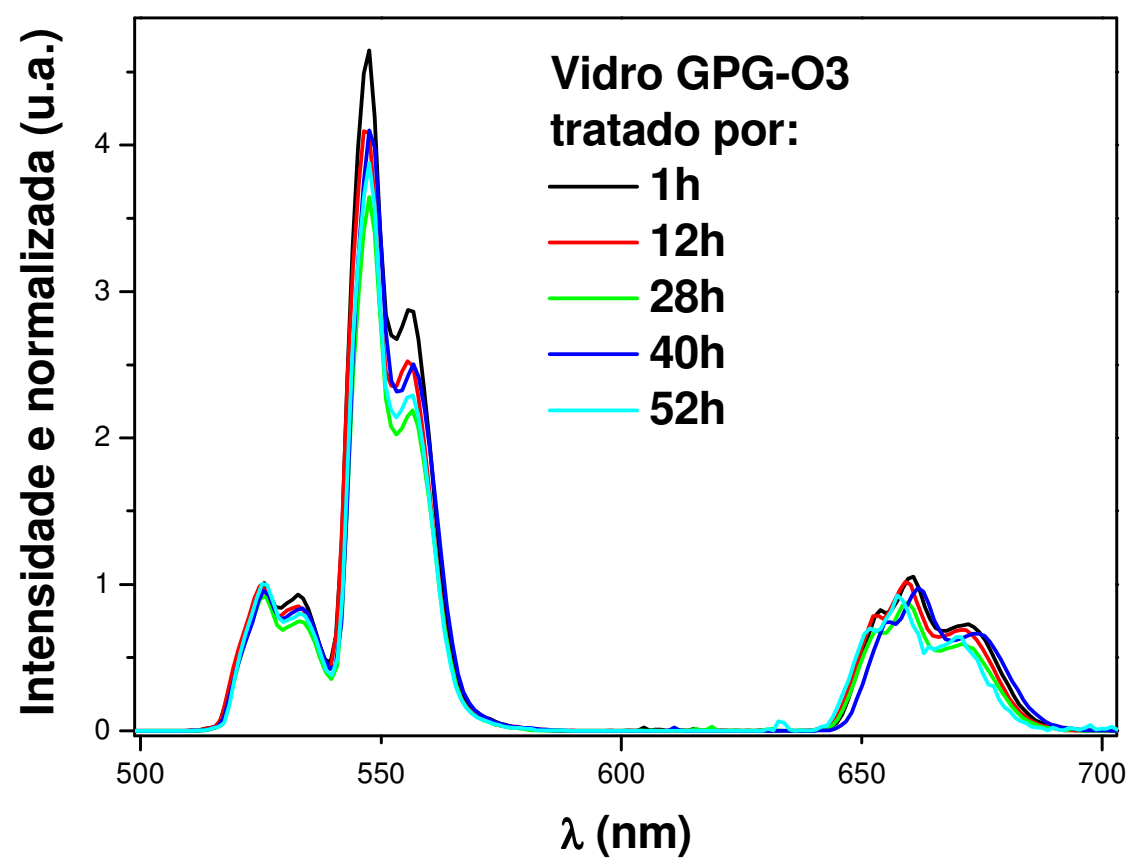

Figura 76 - Espectros de emissão óptica na região do visível do vidro GPG-O3 tratado termicamente por 1, 12, 28, 40 e $72 \mathrm{~h}$.

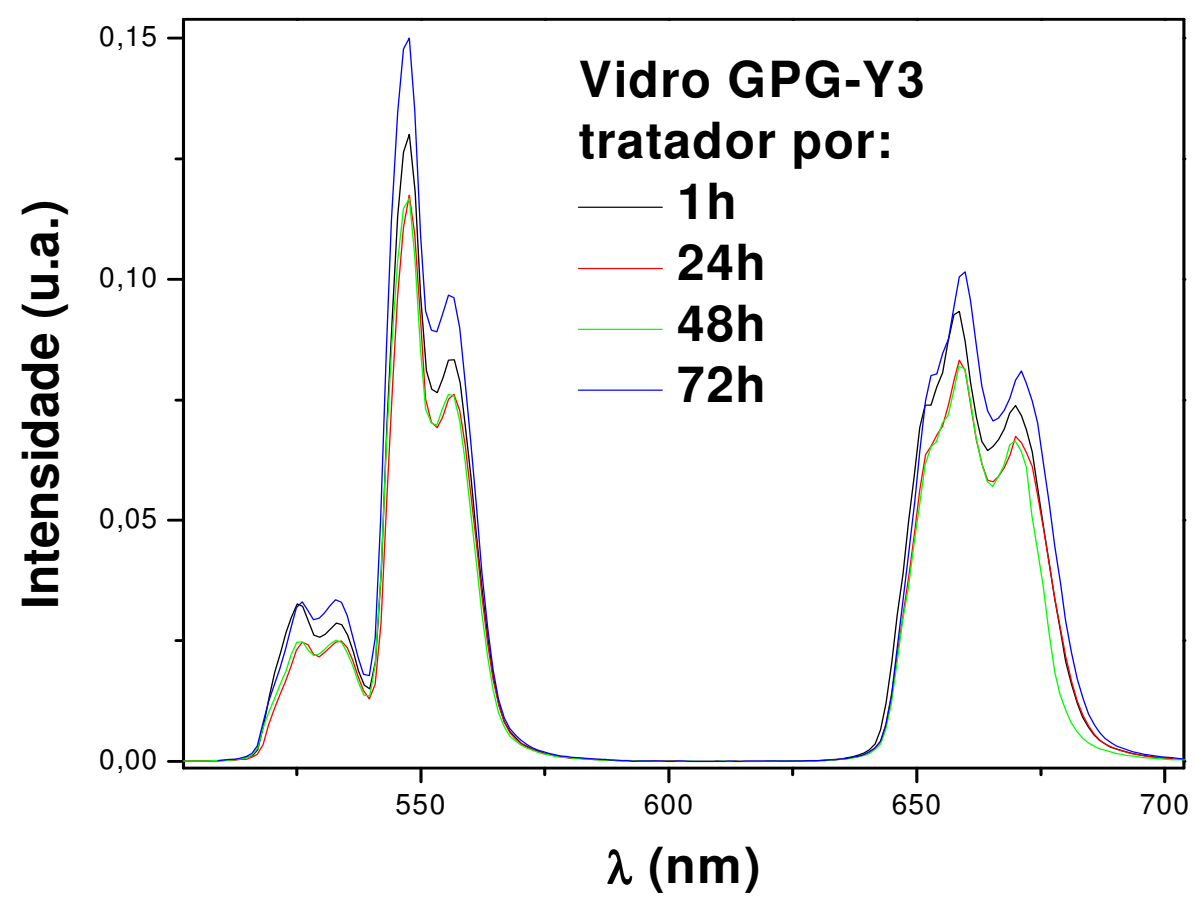

Figura 77 - Espectros de emissão óptica na região do visível do vidro GPG-Y3 tratado termicamente por 1, 12, 48 e $72 \mathrm{~h}$. 


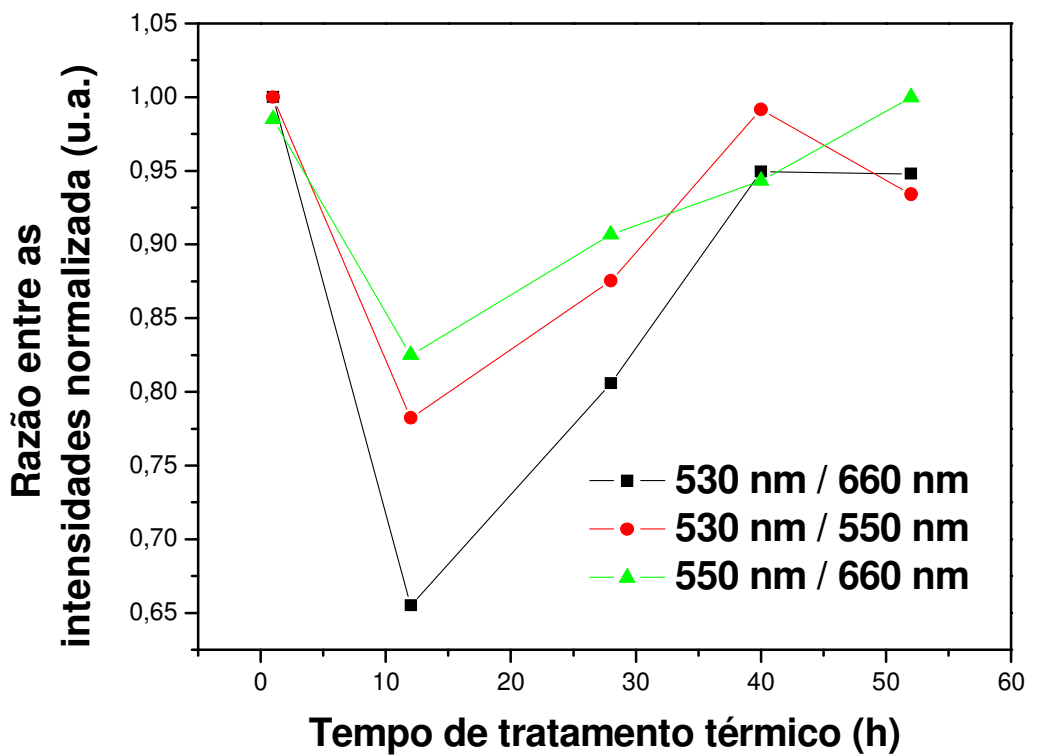

Figura 78 - Razão entre as áreas das bandas de emissão integradas do vidro GPGO3 tratado por 1, 12, 28, 40 e 52h.

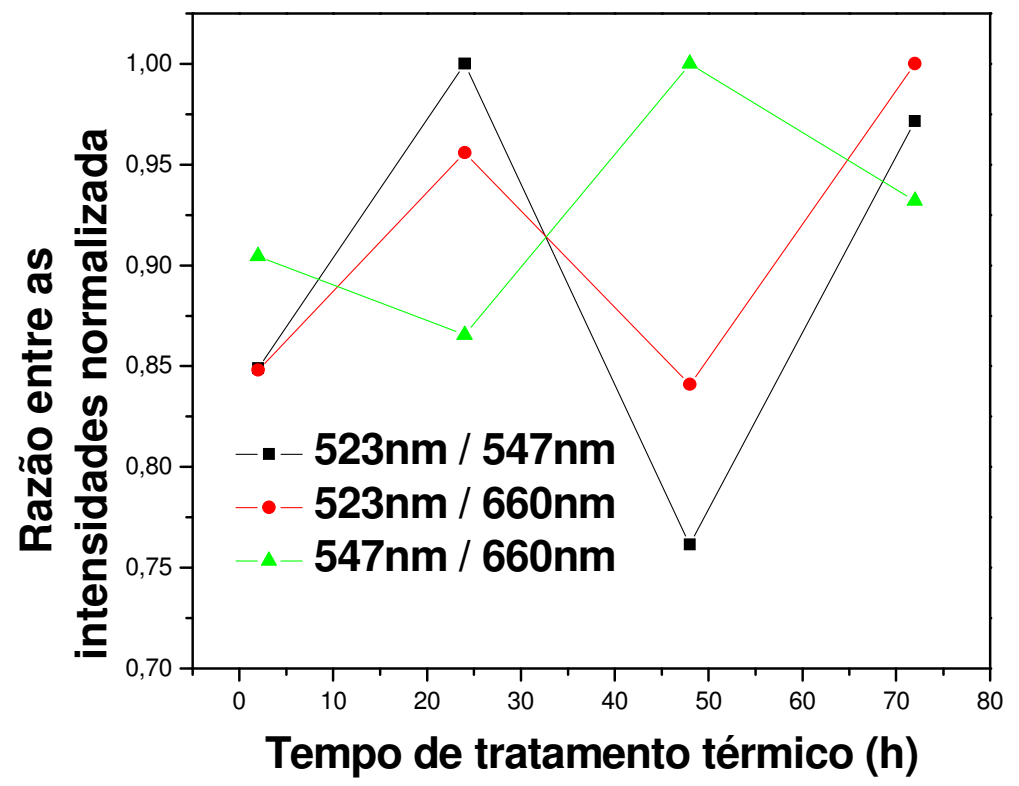

Figura 79 - Razão entre as áreas das bandas de emissão integradas do vidro GPGY3 tratado por 1, 12, 28, 40 e 52h.

Em ambos os vidros, GPG-O3 e GPG-Y3 não é observado nenhuma tendência de aumento ou diminuição das intensidades de emissão em função do 
tempo de tratamento térmico, como mostrado nas Figuras 76 e 77. A única diferença entre os espectros desses dois vidros é a maior intensidade de emissão apresentada pela emissão em $\sim 660 \mathrm{~nm}$ do vidro GPG-Y3, devido a maior concentração de $\mathrm{Yb}_{2} \mathrm{O}_{3}$ presente, que favorece principalmente a transição ${ }^{4} \mathrm{~F}_{9 / 2} \rightarrow{ }^{4} \mathrm{I}_{15 / 2}$ do $\mathrm{Er}^{3+}$.

Observa-se por meio das razões entre as bandas do vidro GPG-O3 (Figura 78), que a emissão mais afetada é na região do vermelho em comparação com o verde. Entretanto, as emissões de CAF do $\mathrm{Er}^{3+}$ (verde e vermelho) mostradas na Figura 78 são menos afetadas do que nas amostras co-dopadas com prata na matriz GP-Y3, como visto anteriormente. O comportamento observado pode estar relacionado com a banda de ressonância plasmônica do ouro presente nos espectros de absorção óptica, localizada em torno de $600 \mathrm{~nm}$ e, portanto, tende a influenciar com maior intensidade a emissão em 660 nm.

Comparando as razões entre as intensidades integradas da Figura 79 do vidro GPG-Y3, que também não há nenhuma tendência de aumento ou diminuição em função do tratamento térmico.

$\mathrm{Na}$ Figura 80 e 81 são apresentados os resultados de intensidade de emissão em torno de 527, 547 e 660 nm dos vidros GPG-O3 e GPG-Y3 em função da potência de bombeio em $980 \mathrm{~nm}$ (em escala logarítmica).

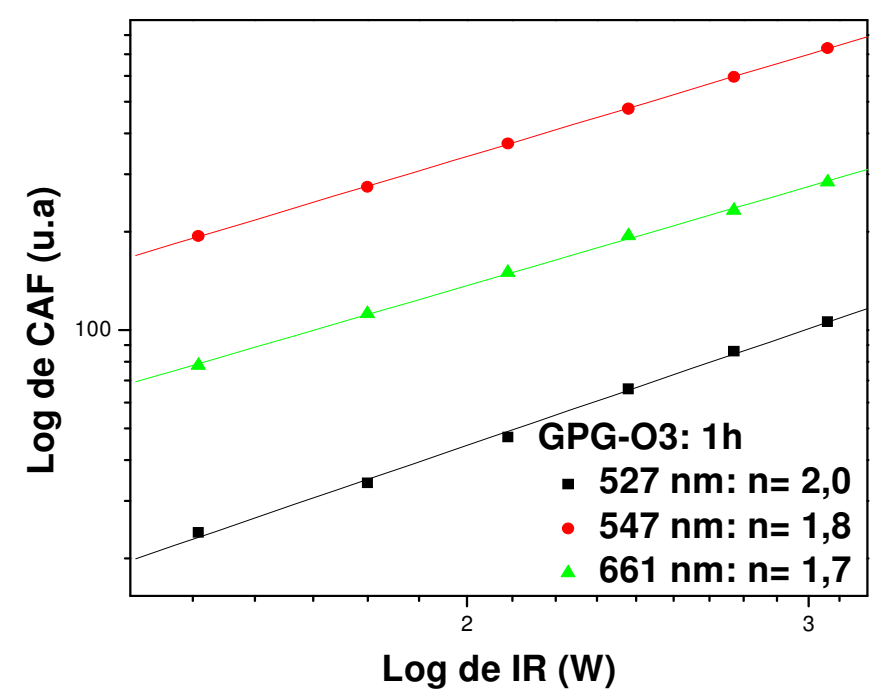

Figura 80 - Intensidade de emissão de CAF em função da excitação em 980 nm do vidro GPG-O3. 


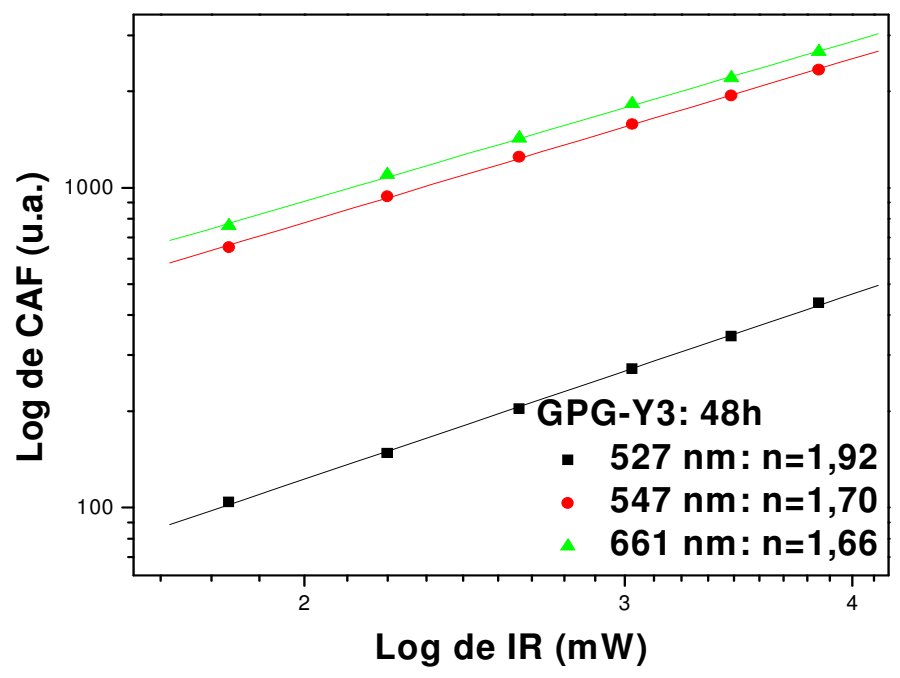

Figura 81 - Intensidade de emissão de CAF em função da excitação em $980 \mathrm{~nm}$ do vidro GPG-Y3.

O mecanismo de CAF não é influenciado pela presença do ouro e tal processo também ocorre por meio da absorção seqüencial de 2 fótons, com 0 coeficiente da reta em torno de 2. Em ambos os casos dois fótons participam do processo de CAF. Os processos associados à população dos estados excitados e as respectivas emissões radiativas nestes vidros são os mesmos dos vidros codopados apenas com $\mathrm{Er}_{2} \mathrm{O}_{3}$ e $\mathrm{Yb}_{2} \mathrm{O}_{3}$, já discutidos anteriormente e mostrados na Figura 36. 


\section{CONCLUSÕES}

$\mathrm{O}$ aumento da conversão ascendente do $\mathrm{Er}^{3+}$ nos vidros $\mathrm{GeO}_{2}-\mathrm{PbO}-\mathrm{Ga}_{2} \mathrm{O}_{3}$ e $\mathrm{GeO}_{2}-\mathrm{PbO}$ co-dopados com diferentes concentrações de $\mathrm{Er}_{2} \mathrm{O}_{3}$ e $\mathrm{Yb}_{2} \mathrm{O}_{3}$ é devido a transferência de energia do íon $\mathrm{Yb}^{3+}$ para o $\mathrm{Er}^{3+}$. Com o aumento da concentração de íons de $\mathrm{Yb}^{3+}$, a emissão de luz ao redor de $660 \mathrm{~nm}$ é mais influenciada pelo processo de transferência de energia do que as emissões na região do verde ( 523 e $547 \mathrm{~nm})$.

Ao explorar simultaneamente, a influência da transferência de energia do íon $\mathrm{Yb}^{3+}$ para o $\mathrm{Er}^{3+}$ e a presença de nanopartículas (NPs) metálicas foi observado o aumento substancial nas emissões de conversão ascendente do íon $\mathrm{Er}^{3+}$ com um discreto favorecimento das emissões centradas em 523 e $547 \mathrm{~nm}$ em relação à emissão em $661 \mathrm{~nm}$ no vidro $\mathrm{GeO}_{2}-\mathrm{PbO}$ devido ao aumento do campo local ao redor das NPs com tamanho médio de aproximadamente 2,0 nm. Em contrapartida, há a diminuição das emissões de conversão do íon $\mathrm{Er}^{3+}$ do vidro $\mathrm{GeO}_{2}-\mathrm{PbO}_{-}-\mathrm{Ga}_{2} \mathrm{O}_{3}$ quando na presença de NPs de ouro de tamanho superiores a $10 \mathrm{~nm}$.

$\mathrm{O}$ vidro $\mathrm{GeO}_{2}-\mathrm{PbO}$ é um candidato promissor para que ocorra o aumento da luminescência de conversão ascendente na presença de NPs, por apresentar boa estabilidade térmica para nucleação das NPs, e boa seletividade para nucleação de prata.

Para que um vidro tenha alta eficiência na luminescência de conversão ascendente do íon $\mathrm{Er}^{3+}$ é necessário baixas energias de fônon e baixa intensidades dessas vibrações. Nesse sentido, o vidro $\mathrm{GeO}_{2}-\mathrm{PbO}-\mathrm{Ga}_{2} \mathrm{O}_{3}$ é considerado o mais adequado, por apresentar baixa concentração de $\mathrm{GeO}_{2}$, e por conseqüência uma menor intensidade de vibração da ligação Ge-O. Mas devido a sua instabilidade térmica, este sistema torna-se impróprio para nucleação de NPs de ouro, já que foram encontradas somente NPs de chumbo.

A partir dos resultados deste trabalho, torna-se evidente que os efeitos promissores da plasmônica podem ser aplicados com a finalidade de aumentar 
ainda mais a eficiência de sistemas lasers baseados na transferência de energia $\mathrm{Yb}^{3+} \rightarrow \mathrm{Er}^{3+}$. 


\section{REFERÊNCIAS}

1 Prasad, P. N., Nanophotonics, Wiley, New Jersey, 2004.

2 Atwater, Harry A., The promise of plasmonics, Scientific American, april 2007, p.38-45, New York, 2007.

3 A. Martucci, M. De Nuntis, A. Ribaudo, M. Guglielmi, S. Padovani, F. Enrichi, G. Mattei, P. Mazzoldi, C. Sada, E. Trave, G. Battaglin, F. Gonella, E. Borsella, M. Falconieri, M. Patrini and J. Fick . Silver-sensitized erbium-doped ion-exchanged sol-gel waveguides. Applied Physics A 80 (2005) 557.

4 O. V. Salata., Applications of nanoparticles in biology and medicine, Journal of Nanobiotechnology, 30 April 2004.

5 J. E. C. Silva, Sá, G. F., Malta, O. L., Santa Cruz, P. A., Primary Color Generation and Control in Fluoride Glasses. Química Nova, v. 21, p. 372-373, 1998.

6 S. Taccheo, G. Sorbello, P. Laporta, G. Karlsson, and F. Laurell. 230-mW DiodePumped Single-Frequency Er:Yb Laser at $1.5 \mathrm{~nm}$. IEEE Photonics Technology Letters, 13 (2001) 1.

7 E. Desurvire, J. R. Simpson, and P. C. Becker, High-gain erbium doped traveling wave fiber amplifier, Opt. Lett. 12, (1987) 888.

8 C. R. Giles and E. Desurvire, Modeling erbium-doped fiber amplifiers, J. Lightwave Technol. 9 (2), 271 (1991)

9 A. Jha, M. Naftaly, S. Jordery, B. N. Samson, E. R. Taylor, D. Hewak, D. N. Payne, M. Poulain and G. Zhang, Design and fabrication of $\mathrm{Pr}^{3+}$-doped fluoride glass

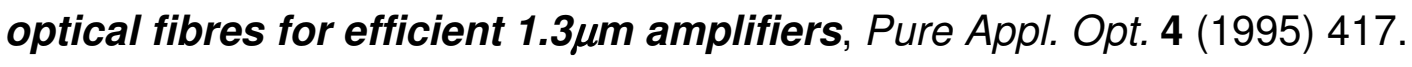

10 L. Feng, J. Wang, Q. Tang, H. Hu, H. Liang, Q. Su, Optical properties of $\mathbf{E r}^{3+}$ singly doped and $\mathrm{Er}^{3+} / \mathrm{Yb}^{3+}$-codoped novel oxyfluoride glasses, Journal of NonCrystalline Solids 352 (2006) 2090.

11 Z. Jin, Q. Nie, T. Xu, S. Dai, X. Shen, X. Zhang, Optical transitions and upconversion luminescence of $\mathrm{Er}^{3+} / \mathrm{Yb}^{3+}$ codoped lead-zinc-tellurite oxide glass, Materials Chemistry and Physics 104 (2007) 62. 
12 M. Yamane, Y. Asahara, Glasses for Photonics (Cambridge University Press, Cambridge, 2000).

13 L. H. V. Vlack, Princípios de Ciências dos Materiais, Editora Edgard Blucher LTDA, 4 edição (1970) 73.

14 Gonzalez-Oliver and and P.F. Jame, Crystal nucleation and growth in a $\mathrm{Na}_{2} \mathrm{O}-$ 2CaO-3SiO 2 glass, Journal of Non-Crystalline Solids, 38 (1980) 699.

15 Paul, A. Chemistry of glasses. 1. ed New York, N.Y.: Chapman and Hall, 1982.

16 O.L., Alves, I.F., Gimenez, I.O., Mazile, Vidros, Cadernos temáticos de Química Nova na Escola. Edição especial, no.13 maio 2001.

17 W. W. Wendlandt, Thermal Analysis, 3a ed., Wiley \& Sons, New York (1986).

18 E.B. Araújo, Estudando Vidros Por Meio de Análise Térmica Diferencial, Revista Brasileira de. Ensino de Física, v.19, no.3 (1997) 325.

19 F.A. Bomfim, Produção e Caracterização de Fibras Ópticas de Germanato dopadas com érbio, Trabalho de conclusão de curso, Fatec-SP, Fevereiro de 2007.

20 W. R. Dumbaugh, Heavy Metal Oxides Glasses Containing $\mathrm{Bi}_{2} \mathrm{O}_{3}$, Physics and Chemistry of Glasses, 27 (1986) 119.

21 J. Zhang, S. Dai, G. Wang, L. Zhang, H. Sun, L. Hu, Investigation on upconversion luminescence in $\mathrm{Er}^{3+} \mathrm{Yb}^{3+}$ codoped tellurite glasses and fibers, Physics Letters $\mathrm{A}$ 345 (2005) 409.

$22 \mathrm{H}$. Sun, L. Wen, Z. Duan, L. Hu, J. Zhang, Z. Jiang, Intense frequency upconversion fluorescence emission of $\mathrm{Er}^{3+} / \mathrm{Yb}^{3+}$-codoped oxychloride germanate glass, Journal of Alloys and Compounds 414 (2006) 142.

23 L. M., Dennis and A. W. Laubengayer, Fused germanium dioxide and some germanium, J. Phys. Chem. 30 (1926) 1510.

24 Krakau, K. A.; USSR Opticomechanical Industry, 4, (1939) 15.

25 K.S. Evstropiev and A.O. Ivanov In: F.R. Matson and G.E. Rindone, Editors, Advances in Glass Technology, Part 2, Plenum, New York (1963) 79.

26 M. K. Murthy and J. Ip, Some Physical Properties of. Alkali Germanate Glasses, Nature , 201 (1964) 285.

27 G.S. Henderson, The germanate anomaly: What do we know?, Journal of NonCrystalline Solids 353 (2007) 1695. 
28 Polukhin, V. N., Proceedings Technology Congress, Vavilov State Optical 120.

29 Polukhin, V. N., Modestov, O V.; Inorganic Materials. 10, (1974) 757.

30 Polukhin, V. N., Burdina, V. A, 45, pat. No. 583104.

31 Polukhin, V. N., Urusovskaya, n.5, pat. No. 5455991977.

32 Demtröder, W., Laser Spectroscopy: Basic Concepts and Instrumentation, Editora Springer, 1996.

33 J.A. Hutchinson and T.H. Allik, Diode array-pumped Er, Yb: phosphate glass laser, Applied physics Letters Lett. 60 (1992) 1424.

34 J.F. Philipps, T. Töpfer, H. Ebendorff-Heidepriem, D. Ehrt, R. Sauerbrey and N.F. Borrelli., Diode-pumped erbium-ytterbium-glass laser passively Q-switched with a PbS semiconductor quantum-dot doped glass, Applied physics B 72 (2001) 399.

35 Y. Kawamoto, et. al., Proceedings of SPIE, vol. 5350 (SPIE, Bellingham, WA, 2004), p. 269.

36 M. Mortier and F. Auzel, Rare-earth doped transparent glass-ceramics with high cross-sections, Journal of Non-Crystalline Solids, 256 (1999) 361.

37 A.S. Oliveira, M.T. Araujo, A.S.N. Gouveia, A.S.B. Sombra, J.A. Medeiros Neto, N. Aranha, Upconversion fluorescence spectroscopy of $\mathrm{Er}^{3+} / \mathrm{Yb}^{3+}$-doped heavymetal $\mathrm{Bi}_{2} \mathrm{O}_{3}-\mathrm{Na}_{2} \mathrm{O}-\mathrm{Nb}_{2} \mathrm{O}_{5}-\mathrm{GeO}_{2}$ glass, Journal of Applied Physics, 83 (1998) 604.

$38 \mathrm{~F}$. Auzel, Up-conversion and excited state absorption in laser crystal and glasses: advantages and disadvantages, France Telecom, Paris (1992).

39 F.A. Bomfim, J.R. Martinelli, L.R.P. Kassab, N.U. Wetter, J.J. Neto, Effect of the ytterbium concentration on the upconversion luminescence of $\mathrm{Yb}^{3+} / \mathrm{Er}^{3+} \mathrm{co}$ doped $\mathrm{PbO}-\mathrm{GeO}_{2}-\mathrm{Ga}_{2} \mathrm{O}_{3}$ glasses, Journal of Non-Crystalline Solids 354 (2008) 4755.

40 V.P. Gapontsev, S.M. Malitsin, A.A. Isninev, V.B. Kravchenko, Erbium glass lasers and their applications, Opt. Laser Tech. 14 (1982) 189.

$41 \mathrm{E}$. Cantelar, F. Cussó, Competitive up-conversion mechanisms in $\mathrm{Er}^{3+} / \mathrm{Yb}^{3+} \mathbf{c o -}$ doped $\mathrm{LiNbO}_{3}$ Journal of Luminescence 102 (2003) 525. 


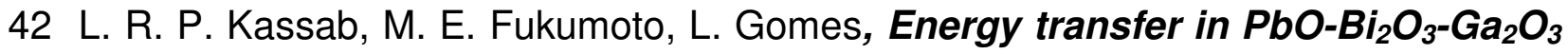
glasses codoped with $\mathrm{Yb}^{3+}$ and $\mathrm{Er}^{3+}$, Journal of the Optical Society of America. B, Optical physics, 22 (2005) 1255.

43 R. Francini, F. Giovenale, U.M. Grassano, P. Laporta, S. Taccheo, Spectroscopy of Er and Er-Yb-doped phosphate glasses, Optical Materials 13 (2000) 417.

44 N. Del Fatti, F. Vallée, C. Flytzanis, Y. Hamanaka, A. Nakamura, Electron dynamics and surface plasmon resonance nonlinearities in metal nanoparticles, Chemical Physics 251 (2000) 215.

45 C. L. Haynes, A. D. McFarland, L. Zhao, R. P. Van Duyne, G. C. Schatz, L. Gunnarsson, J. Prikulis, B. Kasemo and M. Kall, Nanoparticle Optics: The Importance of Radiative Dipole Coupling in Two-Dimensional Nanoparticle Arrays, J. Phys. Chem. B 107(2003) 7337.

46 S. Qu, Y. Zhang, H. Li, J. Qiu, C. Zhu, Nanosecond nonlinear absorption in Au and Ag nanoparticles precipitated glasses induced by a femtosecond laser, Optical Materials 28 (2006) 259.

47 J.A. Jiménez,1 S. Lysenko, G. Zhang and H. Liu, Optical Characterization of Ag Nanoparticles Embedded in Aluminophosphate Glass, Journal of Electronic Materials, 36 (2007) 7.

48 D. M. da Silva, Produção e caracterização de materiais vítreos de germanato com nanopartículas metálicas e íons de érbio para aplicações em fotônica, Dissertação de Mestrado, EPUSP, dezembro de 2007.

49 H. Hovel, S. Fritz, A. Hilger and U. Kreibig, Width of cluster Plasmon resonances: Bulk dielectric functions and chemical interface damping, Physical Review $B, 48$ (1993) 24.

50 T. Kayakawa, S. T. Selvan and M. Nogami, Field enhancement effect of small Ag on the fluorescence from $\mathrm{Eu}^{3+}$-doped $\mathrm{SiO}_{2}$ glass, Applied Physics Letters, 74 (1999) 11.

51 J. J. Mock, M. Barbic, D. R. Smith, D. A. Schultz, and S. Schultz, Shape effects in plasmon resonance of individual colloidal silver nanoparticles, J chemistry physics 116 (2002) 6755. 
52 D.M. da Silva, L. R. P. Kassab, S. R. Luthi, C. B. de Araújo, A. S L. Gomes, B. M. J. Valenzuella, Frequency upconversion in $\mathrm{Er}^{3+}$ doped $\mathrm{PbO}^{-\mathrm{GeO}_{2}}$ glasses containing metallic nanoparticles, Applied physics Letters, 90 (2007) 81913.

53 R.S. Meltzer, W.M. Yen, H. Zheng, S.P. Feofilov, M.J. Dejneka, B. Tissue, H.B. Yuan, Effect of the matrix on the radiative lifetimes of rare earth doped nanoparticles embedded in matrices, Journal of Luminescence 94 (2001) 217.

54 L.R.P. Kassab , F.A. Bomfim , J.R. Martinelli, N.U.Wetter, J.J. Neto, C. B. de Araújo Energy transfer and frequency upconversion in $\mathrm{Yb}^{3+}-\mathrm{Er}^{3+}$-doped $\mathrm{PbO}_{-} \mathrm{GeO}_{2}$ glass containing silver nanoparticles, Applied Physics B, 94 (2007) 239.

55 H. Hofmeister, S. Thiel, M. Dubiel, and E. Schurig, Synthesis of nanosized silver particles in ion-exchanged glass by electron beam irradiation, Appl. Phys. Lett. 70, (1997) 1694.

56 Q. Nie, C. Jiang, X. Wang, T. Xu, H. Li, Upconversion and fluorescence spectral studies of $\mathrm{Er}^{3+} / \mathrm{Yb}^{3+}$-codoped $\mathrm{Bi}_{2} \mathrm{O}_{3}-\mathrm{GeO}_{2}-\mathrm{Ga}_{2} \mathrm{O}_{3}-\mathrm{Na}_{2} \mathrm{O}$ glasses, Spectrochimica Acta Part A 66 (2007) 278.

57 O. Majérus, L. Cormier, D.R. Neuville, L. Galoisy, G. Calas, The structure of $\mathrm{SiO}_{2}-$ $\mathrm{GeO}_{2}$ glasses: A spectroscopic study, Journal of Non-Crystalline Solids 354 (2008) 2004.

58 Q. Nie, L. Lu, T. Xu, S. Daí, X. Shen, X. Liang, X. Zhang, X. Zhang, Upconversion luminescence of $\mathrm{Er}^{3+/} \mathrm{Yb}^{3+}$-codoped natrium-germanium-bismuth glasses, Journal of Physics and Chemistry of Solids 67 (2006) 2345.

59 W. H. Dumbaugh and J. C. Lapp, Heavy-Metal Oxide Glasses, J. Am. Ceram. Soc., 75 (1992) 2315.

$60 \mathrm{H}$. Yamauchi and Y. Ohishi, Spectroscopic properties of $\mathrm{Er}^{3+}$-doped $\mathrm{PbO}_{-} \mathrm{Ga}_{2} \mathrm{O}_{3}-$ $\mathrm{GeO}_{2}$ glass for optical amplifiers, Optical Materials 27 (2005) 679.

61 V. Dierolf, A.B. Kutsenko, A. Ostendorf, W. von der Osten, W. Sohler and H. Suche, Site-selective spectroscopy of $\mathrm{Er}^{3+}: \mathrm{Ti}: \mathrm{LiNbO3}$ waveguides, Appl. Phys. B 68 (1999) 767.

62 S. Ferber, V. Gaebler, Hans-Joachim Eichler, Violet and blue upconversionemission from erbium-doped ZBLAN-fibers with red diode laser pumping, Optical Materials, Optical Materials 20 (2002) 211. 
63 A. Saissy, B. Dussardier, G. Maze, G. Monnom and S. A. Wade, Blue Upconversion Emission in $\mathrm{Er}^{3+}$-Doped Fluoride Fiber, Optical Fiber Technology 2, (1996) 249.

64 H.L. Xu and S. Kroll, Upconversion dynamics in $E r^{3+}$-doped YAG, Journal of Luminescence 111 (2005) 191.

65 B. Ghosh, P. Chakraborty, S. Mohapatra, P.A. Kurian, C. Vijayan, P.C. Deshmukh, P. Mazzoldi, Linear and nonlinear optical absorption in copper nanocluster-glass composites. Materials Letters 61 (2007) 4512. 


\section{PERSPECTIVAS FUTURAS}

Abaixo são citadas algumas sugestões para trabalhos futuros:

$\checkmark$ Estudar com maior intensidade as propriedades físicas e estruturais dos vidros contendo NPs, com o intuito de se conseguir vidros mais estáveis para a nucleação das mesmas;

$\checkmark$ Produzir a nucleação de NPs por meio de outras técnicas, tais como, lasers de femtosegundos e lâmpadas no ultravioleta.

$\checkmark$ Melhorar a qualidade óptica dos vidros produzidos, evitando a introdução de impurezas indesejadas;

$\checkmark$ Estudo das emissões no infravermelho ( 1530nm) dos vidros co-dopados com $\mathrm{Er}^{3+} / \mathrm{Yb}^{3+}$ na presença de NPs;

$\checkmark$ Produção e caracterização de fibras ópticas amplificadoras dopadas com érbio (EDFAs) contendo NPs;

$\checkmark$ Produção de filmes finos vítreos, a partir das amostras produzidas neste trabalho e também de outros sistemas vítreos. 


\section{TRABALHOS PUBLICADOS E PARTICIPÃO EM EVENTOS}

\section{Trabalhos Completos:}

- F.A. Bomfim, J.R. Martinelli, L.R.P. Kassab, N.U. Wetter, J.J. Neto, Effect of the ytterbium concentration on the upconversion luminescence of $\mathrm{Yb}^{3+} / \mathrm{Er}^{3+} \mathrm{co}-$ doped $\mathrm{PbO}-\mathrm{GeO}_{2}-\mathrm{Ga}_{2} \mathrm{O}_{3}$ glasses, Journal of Non-Crystalline Solids 354 (2008) 4755.

- L.R.P. Kassab , F.A. Bomfim , J.R. Martinelli, N.U.Wetter, J.J. Neto, C. B. de Araújo Energy transfer and frequency upconversion in $\mathrm{Yb}^{3+}-\mathrm{Er}^{3+}$-doped $\mathrm{PbO}_{-\mathrm{GeO}_{2}}$ glass containing silver nanoparticles, Applied Physics B, 94 (2007) 239.

\section{Resumos expandidos:}

- Neto, J. J. ; BOMFIM, F. A. ; KASSAB, L. R. P. ; Wetter, N. U. . Study of red upconversion mechanism in $\mathrm{Er} 3+\mathrm{Yb3}+$ co-doped Germanate glasses. In: XXX Encontro de Física da Matéria Condensada, 2007, São Lourenço. Optics Technical Digest, 2007.

\section{Resumos:}

- Bomfim, F. A. ; KASSAB, L. R. P. ; Neto, J. J. ; Wetter, N. U. ; Amancio, C. T. Estudo do mecanismo da conversão ascendente no visível em vidros de telureto codopados com $\mathrm{Er}^{3+}$ e $\mathrm{Yb}^{3+}$. In: IX Simpósio de Iniciação Científica da FATEC- 
SP, 2008, São Paulo. Edição Especial do Boletim Técnico da FATEC-SP: IX Simpósio de Iniciação Científica da FATEC-SP, 2007, 2007.

- Bomfim, F. A. ; KASSAB, L. R. P. ; Martinelli, J. R. ; Wetter, N. U. ; Cid B. de Araújo. The influence of silver nanoparticles in the $\mathrm{Yb}^{3+} / \mathrm{Er}^{3+}$ energy transfer mechanism of PbO-GeO2 glasses. In: NANO 2008 9th International Conference on Nanostructured Materials, 2008, Rio de Janeiro. NANO 2008 9th International Conference on Nanostructured Materials, 2008. v. unico. p. 213-213.

- Martinelli, J ; REIS, S. T. ; ASSUMPCãO, T. A. A. ; BOMFIM, F ; SILVA, D. M. ; W. M. Pontuschka; C. S. Ray . Powder Characterization of JSC-1 Lunar Soil Simulant. In: 7th Brazilian MRS Meeting 2008, 2008, Guaruja. 7th Brazilian MRS Meeting 2008, 2008. v. 1.

- Bomfim, F. A. ; KASSAB, L. R. P. ; Martinelli, J. R. ; Neto, J. J. ; Wetter, N. U. Effect of Ytterbium Concentration on Upconversion Luminescence of $\mathrm{Yb}^{3+} \mathrm{Er}^{3+}$ Co-doped Germanate Glass. In: 8th Brazilian Symposium on Glass and Related Materials and the 4th International Symposium on Non-Crystalline Solids, 2007, Aracaju-Se. ISNCS2007, 2007.

\section{Participacão em Congressos}

- NANO 2008 9th International Conference on Nanostructured Materials. 2008. (Congresso).

- VII Encontro SBPMat. 2008 (Congresso).

- IV International Symposium on NOn-Crytalline Solids and VIII Brazilian Symposiun on Glass and Related Materrials.. 2007. (Simpósio).

- IV International School on Glasses and Related Materials IV-IGRM. 2007. (Oficina). 